\title{
Event-related potentials and cognition in Parkinson's disease: An integrative review
}

\author{
${ }^{1}$ Caroline Seer ${ }^{\dagger} *,{ }^{1}$ Florian Lange ${ }^{\dagger, *},{ }^{2,3}$ Dejan Georgiev, ${ }^{2}$ Marjan Jahanshahi, ${ }^{1}$ Bruno Kopp \\ ${ }^{1}$ Department of Neurology, Hannover Medical School, Hannover, Germany \\ ${ }^{2}$ Sobell Department of Motor Neuroscience and Movement Disorders, \\ Institute of Neurology, University College London, UK \\ ${ }^{3}$ Department of Neurology, University Medical Centre Ljubljana, Ljubljana, Slovenia
}

these authors contributed equally and are joint first authors

This manuscript will be published in Neuroscience \& Biobehavioral Reviews.

*Correspondence to:

Caroline Seer or Florian Lange

Hannover Medical School

Department of Neurology

Carl-Neuberg-Str. 1

D-30625 Hannover

Germany

seer.caroline@mh-hannover.de

lange.florian@mh-hannover.de

+49-511-532-3145 


\begin{abstract}
Cognitive impairment is a common non-motor symptom of Parkinson's disease (PD), but the nature of cognitive changes varies considerably between individuals. According to the dualsyndrome hypothesis, one cluster of patients is characterized by deficits in executive function that may be related to fronto-striatal dysfunction. Other patients primarily show non-frontal cognitive impairments that progress rapidly to PD dementia (PDD). We provide a comprehensive review of event-related potential (ERP) studies to identify ERP measures substantiating the heterogeneity of cognitive impairment in PD. Our review revealed evidence for P3b and mismatch-negativity alterations in PDD, but not in non-demented PD, indicating that alterations of these ERPs constitute electrophysiological markers for PDD. In contrast, ERP correlates of executive functions, such as NoGo-P3, N2, and error(-related) negativity $\left(\mathrm{N}_{\mathrm{e}} / \mathrm{ERN}\right)$, appear to be attenuated in non-demented PD patients in a dopamine-dependent manner. Hence, ERP measures confirm and yield distinct electrophysiological markers for the heterogeneity of cognitive impairment in PD. We discuss limitations and open questions of the ERP approach and provide directions and predictions for future ERP research.

Keywords: Parkinson's disease, Cognition, Dementia, Executive function, Basal ganglia, Dopamine, Event-related potentials (ERPs), P3, P3a, P3b, MMN, NoGo-P3, N2, Ne/ERN
\end{abstract}




\section{Introduction}

Event-related potentials (ERPs) represent neural activities that are gained from the scalprecorded electroencephalogram (EEG) (Luck, 2014). ERPs are usually calculated by averaging EEG activity that is time-locked to the occurrence of an observable event, e.g., a sensory stimulus (i.e., stimulus-locked ERP), or the onset of a motor reaction (i.e., response-locked ERP). ERPs are thought to reflect the summation of postsynaptic potentials of large ensembles of synchronously active pyramidal neurons in the cerebral cortex (Woodman, 2010). Distinct waveforms of the ERP are characterized by their polarity, scalp distribution, latency, and by their sensitivity to particular experimental manipulations. These fluctuations can be conceived of as neural correlates of information processing (Duncan et al., 2009). ERP measurements have an excellent temporal resolution that allows for the investigation of cognitive processes that occur in rapid succession. In addition, ERPs also provide a non-invasive tool also for the assessment of disease-related changes in brain functioning (e.g., Duncan et al., 2009; Verleger, 2003).

ERP latencies are related to the time course of cognitive processes, such as the evaluation of a stimulus and the selection and preparation of an appropriate response. ERP amplitudes are considered to indicate the extent to which neural resources are allocated to these processes. The measurement of ERP latencies and/or amplitudes can thus provide valuable diagnostic information about cognitive and neural functions and dysfunctions, over and above behavioral performance measures (Duncan et al., 2009).

The present work presents an overview of the literature concerning ERP correlates of cognitive dysfunction and decline in idiopathic Parkinson's disease (PD). In the following sections, we will briefly review the cognitive impairment in PD, and we will introduce the most common and important ERPs related to cognitive functions in general and executive control in particular. Our focus is on four major cognitive ERP waveforms: mismatch negativity (MMN), 
P3, N2, and error(-related) negativity $\left(\mathrm{N}_{\mathrm{e}} / \mathrm{ERN}\right)$. All these ERPs have been well characterized in terms of their eliciting events, and they have been related to quite specific cognitive processes and/or functional neural networks.

\subsection{Cognition in Parkinson's disease}

$\mathrm{PD}$ is one of the most common neurodegenerative disorders, with an incidence of 8-18 per 100,000 person-years (de Lau and Breteler, 2006). The prime characteristic of PD at the time of clinical diagnosis is degeneration of dopaminergic neurons in the substantia nigra pars compacta, which results in a depletion of dopamine in the basal ganglia. The cardinal motor symptoms of PD are bradykinesia, resting tremor, rigidity, and postural instability. However, PD is a multisystem neurodegenerative disorder. Namely, the intracerebral formation of Lewy bodies begins at defined anatomical brain sites and advances in a topographically predictable sequence. During pre-clinical stages, pathology is confined to the medulla oblongata/pontine tegmentum and olfactory bulb/anterior olfactory nucleus. In early symptomatic stages, the substantia nigra becomes the focus of pathological changes, whereas in the end-stages of the disease, the Lewyrelated pathological processes enter the neocortex, and the disease manifests itself in all of its clinical dimensions (Braak and Del Tredici, 2008; Hawkes et al., 2010).

In addition to the motor symptoms, the course of neuropathological alterations in PD is associated with specific cognitive dysfunction and cognitive decline. In early clinical stages, cognitive dysfunction may be mainly attributed to the disruption of dopaminergic signaling in fronto-striatal loops, whereas the progression of the disease to its end stages may lead to Parkinson's disease dementia (PDD) in up to 90\% of the patients with PD (Gratwicke et al., 2015). Furthermore, it appears that the patterns of cognitive impairment in PD are heterogeneous in nature (Miller et al., 2013), which has led to the proposition of two clusters of PD patients. According to this 'dual-syndrome hypothesis' (Kehagia et al., 2013; Robbins and Cools, 2014), 
one cluster is formed by non-demented PD patients with mild cognitive impairment who show deficits in tests of planning, task switching, inhibition, conflict processing, phonemic fluency, working memory, and feedback-based learning. This pattern of deficits in executive function likely reflects fronto-striatal dysfunction (Dirnberger and Jahanshahi, 2013), and has been shown to be partly reversible by dopaminergic medication (Kehagia et al., 2013). In contrast, the second cluster of PD patients has been described to show early deficits in non-frontal cognitive functions (such as visuospatial abilities) that are predictive of rapid progression to dementia (PDD) (Robbins and Cools, 2014; Williams-Gray et al., 2009). PDD involves a wide range of cognitive and psychiatric symptoms that have been attributed to dysfunction in temporal and parietal areas of the cortex (Gratwicke et al., 2015; Kehagia et al., 2013). These cognitive symptoms in PDD (assessed, for instance, using the Mini-Mental State Examination, MMSE, Folstein et al., 1975) are apparently unresponsive to dopamine substitution, but may instead benefit from cholinergic treatment (Emre et al., 2004; Robbins and Cools, 2014).

Apart from the discussion of dopaminergic/cholinergic medication for dementia in PD, it is important to note that the effect of dopaminergic medication on cognition is variable - even in early (non-demented) PD patients. While in these patients dopaminergic medication can improve cognitive functions mediated by the motor or associative fronto-striatal circuits, it can lead to 'overdosing' and impairment of performance on cognitive tasks that rely on the limbic or orbitofrontal circuits, which are not dopamine-depleted in early stages of the disease (Cools et al., 2001; Cools, 2006; Gotham et al., 1988; Jahanshahi et al., 2010; Swainson et al., 2006). This issue will be discussed in more detail in Section 4.4.

\subsection{Cognitive ERPs}

In the next two paragraphs, we will introduce classical ERPs that might qualify as indicators of cognitive decline in PDD, as well as ERP correlates of executive processes that have 
been used to examine the specific cognitive sequelae of fronto-striatal dysfunction in nondemented PD patients.

\subsubsection{Classical cognitive ERPs}

The P3b, first described by Sutton et al. (1965) and often also referred to as P300, is perhaps the most-studied ERP component, partly due to its relatively large amplitude and facile elicitation in experimental contexts (for reviews, see Kok, 2001; Polich, 2007). It emerges as a positivity with a parietal scalp distribution and is possibly related to noradrenergic signaling from the locus coeruleus (Nieuwenhuis et al., 2005). Timing of this ERP may range widely, from 250 ms and extending to up to $1000 \mathrm{~ms}$. The P3b is commonly assessed using the 'oddball' paradigm, in which a random sequence of stimuli (of either visual, auditory or somatosensory modality) is presented (Fig. 1). Participants are required to mentally count or to press a button in response to rare target events ('oddballs') and hence to discriminate them from frequent standard events. In this two-stimulus oddball paradigm, stimuli belonging to the target category elicit the P3b, and P3b amplitudes increase with decreasing target category probability (Kolossa et al., 2013; Ritter and Vaughan, 1969). This inverse relation between the probability of the target category and P3b amplitude implies that $\mathrm{P} 3 \mathrm{~b}$ is elicited only after the stimulus has been evaluated as belonging to the frequent or infrequent category. Hence, P3b peak latency is commonly assumed to co-vary with the duration of stimulus evaluation. This relationship between P3b latency and stimulus evaluation time is further supported by the observation that P3b latency increases when the categorization of a stimulus as belonging to the target or standard category becomes more difficult (Kutas et al., 1977; Luck, 2014). In contrast, P3b latency appears to be relatively insensitive to increased demands for response selection (McCarthy and Donchin, 1981). Given the link between P3b peak latency and the duration of stimulus evaluation, P3b recordings can be used to decompose the variance in the speed of behavioral responses into an early portion 
associated with stimulus evaluation and a late portion associated with post-perceptual processing. In addition, the amplitude of the $\mathrm{P} 3 \mathrm{~b}$ has been proposed to reflect the amount of attentional resources allocated to the target stimulus (Johnson, 1988).

If task-irrelevant novel and/or salient stimuli are added to the oddball task (i.e., threestimulus oddball; Fig. 1), these deviant events also elicit a positive-going ERP waveform that has been labeled P3a (usually elicited by salient deviants; Squires et al., 1975) or novelty P3 (usually elicited by novel deviants; Friedman et al., 2001). As P3a and novelty P3 are commonly regarded as variants of the same ERP waveform (Polich, 2007; Spencer et al., 2001), we will collectively refer to both waveforms as P3a in the remainder of this review. The P3a can be distinguished from the $\mathrm{P} 3 \mathrm{~b}$ on the basis of earlier peak latency and a scalp distribution with a fronto-central maximum, relative to the more parietally distributed P3b maximum (Polich, 2007). The relation between P3a and P3b has not been fully clarified and remains an issue of theoretical debate. The P3a is often portrayed in the context of distraction through task-irrelevant events (Escera and Corral, 2007); however, the processing of salience and/or novelty may constitute an important alerting (or orienting) response of the brain to surprising events (Barceló et al., 2002; Kopp and Lange, 2013; Lange et al., 2015; Seer et al., 2016). EEG source modeling of scalp-recorded ERPs, intracranial investigation, studies with patients with focal brain lesions, and combined ERP/functional neuroimaging (fMRI) studies converge in suggesting that the main regions consistently attributed to generating the scalp-recorded P3b include the temporal-parietal junction and the medial temporal lobes, whereas generation of the P3a has been attributed to the prefrontal cortex (Polich, 2007; Volpe et al., 2007; Wronka et al., 2012).

The MMN (Näätänen et al., 1978; for reviews, see Näätänen and Winkler, 1999; Näätänen et al., 2007) is elicited by changes in auditory stimulation, and MMN amplitudes are related to the discriminability of these changes. The MMN is typically seen as a fronto-central 
negativity, occurring in the latency range around 100-250 ms. It is generated from the auditory cortices bilaterally, but there may also be a contribution from the right lateral prefrontal cortex (Giard et al., 1990). The MMN is thought to reflect an automatic process that detects differences between an incoming stimulus and the sensory memory trace of immediately preceding stimuli (Näätänen et al., 2007).

\subsubsection{Cognitive ERP correlates of executive control}

One of the standard tasks to examine inhibitory control is the Go/NoGo task, in which participants are asked to respond to some stimuli and to refrain from responding to other stimuli (Fig. 1). ERPs measured in Go/NoGo tasks consist of a negative deflection (NoGo-N2) and a subsequent positivity (NoGo-P3) in NoGo-trials as compared to Go-trials (Falkenstein et al., 1995; Karlin et al., 1970). Both ERP waveforms show fronto-central scalp topography.

The NoGo-P3 has been related to neural processes for inhibition by many researchers (e.g., Roberts et al., 1994). However, the NoGo-P3 could simply reflect a separate inhibitionmonitoring process (Bruin et al., 2001; Huster et al., 2013; Roche et al., 2005). Accordingly, the NoGo-P3 has been associated with the efficiency of inhibitory control and with the evaluation of the inhibition process (Liotti et al., 2005; Schmajuk et al., 2006; see also Kopp et al., 1996a). The network underlying NoGo-P3 generation shows a broad distribution of sources including medial prefrontal and pre-central sources and associations with pre-supplementary motor area (SMA), temporo-parietal regions, the insulae as well as parts of the basal ganglia (Huster et al., 2013).

The NoGo-N2 amplitude is smaller and NoGo-N2 latency is delayed in participants with higher error (false alarm) rates compared to participants with lower error rates (Falkenstein et al., 1999), supporting the view that the NoGo-N2 is related to inhibitory processing (Kopp et al., 1996a). The view that the NoGo-N2 reflects cognitive processes for inhibition was challenged by Nieuwenhuis et al. (2003) and Donkers and van Boxtel (2004), who suggested that the NoGo-N2 
reflects response conflict rather than inhibitory control. This 'response conflict' view is consistent with the fact that simultaneous activation of competing response tendencies - as it occurs in conflict (or interference) tasks (such as the Eriksen flanker task, Eriksen and Eriksen, 1974; see Fig. 1) - is associated with enhanced fronto-central (conflict-)N2 amplitudes. Thus, both the NoGo-N2 (Kopp et al., 1996a) and the conflict-N2 elicited in interference tasks (Kopp et al., 1996b) have been claimed to indicate the resolution of response conflict by executive control processes (Folstein and Van Petten, 2008). EEG source modeling (Bekker et al., 2005; Bokura et al., 2001) and combined ERP/fMRI (Mathalon et al., 2003) studies suggest that the NoGo-N2 and conflict-N2 reflect activity in medial and lateral prefrontal cortices. The medial source seems to be located in the mid-cingulate cortex (Huster et al., 2013), whereas the lateral source has been attributed to the right (Lavric et al., 2004) and the left inferior prefrontal cortex (Huster et al., 2010). Note that the available data are still insufficient to unambiguously relate NoGo-N2, conflict-N2, and NoGo-P3 ERP measures to specific executive functions (Huster et al., 2013). Incorrect responses in various choice-response tasks are typically followed by a frontocentrally distributed negative deflection that has been termed 'error negativity' $\left(\mathrm{N}_{\mathrm{e}}\right.$; Falkenstein et al., 1991) or 'error-related negativity' (ERN; Gehring et al., 1993). It starts around the time of an overt erroneous response and peaks around $50-100 \mathrm{~ms}$ later. The $\mathrm{N}_{\mathrm{e}} / \mathrm{ERN}$ has thus been regarded as a correlate of performance monitoring, and several models have sought to explain its functional significance (Bernstein et al., 1995; Botvinick et al., 2001; Holroyd and Coles, 2002; for review and discussion, see Ullsperger et al., 2014b). Specifically, the reinforcement learning model of the $\mathrm{N}_{\mathrm{e}} / \mathrm{ERN}$ (Holroyd and Coles, 2002) views the $\mathrm{N}_{\mathrm{e}} / \mathrm{ERN}$ as neural activity related to the processing of a prediction error which is conveyed by midbrain dopamine neurons and broadcasted to prefrontal cortices. Accordingly, the $\mathrm{N}_{\mathrm{e}} / \mathrm{ERN}$ is considered to be generated in the 
posterior medial prefrontal cortex (mainly the anterior mid-cingulate cortex; Ullsperger et al., 2014a).

\subsection{The present review}

In the following, we comprehensively review the literature on the ERP correlates of cognitive dysfunction in PD. Our review is based on an exhaustive literature search using ISI Web of Science, PubMed, and Google Scholar, conducted in late 2014/early 2015 and updated in early 2016. To be included in this review, studies were required to report at least one ERP measure recorded from at least two patients with PD (i.e., single-case studies were not considered). Studies focusing on movement-related potentials in PD are reviewed by us in a related article (Georgiev et al., 2016). A small number of studies were published after we had updated our literature review (i.e., during the review and revision process), and these studies (Garrido-Vásquez et al., 2016; Kaufman et al., 2016; Tang et al., 2016) were not included in the systematic overviews presented below. From the review, it becomes evident that two major lines of cognitive ERP research in PD have been pursued over the last three decades. On the one hand, clinically-oriented research has focused on recording classical ERPs elicited in simple discrimination tasks. Specifically, there is a long-standing debate as to whether P3b latency might qualify as an electrophysiological biomarker for PD. Here, we provide a quantitative overview of $\mathrm{P} 3 \mathrm{~b}$ studies in $\mathrm{PD}$ which reveals that the prolongation of the P3b latency is related to the presence of dementia in PD rather than to PD itself. On the other hand, theory-driven research has investigated a broader variety of ERPs as candidate biomarkers of cognitive dysfunction in PD. These studies used diverse tasks to identify the neural substrates of PD-specific cognitive alterations, most notably though not exclusively, in the domain of executive functioning. ERP research in this area has revealed particularly intriguing insights with regard to attentional orienting (P3a), conflict processing (N2), and performance monitoring $\left(\mathrm{N}_{\mathrm{e}} / \mathrm{ERN}\right)$ in $\mathrm{PD}$. In sum, 
based on the evidence reviewed, we will establish that the clinically-oriented research on classical cognitive ERPs and the experimentally-oriented analyses of 'executive ERPs' complement each other in revealing the multifaceted nature of the neural substrates of cognitive deficits in PD (see above).

\section{P3b: allocation of attentional resources and stimulus evaluation duration}

The cognitive ERP most frequently studied in patients suffering from PD is the P3b. The P3b peak latency has been considered a promising tool to quantify cognitive impairments (particularly cognitive slowing) associated with PD (Hansch et al., 1982). The P3b latency can be quantified in the absence of any overt response (e.g., by instructing the participant to silently count the target stimuli). Hence, in contrast to response time measures, P3b latency may be a good measure for the efficiency of cognitive processing in PD which is not confounded by the patients' motor impairments and can be measured even in patients with severe symptoms. Building on this premise, dozens of research groups have recorded the oddball P3b in PD patients to examine whether patients differ from healthy controls with regard to the speed of stimulus evaluation, as indicated by P3b latency, or with regard to the allocation of attention, as indicated by P3b amplitude. Further issues related to P3b measures are whether they can help to discriminate PD patients with and without dementia, and whether P3b assessment can contribute to the differential diagnosis of idiopathic PD from other types of parkinsonism. How far have we come with regard to answering these questions?

We have identified 65 studies that present P3b data from 74 samples of PD patients (Table 1). All of these studies applied the oddball paradigm and compared at least one P3b measure (latency or amplitude) between the patient group and an age-matched group of healthy controls. In 54 studies that quantified and compared P3b amplitudes, PD patients' amplitude measures were decreased in ten (19\%), increased in five (9\%), and indistinguishable from 
waveforms recorded in healthy controls in $39(72 \%)$ samples, a pattern that might be best explained by chance variation.

P3b latency on the other hand was significantly prolonged in 39 (or 53\%) of the samples, with only one study reporting shorter P3b latencies in PD patients than in controls. While such a large proportion of significant results can certainly not be attributed to error variance, it also highlights that there is no reliable pattern of P3b prolongation in PD. Basically, two alternative explanations might account for this observation: either the magnitude of the group difference between PD patients and healthy controls is not large enough, or the group difference is substantially influenced by a moderating factor. If the former is the case, studies involving a large sample size should be more likely to detect significant P3b latency differences. However, largesample studies (as defined by a median split over $N$; the median number of participants was $N=$ 38) did not generate a significantly larger number of significant results than small-sample studies (large $N: 58 \%$, small $\left.N: 49 \% ; \chi^{2}(1, n=73)=0.69, p=0.41\right)$. To address the second possibility, we tested whether the likelihood of finding significantly prolonged P3b latencies in PD patients depends on a number of sample characteristics (medication status [on vs. off dopamine replacement therapy vs. non-selected samples], age, disease duration, Hoehn \& Yahr stage [HY], dementia status [diagnosis of dementia vs. no diagnosis of dementia vs. non-selected samples]), or on task settings of the oddball paradigm (two-stimulus vs. three-stimulus oddball, modality, target probability, response mode). For this purpose, continuous measures were transformed into binary variables by median split (median HY: 2.33; median age: 64.1 years; median disease duration: 5.4 years; median target probability: 0.20). As displayed in Fig. 2, the likelihood of finding significant P3b prolongations in PD was not affected by any of the factors (all $\chi^{2}<2.46$, all $p>0.11$ ) with the exception of the presence or absence of a diagnosis of dementia in the PD sample $\left(\chi^{2}(1, n=72)=11.74, p=0.001\right)$ and HY stage $\left(\chi^{2}(1, n=54)=4.75, p=0.03\right)$. When 
included in a logistic regression model $\left(R^{2}=0.27\right)$, only dementia status $(\operatorname{Exp}(\mathrm{B})=6.63,95 \% \mathrm{CI}$ $=[1.54-28.44]$, Wald $(1)=6.47, p=0.01)$, but not $\mathrm{HY}(\operatorname{Exp}(\mathrm{B})=2.31,95 \% \mathrm{CI}=[0.68-7.84]$, Wald $(1)=1.79, p=0.18$ ) emerged as a significant predictor of the prolongation of P3b latency. When demented PD patients were excluded from consideration, only 19 of 50 studies (38\%) yielded significant P3b latency differences. However, 10 out of 14 studies on non-selected samples and all of the eight studies on samples that only included demented PD patients demonstrated significantly increased P3b latencies in these patients in comparison to healthy controls.

While P3b latency appears to be a sensitive biomarker for PD dementia (PDD), the data accumulated and reviewed here do not support previously suggested hypotheses with regard to the moderating factors of the prolongation of P3b latency in PD. For instance, Hayashi et al. (1996) proposed that P3b latency prolongation depends on disease severity, and Kutukcu et al. (1998) suggested that P3b in non-demented PD patients is only prolonged when overt responses are required. However, even when we excluded samples involving demented patients from the analysis, the likelihood of significant P3b prolongation was neither affected by HY stage $\left(\chi^{2}(1, n\right.$ $=37)=0.59, p=0.44)$, nor by response mode $\left(\chi^{2}(1, n=46)=1.31, p=0.25\right.$; in fact, studies were numerically more likely to yield significant group differences when they did not require participants to make an overt response). In sum, there is reliable evidence for prolongation of P3b latency in demented, but not in non-demented PD patients, suggesting that a decrease in the speed of stimulus evaluation occurs in PDD, but not in PD.

\subsection{P3b and the specificity of cognitive changes in PD}

Having established that P3b latency is sensitive to dementia in PD, it should not be surprising to find associations between P3b latency and global measures of cognitive ability in PD patients. The degree of global cognitive impairment has been linked to P3b latency by studies 
showing correlations between P3b latency and neuropsychological measures of general intelligence (Bodis-Wollner et al., 1995; Hansch et al., 1982; Katsarou et al., 2004), processing speed (O'Donnell et al., 1987), and, most frequently, the global score on the MMSE (Lukhanina et al., 2009; Maeshima et al., 2002; Matsui et al., 2007; Sartucci et al., 1990; Stamenović et al., 2005; Tachibana et al., 1997; but see Elwan et al., 1996; Lukhanina et al., 2008).

Some studies have also evaluated the relationship between P3b latency and cognitive functions that might be indicative of specific fronto-striatal alterations. Specifically, P3b latency appears to be related to prototypical executive functions such as set-shifting (Iijima et al., 2000; Katsarou et al., 2004; Stamenović et al., 2005; but see Stanzione et al., 1998), trail-making (Matsui et al., 2007; Stamenović et al., 2005; but see Elwan et al., 1996), verbal fluency (BodisWollner et al., 1995; Chen et al., 2006), working memory (O'Donnell et al., 1987), and planning (Kim et al., 1995), even in non-demented patients. However, to date it is not clear whether the association between P3b latency and executive functioning in PD is actually specific, because previous studies did not control for the variance shared with measures of global cognitive ability. Future studies involving larger samples sizes and neuropsychological test batteries are required to establish whether P3b latency relates to distinct or generalized alterations in cognitive functioning in PD.

Along similar lines, more data are needed to support the notion that P3b latency prolongation can serve as a diagnostic tool to differentiate PD or PDD from other types of dementia or parkinsonian syndromes. P3b latency has been found to be prolonged in multiple system atrophy (MSA; Deguchi et al., 2001; Kamitani et al., 2002; Kamitani and Kuroiwa, 2009), corticobasal degeneration (CBD; Takeda et al., 1998; Wang et al., 2000), progressive supranuclear palsy (PSP; Pierrot-Deseilligny et al., 1989; Takeda et al., 1998), dementia with Lewy bodies (DLB; Kurita et al., 2010), and Alzheimer's disease (AD; Golob and Starr, 2000; 
Olichney et al., 2011; Polich et al., 1990). Only a few studies have recorded the P3b in more than a single group of patients to allow for direct comparison of P3b latency across diagnostic groups. In general, $\mathrm{P} 3 \mathrm{~b}$ latency prolongation, while being related to the progression of cognitive decline in different types of dementia (Polich et al., 1986), does not seem to differ between AD and PDD patients (Filipović et al., 1990; Hanafusa et al., 1991; Tachibana et al., 1992; but see Goodin and Aminoff, 1986). However, more recent work by Kurita et al. (2010) suggests that P3b latency prolongation might in fact be more pronounced in PDD than in AD, especially in those PDD patients who suffer from visual hallucinations.

A further promising study involving non-demented patients suffering from different parkinsonian syndromes demonstrated that P3b latency was only prolonged in CBD, but not in non-demented PD or PSP patients, while P3b amplitude was selectively decreased in PSP patients (Wang et al., 2000). Whereas the dissociation regarding P3b latencies was not replicated in a study with a similar design (Pirtošek et al., 2001), P3b amplitude appears to be reproducibly larger in non-demented PD patients when compared to patients suffering from PSP (Johnson, 1995; Pirtošek et al., 2001). Clearly, however, more comparative studies involving sufficient sample sizes are required to establish the utility of P3b amplitude measures in differentiating PD and PSP. Most other approaches to use P3b measures for differential diagnosis were rather exploratory and were not followed up by systematic replication. In the study by Antal et al. (2000), P3b latency was substantially prolonged in PD patients, but not in patients suffering from essential tremor (ET). More recent work by Balaban et al. (2012) demonstrated, however, that ET patients also showed marked prolongations of P3b latency. Moreover, P3b latency appeared to be shorter in juvenile PD when compared to idiopathic PD patients (Kaseda et al., 1996), while the extent of P3b latency prolongation was observed to be similar in idiopathic PD and vascular PD patients (Oishi et al., 1996). However, in the study by Oishi et al. (1996), P3b latency was 
reduced by levodopa administration in idiopathic PD, but not in vascular PD. This latter finding illustrates a further potential field of application for P3b measures: the study of medication effects on cognitive functioning in PD.

\subsection{P3b and dopaminergic medication in PD}

Investigations comparing P3b measures in PD patients on and off medication have been used (a) to improve the understanding of dopaminergic involvement in PD-related cognitive deficits (Růžička et al., 1994) and (b) as a human model to study dopaminergic contributions to P3b generation (Stanzione et al., 1991). In most of the studies on levodopa effects, nevermedicated PD patients or patients who underwent a drug washout period ( $12 \mathrm{~h}-14$ days) were tested on an oddball procedure, first off and then on medication. We identified nine studies employing such a study design with five of them demonstrating a reduction of $\mathrm{P} 3 \mathrm{~b}$ latency following levodopa administration (Lukhanina et al., 2009; Oishi et al., 1996; Sohn et al., 1998; Stanzione et al., 1991; Starkstein et al., 1989). However, P3b latency was not significantly decreased by levodopa in the studies by Chia et al. (1995), Kobayashi et al. (2004), and Mathis et al. (2014) and even increased under levodopa in the study by Prasher and Findley (1991). Although the majority of these studies suggest that PD-related P3b latency prolongation is normalized by levodopa, this finding is far from reliably established. First, none of the studies employed a placebo-controlled design or an on vs off medication counterbalancing procedure controlling for order effects. Hence, medication effects were always confounded with potential effects of learning, fatigue or habituation. In a recent study that controlled for these factors (Georgiev et al., 2015), no differences in P3b latency have been found as a function of PD patients' dopaminergic status (see also Vieregge et al., 1994). Second, it has to be noted that sample sizes were considerably smaller in the studies reporting a levodopa-associated decrease in P3b latency (mean $N=14.8$ ) than in the studies reporting no such effect (mean $N=23.5 ; p_{\text {one-tailed }}$ 
$t$-test $=0.03$ ), thus challenging the reliability of the proposed levodopa effect. With regard to P3b amplitude, no differences associated with levodopa treatment in PD have been reported to date.

Only a few studies are available on the effects of dopamine agonists on P3b latency in PD. While neither amplitude nor latency of the P3b was altered by bromocriptine administration (Rumbach et al., 1993), apomorphine appeared to increase P3b latency and to decrease P3b amplitude (Růžička et al., 1994, 1998). Notably, ERP measures were negatively affected in the latter studies while substantial motor improvements were observed following drug administration, indicating that P3b might potentially qualify as an objective indicator of the cognitive side effects of dopamine agonists. Moreover, in a more controlled, experimental design P3b latency was surprisingly found to be prolonged in PD patients under the influence of the peptide hormone cholecystokinin, which is thought to increase dopaminergic firing in the basal ganglia (Smolnik et al., 2002).

Medication studies targeting non-dopaminergic mechanisms identified shortened P3b latencies following administration of the glutamate antagonist amantadine (Bandini et al., 2002), while P3b measures appeared not to be affected by the noradrenergic agonist naphtoxazine (Bédard et al., 1998). More recent studies have also focused on the effect of deep brain stimulation (DBS) of the subthalamic nucleus (STN) on scalp-recorded P3b amplitudes of PD patients (Gerschlager et al., 2001; Kovacs et al., 2008; Naskar et al., 2010). P3b latency and amplitude have been found to be unaffected by STN DBS in all of these studies.

In summary, the lack of consistent effects of both dopaminergic medication and STN DBS on P3b measures in PD suggests that the cognitive mechanisms reflected by the P3b might not depend to a crucial extent on the integrity of dopaminergic pathways. Specifically, PD-related P3b latency prolongation cannot easily be attributed to nigro-striatal dopamine depletion, a conclusion that is further supported by the evidence reviewed above that P3b latency alterations 
are predominantly observed in PDD patients for whom signs of neurodegeneration involve wide areas of the neocortex (Wolters and Braak, 2006).

\subsection{P3b in PD: conclusions and future directions}

Over the last decades, the study of cognitive ERPs in PD was largely dominated by an interest in potential $\mathrm{P} 3 \mathrm{~b}$ alterations and their functional significance. The evidence from a large number of independent investigations can be summarized as the prolongation of P3b latency being sensitive to the presence of dementia in PD, whereas P3b latency is not generally prolonged in non-demented PD patients (Fig. 3, left panel). P3b latency prolongation cannot easily be reversed by means of dopamine replacement therapy or DBS, and it is not specifically related to executive function deficits, which are characteristic of fronto-striatal dysfunction in PD. Congruent with the prevailing interpretation of P3b latency as a measure of stimulus evaluation time, P3b latency prolongation might rather serve as a sensitive biomarker for global cognitive decline as it occurs in PDD. However, P3b latency prolongation is not a specific feature of PDD, as it can also be observed in other dementing diseases, including Alzheimer's disease, and atypical parkinsonian syndromes.

Future investigations of P3b latency prolongation in PD should explore the moderators of this effect, i.e., clarify under which conditions P3b latency is prolonged in PD. Studies addressing this question might benefit from manipulating the demands for stimulus evaluation. For instance, stimulus evaluation time (as mirrored in P3b latency) is typically shorter when target stimuli occur in a predictable manner; however, this shortening of latency by predictability does not occur in PD patients (Fogelson et al., 2011). Similarly, PD-related P3b latency prolongation has been shown to depend on the choice of the task-relevant stimulus dimension (with prolonged motion discrimination time and normal color discrimination time in PD patients) and thus on the recruited processing pathways within the visual system (Arakawa et al., 1999). 
In contrast to its latency, P3b amplitude has generally been found to be unaltered in PD patients, even in those suffering from dementia. While indicating that PD patients do not seem to have difficulties allocating processing resources to relevant target stimuli in the oddball paradigm, this finding is not particularly surprising. The detection of clearly identifiable target stimuli in the absence of any conflicting information is certainly not the ideal task to tax those cognitive processes that may be impaired in PD or in PDD. In the future, P3b investigations that are tailored to PD-related cognitive deficits may be more promising.

A recent example of such a study has been reported by Verleger et al. (2013) who measured the P3b in a flanker paradigm (Fig. 1) not only in the conventional way (i.e., stimulussynchronized), but also time-locked to the participants' responses. In healthy controls, stimulusand response-locked P3b amplitudes were indistinguishable, suggesting that the associated stimulus-response links (possibly supported by the basal ganglia) were largely intact. However, in PD patients, response-locked amplitudes were substantially smaller than stimulus-locked potentials, and the authors attributed the response-locked P3b amplitude attenuation in PD patients to nigro-striatal dopamine depletion.

In a further study (Münte et al., 2015), P3b has been recorded in a dual-task paradigm to test the hypothesis that PD may be associated with decreased attentional processing capacity. PD patients and healthy controls were presented with a classical two-stimulus oddball procedure as a secondary task while they also completed a primary task that placed either high (random number generation; participants were asked to press number keys in a random order) or low (ordered number generation; participants are asked to press number keys in a canonical order) demands on participants' processing capacities. In healthy controls rare target stimuli in the oddball task elicited P3b waveforms of similar amplitude in the high-demanding and in the low-demanding 
task. In PD patients, however, P3b amplitude was selectively decreased in the more demanding version of the primary task, indicating a PD-related limitation of attentional processing resources.

The data that were obtained from these two studies illustrate that P3b amplitudes might indeed provide interesting insights about neural and cognitive dysfunctions associated with PD. One prerequisite for successful P3b-based ERP studies of PD is to tailor experimental designs and data analyses toward specific hypotheses about PD-related neural and cognitive alterations.

\section{P3a, mismatch negativity, and reorienting negativity: novelty processing and}

\section{deviance detection}

PD patients may have difficulties shifting attention and adapting to novelty in the environment (Dubois and Pillon, 1997; Rustamov et al., 2014). Hence, investigating ERP responses related to attentional processes in PD patients may be of particular relevance for understanding some of the cognitive changes associated with the disease. In this context, previous research has focused on the assessment of the P3a waveform in the three-stimulus oddball task (Fig. 1) as well as in the distraction paradigm (see below).

Specifically, P3a measures have been analyzed in about a dozen studies involving patients with PD (Table 2). The emerging findings are rather heterogeneous. While only two studies reported prolonged $\mathrm{P} 3 \mathrm{a}$ latencies in $\mathrm{PD}$, it is remarkable that neither of these studies reported PDrelated P3b prolongation in response to target oddball stimuli (Tsuchiya et al., 2000; Zeng et al., 2002), suggesting a potential dissociation between P3a and P3b latency in PD. This dissociation is further supported by the observation that P3a latency does not seem to differ between PDD patients and PD patients without dementia (Tachibana et al., 1992; Toda et al., 1993).

P3a amplitude has been found to be attenuated in PD in some studies ( $\mathrm{Li}$ et al., 2005; Solís-Vivanco et al., 2011, 2015; Tsuchiya et al., 2000; Wang et al., 1999, 2000), but not in others (Bocquillon et al., 2012; Gaudreault et al., 2013; Georgiev et al., 2015; Hozumi et al., 
2000; Pirtošek et al., 2001; Tachibana et al., 1992; Toda et al., 1993; Zeng et al., 2002). These differences can hardly be explained by different task characteristics, as, for instance, the studies by Tachibana et al. and Toda et al. (no amplitude reduction) used the same procedures as the studies by Li et al. and Wang et al. (significant amplitude reduction). It seems more likely that the PD-related P3a amplitude attenuation constitutes a medium-sized effect that sometimes fails to reach significance due to insufficient statistical power (Cohen, 1992). Enhanced P3a amplitudes in oddball tasks have been interpreted to indicate stronger distractibility in several clinical populations (Escera et al., 2000). In addition, smaller P3a amplitudes obtained from threestimulus oddball tasks have been associated with more efficient performance in more demanding tasks (Lange et al., 2015). Against this background, PD-related attenuation of P3a amplitudes in three-stimulus oddball tasks may indicate enhanced resistance to distraction in PD patients. Alternatively, reduced P3a amplitudes may reflect a PD-related impairment in directing attention to potentially important changes in the environment (Barry et al., 2011).

The functional significance of orienting responses to novel stimuli is illustrated by a study by Schomaker et al. (2014). In this study, patients and controls were required to memorize words that were either presented in a standard font or in one of multiple novel fonts. Healthy controls showed the typical von Restorff effect (i.e., better memory for words that were written in novel fonts; von Restorff, 1933). In contrast, PD patients did not benefit from the word being written in a novel font. Likewise, P3a amplitudes were enhanced in response to novel font words in controls, but not in PD patients, suggesting that patients have difficulties allocating attentional resources to novel features (Schomaker et al., 2014).

The adaptive nature of attentional orienting is further illustrated by the sensitivity of P3a amplitude to habituation. As a cortical correlate of the orienting response, the P3a amplitude decreases with an increasing number of stimulus repetitions (Friedman et al., 2001). This 
habituation is entirely lacking in PD patients (Tsuchiya et al., 2000), thereby mirroring the pattern observed in patients with dorsolateral prefrontal cortex lesions (Knight, 1984). In this context, it is remarkable that the PD-related P3-amplitude attenuation has been related to perseverative behavior on the Wisconsin Card Sorting Test (WCST; Heaton et al., 1993), a well-established neuropsychological test of cognitive flexibility (Tsuchiya et al., 2000). Perseverative tendencies on this test are commonly regarded as a hallmark of executive dysfunctions in both PD patients (Dirnberger and Jahanshahi, 2013; Gotham et al., 1988) and patients with prefrontal cortex lesions (Demakis, 2003; Milner, 1963). In conclusion, P3a amplitude attenuation in PD patients may be an electrophysiological correlate of PD-related behavioral deficits in adjusting rapidly and efficiently to novel environmental demands, an executive function that is supported by the integrity of fronto-striatal loops (Monchi et al., 2001, 2004).

Another recent finding that underscores the functional relevance of P3a in PD has been reported by Solís-Vivanco et al. (2015). These authors found the degree of P3a amplitude attenuation in $55 \mathrm{PD}$ patients to be linearly related to disease duration, even when controlling for covariates such as age and MMSE score. This finding has been suggested to indicate that P3a amplitude may qualify as a reliable biomarker of disease progression (Solís-Vivanco et al., 2015). Along similar lines, the P3a amplitude attenuation has been found to be associated with apathy (Mathis et al., 2014) and akinesia (Wang et al., 2000) in PD patients. Further studies investigating P3a amplitude attenuation in PD and the links between this ERP measure and clinical or cognitive variables are essential for establishing the utility of P3a measurement for an understanding of neural and cognitive sequelae of PD.

However, the utility of P3a amplitude measures for differential diagnosis seems limited. In the study by Wang et al. (2000), the P3a was reduced in PD, but not in CBD, while the opposite pattern was observed by Pirtošek et al. (2001). Interestingly, however, P3a latency, but 
not P3a amplitude or P3b measures, significantly differed between PDD patients and AD patients (Tachibana et al., 1992).

When the P3a is recorded in the distraction paradigm (Schröger and Wolff, 1998), as for example in the studies by Solís-Vivanco et al. $(2011,2015)$, it is typically preceded by the Mismatch Negativity (MMN), an index of relatively automatic deviance detection (Näätänen et al., 2007). In the distraction paradigm, participants are instructed to attend to one stimulus dimension (e.g., tone duration), while the presented stimuli also vary on a second, task-irrelevant dimension (e.g., tone pitch). Unexpected changes in the task-irrelevant stimulus dimension (e.g., a rare high-pitched tone in a series of frequent low-pitched tones) elicit the MMN. Alternatively, the MMN can also be recorded in response to oddball stimuli when participants are asked to ignore the oddball sequence (e.g., Karayanidis et al., 1995; Pekkonen et al., 1995). Further, in the distraction paradigm, MMN and P3a are followed by the Reorienting Negativity (RON) that is related to reorienting attention toward performing the task following distraction (Schröger and Wolff, 1998).

Overall, studies of MMN in PD do not point to a pronounced disease-related deficit in pre-attentional mechanisms of deviance detection (Table 2). Although MMN amplitude in response to deviant sounds has been reported to be attenuated in non-demented PD patients in one study (Pekkonen et al., 1995), no such differences could be found in six other studies (Brønnick et al., 2010; Karayanidis et al., 1995; Pekkonen et al., 2000; Solís-Vivanco et al., 2011, 2015; Vieregge et al., 1994). However, in the study by Brønnick et al. (2010), MMN amplitude was markedly attenuated in PDD patients and, surprisingly, the extent of the MMN attenuation was more pronounced in PDD patients than it was in AD or DLB patients. Hence, MMN amplitude reduction might share the sensitivity of P3b latency prolongation for PDD (see above) without suffering from a lack of specificity. 
With regard to RON, only limited data have been reported so far. No differences in the RON amplitude have been observed when PD patients were on dopaminergic medication (SolísVivanco et al., 2011; Solís-Vivanco et al., 2015). However, the RON amplitude was significantly reduced in non-medicated patients when compared to both medicated patients and healthy controls (Solís-Vivanco et al., 2011). Hence, the RON amplitude might be susceptible to dopaminergic influence. Future studies employing the distraction paradigm in PD patients varying in presence/absence of dementia and medication status are needed to further investigate the differential sensitivity of MMN and RON to the presence of PDD and to variations in dopamine activity, respectively.

\subsection{P3a, MMN, and RON in PD: conclusions and future directions}

In contrast to the good evidence for P3b latency prolongation in PDD, the available MMN data are much less clear-cut, but they suggest that MMN amplitude may be attenuated in PDD in a nosologically specific manner. The RON obtained from distraction paradigms potentially provides a state marker of nigro-striatal dopamine depletion in PD (Solís-Vivanco et al., 2011). Overall, the P3a amplitude findings in PD must be considered equivocal, and it appears that differences between PD patients and controls are not very large. Researchers interested in studying this waveform in PD should focus on systematically deducted research questions, and tailor their paradigms to precisely answer these questions. Studies should be conducted in large samples to obtain a reliable estimate of the effect sizes. One study (Solís-Vivanco et al., 2015) reported an association between $\mathrm{P} 3 \mathrm{a}$ amplitude attenuation and disease duration in PD. Future studies employing longitudinal designs are required to examine the utility of P3a amplitude as a biomarker of disease progression in PD.

\section{NoGo-P3, N2, and error(-related) negativity: executive control}


The Go/NoGo task (Fig. 1) is among the standard tasks to examine executive control in PD. ERPs measured in Go/NoGo tasks consist of more pronounced stimulus-synchronized negative deflections (NoGo-N2) and a subsequent positivity (NoGo-P3) in NoGo-trials as compared to Go-trials with a fronto-central scalp topography. Fronto-centrally distributed stimulus-synchronized (conflict-)N2 waveforms are also observed in conflict (or interference) tasks (such as the Eriksen flanker task, see Fig. 1). Thus, both the NoGo-N2 and the N2 elicited in interference tasks have been claimed to indicate the resolution of response conflict by executive control processes (Kopp et al., 1996a,b). Incorrect responses in various choice-response tasks are typically followed by a prominent $\mathrm{N}_{\mathrm{e}} \mathrm{ERN}$, i.e., a fronto-centrally distributed, responsesynchronized negative deflection in ERP waveforms. The $\mathrm{N}_{\mathrm{e}} / \mathrm{ERN}$ provides a neurophysiological indicator of the integrity of neural networks for performance monitoring (Ullsperger et al., 2014a).

\subsection{NoGo ERPs: response conflict and inhibition}

As will be seen, the studies assessing ERPs in Go/NoGo tasks (Pires et al., 2014; see Fig. 1) in PD differ considerably with regard to the statistical comparisons which they report (Table 3). Some studies report group main effects on ERP amplitudes and latencies (i.e., disregarding potential differences between Go-ERPs and NoGo-ERPs), whereas other studies report trialspecific effects (e.g., Go-P3, NoGo-P3). Furthermore, some studies refer to the difference potential that is obtained by subtracting Go-ERP amplitudes or latencies from the respective NoGo-ERP measures (i.e., NoGo - Go). This heterogeneity between studies hinders comparisons between and conclusions from the studies; more standardization would increase the comparability between studies and would be desirable.

In the Go/NoGo task (Fig. 1), participants are asked to respond to some stimuli ('Go'trials) and to refrain from responding to other stimuli ('NoGo' trials). Due to the usually large 
proportions of Go-trials, the participants develop a predominant tendency to respond that places high demands on executive processes of action restraint on NoGo-trials (Eigsti et al., 2006; Lange et al., 2014; Lange and Eggert, 2015). As displayed in Table 3, NoGo-P3 amplitudes were repeatedly reported to be attenuated in PD patients (Beste et al., 2009a; Bokura et al., 2005; Osawa et al., 2005; Pulvermüller et al., 1996; but see Beste et al., 2010). Note that Beste et al. (2009a), Bokura et al. (2005), and Pulvermüller et al. (1996) studied PD patients on their dopaminergic medication, whereas Beste et al. (2010) reported results that were obtained from PD patients off their dopaminergic medication. P3 latencies did not differ significantly between controls and PD patients in the two studies by Beste et al. (2009a, 2010). The difference between NoGo-P3 latencies minus Go-P3 latencies was enhanced in PD patients in the study by Beste et al. (2009a); however, the effect was confined to a version of the Go/NoGo task which involved semantic incompatibility between stimuli and responses (i.e., 'STOP' signaled Go-trials and 'PRESS' signaled NoGo-trials), thereby posing particularly high demands on executive control. Moreover, Bokura et al. (2005) found prolonged NoGo-P3 latencies in PD patients, whereas GoP3 latencies did not differ from those observed in controls.

Two ERP studies in PD patients employing Go/NoGo tasks revealed generally enhanced (i.e., more negative) N2 amplitudes in patients with PD (Beste et al., 2009a, 2010). These studies differ with regard to the precise N2 amplitude effects: While Beste et al. (2009a) found enhanced NoGo-N2 amplitudes in PD, the later study by Beste et al. (2010) reported unaltered NoGominus-Go N2 amplitude differences in PD. Yet another study showed attenuated NoGo-minusGo N2 amplitude differences in PD (Bokura et al., 2005). Only one study found N2 latencies to be generally prolonged in PD patients (Beste et al., 2009a), whereas the NoGo-minus-Go N2 latency differences appear to be unaltered in PD (Beste et al., 2009a; Bokura et al., 2005). 
To conclude, the available studies assessing ERPs in Go/NoGo tasks yielded quite inconsistent findings, with the sole exception that four studies reported attenuated NoGo-P3 amplitudes in PD. The only study that did not report attenuated NoGo-P3 amplitudes in PD patients looked at PD patients off their dopaminergic medication (Beste et al., 2010). A reasonable integration of these data across studies is, however, hampered by the heterogeneity of study designs and ERP measures.

\subsection{N2: conflict processing}

ERP indicators of conflict processing are usually examined in interference tasks in which automatic processes interfere with the selection of task-relevant responses. A prominent example is the Stroop task (Stroop, 1935). Here, the identity of a color word can interfere with the participants' ability to name the color in which the word is displayed. For example, saying "green" (i.e., the task-relevant response) in response to the word "red" (triggering the taskirrelevant response of saying "red") written in green ink is more difficult compared to saying "green" in response to the word "green" written in green ink. In this latter case, the task-relevant response is identical to the task-irrelevant response. However, there is no ERP study of conflict processing in PD which relied on the Stroop task. Table 4 provides details of the available ERP studies which examined conflict processing using other interference tasks in PD.

\subsubsection{Simon task}

The Simon effect (Simon and Rudell, 1967) refers to the finding that spatially arranged responses to non-spatial stimulus features (such as shape, color etc.) are faster when the taskirrelevant stimulus location and response location correspond compared to when they do not correspond (Leuthold, 2011). For instance, the participant is asked to press a key using the left hand when a blue stimulus occurs and to press another key using the right hand when a red stimulus occurs. Reactions are typically slower and more errors occur when the stimulus is 
displayed contralaterally to the correct response hand. To date, only one study examined N2 amplitudes in PD patients using a Simon task that reported reduced N2 amplitudes in PD (Praamstra and Plat, 2001).

\subsubsection{Flanker task}

In the flanker task (Eriksen and Eriksen, 1974; Kopp et al., 1996b; Seer et al., 2015), a central target stimulus (e.g. '>’) serves as the task-relevant stimulus which is surrounded by either congruent ('>>>>>>) or incongruent (' $<<><<$ ') task-irrelevant distractor stimuli, and the typical finding is that the automatic processing of task-irrelevant distractors interferes with the selection of task-relevant responses. Pronounced fronto-central N2 waveforms are observable on incongruent trials of the flanker task (Danielmeier et al., 2009; Folstein and Van Petten, 2008; Kopp et al., 1996b; Yeung et al., 2004). Fronto-central N2 waveforms are not only sensitive to congruency; they are also modulated by the congruency sequence across successive trials: N2 amplitudes on incongruent trials are attenuated when the preceding trial was incongruent compared to when the preceding trial was congruent (Clayson and Larson, 2011a,b, 2012; Forster et al., 2011; Larson et al., 2012). This contextual modulation of N2 amplitudes has been attributed to an adaptation to the presence or absence of environmental conflicts, respectively ('conflict adaptation', Botvinick et al., 2001; for detailed discussion, see Egner, 2007).

Inspection of Table 4 reveals that $\mathrm{N} 2$ amplitudes in the flanker task have repeatedly been found unaltered in chronically medicated PD patients (Praamstra et al., 1998; Stemmer et al., 2007; Verleger et al., 2010; Willemssen et al., 2011). Similarly, congruency affects N2 amplitudes normally in chronically medicated PD patients, with larger N2 amplitudes elicited on incongruent compared to congruent trials (Rustamov et al., 2013). However, one study found attenuated N2 amplitudes on incongruent trials in asymptomatic (and hence non-medicated) carriers of Parkin or PINK1 mutations who are considered to represent pre-clinical PD patients 
(Verleger et al., 2010). In a similar vein, Willemssen et al. (2011; de novo | pre medication) found diminished $\mathrm{N} 2$ congruency effects in a group of newly diagnosed, drug-naive PD patients. Following the initiation of dopaminergic medication, N2 congruency effects no longer differed from that observed in a control group, potentially indicating that dopaminergic medication might remedy altered N2 congruency effects in drug-naive PD patients (Willemssen et al., 2011; de novo | post medication). Thus, the role of dopaminergic medication on $\mathrm{N} 2$ congruency effects in PD remains to be clarified in future studies. In particular, the effects of medication should be disentangled from learning effects; these two factors were (necessarily) confounded in the study by Willemssen et al. (2011) in which the patients were always drug-naive at initial testing, and always medicated at subsequent testing.

Other ERP measures (N2 latencies: Praamstra et al., 1998; Rustamov et al., 2013; Willemssen et al., 2011; P3 amplitudes and latencies: Praamstra et al., 1998; Stemmer et al., 2007; Willemssen et al., 2011; but see Verleger et al., 2013) were unaltered in PD when examined in flanker tasks. Overall, the evidence suggests that electrophysiological correlates of conflict processing are unaltered in medicated PD patients. However, it remains to be delineated whether N2 amplitude congruency effects provide a biomarker of nigro-striatal dopamine depletion in PD that is counteracted by dopaminergic medication.

The contextual modulation of $\mathrm{N} 2$ amplitudes in the flanker task was found to be attenuated in medicated PD patients (Rustamov et al., 2013). Specifically, control participants showed the typical congruency sequence effect, i.e., substantially enhanced N2 amplitudes on incongruent trials when the preceding trial was congruent compared to when the preceding trial was incongruent. In contrast, N2 amplitudes were not differentially affected by the congruency sequence in PD patients. This finding may suggest that conflict adaptation is disturbed in PD; however, the functional significance of the congruency sequence effect is subject to debate (for 
detailed discussion, see Rustamov et al., 2013). Another study (Rustamov et al., 2014) combined the flanker task with attentional set shifting such that central or peripheral stimuli were taskrelevant throughout short series of trials after which the spatial location of the task-relevant stimulus was altered back and forth. Control participants showed strong evidence for contextual modulation of ERPs across these series of trials. Specifically, N2 and P3 amplitudes on incongruent trials were enhanced on shift trials, and both amplitudes gradually decreased across repetition trials. In contrast, medicated PD patients did not show evidence for this contextual modulation of N2 and P3 amplitudes. Taken together, these two studies suggest that the analysis of contextual modulation of ERPs in the flanker task might be a more promising tool than the effects of flanker congruency on ERPs in PD.

\subsection{Ne/ERN: performance monitoring}

The flanker task has been frequently used to assess electrophysiological correlates of performance monitoring, most frequently the error negativity $\left(\mathrm{N}_{\mathrm{e}}\right.$; Falkenstein et al., 1990; Falkenstein et al., 1991) or error-related negativity (ERN; Gehring et al., 1993). The $\mathrm{N}_{\mathrm{e}} / \mathrm{ERN}$ is an early negative deflection in response-synchronized ERP waveforms occurring at fronto-central scalp regions shortly after erroneous responses. Correct responses are also associated with a somewhat less pronounced response-synchronized negative waveform, which has been termed correct negativity $\left(\mathrm{N}_{\mathrm{c}}\right)$ or correct-related negativity (CRN; Falkenstein et al., 2000; Vidal et al., 2000). Erroneous responses further elicit positive response-synchronized waveform deflections which are referred to as error positivity ( $\mathrm{P}_{\mathrm{e}}$; Falkenstein et al., 1990; Falkenstein et al., 1991). The $\mathrm{P}_{\mathrm{e}}$ can be subdivided into an early, fronto-centrally distributed $\mathrm{P}_{\mathrm{e}}$ and a late, parietally distributed $\mathrm{P}_{\mathrm{e}}$ (Ullsperger et al., 2014a). Finally, a response-synchronized positive waveform deflection occurs after correct responses ( $\mathrm{P}_{c}$; e.g., Ito and Kitagawa, 2006; Olvet and Hajcak, 2012). 
Table 5 shows the available $\mathrm{N}_{\mathrm{e}} / \mathrm{ERN}$ and $\mathrm{N}_{\mathrm{c}} / \mathrm{CRN}$ studies in PD. Attenuated $\mathrm{N}_{\mathrm{e}} / \mathrm{ERN}$ amplitudes in PD patients have been repeatedly reported (for an earlier overview, see Jocham and Ullsperger, 2009), most notably in the flanker paradigm (Beste et al., 2009b; Falkenstein et al., 2001; Rustamov et al., 2014; Stemmer et al., 2007; Willemssen et al., 2008, 2009), but also in the Simon task (Falkenstein et al., 2001), in the Go/NoGo paradigm (Falkenstein et al., 2001), and in a lexical decision task (Ito and Kitagawa, 2006). Only two studies reported unaltered $\mathrm{N}_{\mathrm{e}} / \mathrm{ERN}$ amplitudes in PD (Holroyd et al., 2002; Verleger et al., 2013). It seems likely that the absence of statistically significant group differences is a result of the small samples sizes used in these studies. In fact, given the rather low statistical power associated with typical ERP studies in PD, the obtained pattern of results (11 out of 13 studies reporting significant group differences) is statistically more credible than one with 13 out of 13 studies reporting significant group differences (this latter pattern would rather suggest selective reporting of positive findings; Schimmack, 2012). In contrast, $\mathrm{N}_{\mathrm{e}} / \mathrm{ERN}$ latencies do not seem to be altered by PD (Beste et al., 2009b; Ito and Kitagawa, 2006; Verleger et al., 2013; Willemssen et al., 2009). Falkenstein et al. (2001) found decreased $\mathrm{N}_{\mathrm{e}} / \mathrm{ERN}$ latencies in PD using a Simon task, but $\mathrm{N}_{\mathrm{e}} / \mathrm{ERN}$ latencies were unaltered in the same patients in a flanker task and in a Go/NoGo task. This pattern (no PDrelated $\mathrm{N}_{\mathrm{e}} / \mathrm{ERN}$ latency difference in four studies, latency decrease in one single task on a multiple-task study) is compatible with random error variance around a null effect.

$\mathrm{N}_{\mathrm{c}} / \mathrm{CRN}$ amplitudes have been found unaltered in four studies (Beste et al., 2009b; Falkenstein et al., 2001; Ito and Kitagawa, 2006; Willemssen et al., 2008), whereas one study found enhanced $\mathrm{N}_{\mathrm{c}} / \mathrm{CRN}$ amplitudes in PD patients (Willemssen et al., 2009). $\mathrm{N}_{\mathrm{c}} / \mathrm{CRN}$ latencies were consistently found to be unaffected by PD (Beste et al., 2009b; Falkenstein et al., 2001; Ito and Kitagawa, 2006; Willemssen et al., 2009). Falkenstein et al. (2001) assessed late $\mathrm{P}_{\mathrm{e}}$ amplitudes in PD patients using a flanker task, a Simon task, and a Go/NoGo task, and they did 
not find differences between PD patients and control participants. However, Ito and Kitagawa (2006) reported attenuated early $\mathrm{P}_{\mathrm{e}}$ and $\mathrm{P}_{c}$ amplitudes in $\mathrm{PD}$ patients, whereas early $\mathrm{P}_{\mathrm{e}}$ and $\mathrm{P}_{c}$ latencies were normal.

\section{4 $\quad \mathrm{N}_{\mathrm{e}} / \mathrm{ERN}$ and dopaminergic medication in PD}

The reviewed body of evidence reveals disturbed neural activities for performance monitoring in $\mathrm{PD}$, as assessed by $\mathrm{N}_{\mathrm{e}} / \mathrm{ERN}$ amplitudes. However, additional work is required to dissect the relative effects of disease and dopaminergic treatment on performance monitoring in PD. It is well recognized that the relation between dopamine and performance follows an inverted U-shaped function, implying that both insufficient and excessive levels of dopamine impair performance on cognitive tasks (Cools and D'Esposito, 2011; Fallon et al., 2013; Gotham et al., 1988). In early clinical stages of $\mathrm{PD}$, the degeneration of dopamine-producing cells is most pronounced in the substantia nigra, leading to severe dopamine depletion in the dorsal striatum, whereas mesocortical dopamine projections as well as ventral cortico-striatal loops are less affected (see Introduction). Dopaminergic replacement therapy, administered to alleviate motor symptoms associated with the affected dorsal cortico-striatal loops, can at the same time impair, through overdosing, functions relying on otherwise intact prefrontal (Gotham et al., 1988) and ventral cortico-striatal loops (Cools, 2006). Thus, it remains a possibility that most of the relevant $\mathrm{N}_{\mathrm{e}} / \mathrm{ERN}$ findings occurred as a corollary of excessive levels of dopamine in the prefrontal cortex and/or in the ventral striatum in medicated PD patients, rather than consequent to dopamine depletion in the dorsal striatum (Rustamov et al., 2014).

Inspection of Table 5 reveals that the majority of relevant results was obtained from medicated PD patients and may thus be confounded by excessive levels of dopamine in the prefrontal cortex and/or in the ventral striatum due to dopaminergic medication. However, there are three studies which examined $\mathrm{N}_{\mathrm{e}} / \mathrm{ERN}$ amplitudes in never-medicated PD patients (Beste et 
al., 2009b; Stemmer et al., 2007; Willemssen et al., 2009) and three studies of PD patients who underwent a drug washout period (i.e., were tested after overnight withdrawal; Beste et al., 2009b; Holroyd et al., 2002; Willemssen et al., 2008). Except the study by Holroyd et al. (2002), all these studies revealed attenuated $\mathrm{N}_{\mathrm{e}} / \mathrm{ERN}$ amplitudes in PD patients who were either drugnaive or off dopaminergic medication, suggesting that insufficient levels of dopamine disturb neural activities for performance monitoring.

Direct comparisons between PD patients on and off (or drug-naive) dopaminergic replacement therapy are scarce. Willemssen et al. (2008) studied 18 PD patients at early stages of the disease (mean UPDRS Part III on medication $=10.8$; off medication $=14.8$ ). These authors conducted intra-individual comparisons, and they counterbalanced the order of on-medication and off-medication testing. No effects of acute dopaminergic medication on $\mathrm{N}_{\mathrm{e}} / \mathrm{ERN}$ amplitudes could be discerned. The studies which compared drug-naive PD patients with chronically medicated PD patients did not report $\mathrm{N}_{\mathrm{e}} / \mathrm{ERN}$ amplitude differences between these groups, neither when the latter patients were on medication (Stemmer et al., 2007) nor when they were off medication (Beste et al., 2009b) during testing. In a more recent study, Siegert et al. (2014) found differential effects of dopaminergic therapy on task performance in a flanker task depending on the patients' age and disease onset, supporting a dopamine overdose effect in younger patients with early onset of PD; these behavioral changes corresponded to the modulation of $\mathrm{N}_{\mathrm{e}} / \mathrm{ERN}$ amplitudes.

\subsection{NoGo-P3, N2, and Ne/ERN: conclusions and future directions}

From the reviewed body of evidence about ERP correlates of executive dysfunctioning in PD there is reasonably good evidence for attenuated NoGo-P3 amplitudes in medicated PD patients. The N2 data are much less clear-cut, but they point in the direction that N2 amplitudes might be attenuated in individuals at risk for developing PD (i.e., pre-symptomatic carriers of 
gene mutations associated with PD) as well as in drug-naive, but not in chronically medicated PD patients. Thus, $\mathrm{N} 2$ amplitudes have the potential to provide a biomarker of nigro-striatal dopamine depletion in PD. An analysis of the contextual modulation of N2 amplitudes in the flanker paradigm is a promising candidate for further experimentation in that direction. Overall, the $\mathrm{N}_{\mathrm{e}} / \mathrm{ERN}$ amplitude findings in PD provide the most compelling evidence for a disturbance in the neural substrates of executive functions in PD (Fig. 3, right panel). Taken together, the reviewed $\mathrm{N}_{\mathrm{e}} / \mathrm{ERN}$ data imply that both insufficient and excessive levels of dopamine impair performance monitoring in PD. We depict our main conclusions from this review of the literature in Fig. 4 (left panel).

\section{Approaches exploring ERPs in other cognitive domains}

\section{$5.1 \quad$ Language}

Language processing in PD has been investigated against the background of the influential declarative/procedural model of language (Ullman, 2001). The model holds that the (declarative) mental lexicon is represented in temporal cortical areas while the (procedural) mental grammar relies on the integrity of frontal cortex and the basal ganglia. In accordance with this idea, patients suffering from PD appear to have difficulties in syntactic, but not semantic language processing (Friederici et al., 2003). ERP analysis has been proven to be highly useful in generating evidence for this dissociation. Compared to sentences in which the final word meets the individual's expectations (e.g., "The shirt has been ironed."), when the final word of a sentence is semantically incongruent (e.g., "The thunderstorm has been ironed."), these incongruent word stimuli typically elicit a centroparietal negativity, the N400 (Kutas and Hillyard, 1980). In contrast, syntactical violations (e.g., the "to" in "The mother induced to watch the children.”) are followed by a centroparietal positivity, the P600, in comparison to syntactically correct events (e.g., the "to" in "The mother agreed to adopt the child.") (Osterhout 
and Holcomb, 1992). Hence, the N400 and P600 can be regarded as electrophysiological correlates of semantic and syntactic processing, respectively. In a group of medicated, nondemented PD patients, the N400 was found to be unaltered, while the P600 appeared to be modulated by the disease (Friederici et al., 2003). Furthermore, while the P600 amplitude did not significantly differ as a function of syntactic correctness in PD, early automatic parsing processes (as indexed by the Early Left Anterior Negativity, ELAN) seemed to be largely preserved. These analyses were taken to suggest that syntactic rather than semantic and late integrational rather than early automatic processes are affected by PD. Note, however, that these dissociations are based on the absence of a significant P600 effect in PD, and not on a significant reduction of the P600 effect in PD patients when compared to healthy controls. Future studies involving larger sample sizes are required to establish the absence of P600 effects as a correlate of altered syntactic integration in PD patients and dissociate the influence of PD pathology from the effects of dopaminergic medication on language processing (De Letter et al., 2012).

\subsection{Memory}

In the section on novelty processing, we have already discussed the observation that PD patients lack the typical von Restorff effect (i.e., better memory for a word when it is written in a novel font), possibly as a result of a failure to allocate attentional resources to the novel information (Schomaker et al., 2014). This finding is compatible with further studies on the ERP correlates of memory processes in PD. Kida et al. (2007) presented patients and healthy controls with a series of unfamiliar faces and contrasted ERPs elicited by the first presentation of a face with the potentials evoked by the same stimulus when it was repeated later in the series. Healthy controls showed an enhanced positive waveform between 300 and $500 \mathrm{~ms}$ after stimulus presentation for repeated compared to novel faces. This ERP repetition positivity was absent in patients with PD, which may point to a disease-related deficit in recognition memory. In support 
of this conclusion, response latency and accuracy data collected in this study revealed that PD patients had difficulties judging new stimuli as being new. The same recognition deficit could be found in a similar study using auditory presentation of words (Minamoto et al., 2001). The PDrelated memory impairment was accompanied by reduced amplitudes of a negative waveform peaking in the same latency range as the potential analyzed by Kida et al. (2007). Hence, N400like waveforms appear to reflect altered recognition memory in PD, a conclusion that is further corroborated by a study of Tachibana et al. (1999). Here, in comparison to the first presentation, the second presentation of a word resulted in attenuated N400-like amplitudes in healthy controls, both when the repetition occurred on successive trials and when up to 77 words were interspersed between the first and the second presentation. In PD patients, however, this ERP repetition effect was only present when the word was directly repeated and had already vanished when the repetition occurred after five words. Together, these three studies on ERP waveform modulations in the N400 time range point to a consistent alteration in memory processes in PD, specifically when it comes to the integration of incoming stimulus information with the recent memory context.

In addition, the results presented by Lee et al. (2010) point to a potential deficit in visual working memory in PD patients. In this study, participants were asked to remember the orientation of objects appearing on one side of the screen. After a retention interval of $800 \mathrm{~ms}$, the display was presented again and participants had to indicate whether the objects' orientation had changed. During the retention interval, contralateral delay activity (CDA) was measured as a sustained negativity over posterior electrodes contralateral to the side of stimulus presentation. The CDA amplitude likely reflects the number of items held in working memory (Luria et al., 2016; Vogel and Machizawa, 2004). In contrast to healthy controls, the CDA amplitude was 
attenuated in PD patients, possibly indicating that PD patients have difficulty retaining all relevant information in visual working memory.

\subsection{Feedback evaluation in decision-making}

Value-based decision-making in PD patients is an interesting issue due to the close link between this cognitive function and dopaminergic brain networks (Rangel et al., 2008). While PD patients have been repeatedly demonstrated to be impaired on tasks that require adaptive decisions among a set of options, this deficit does not seem to be a general one (Ryterska et al., 2013). First, decision-making in PD typically improves when patients are tested off their dopaminergic medication (e.g., Cools et al., 2003). Second, PD does not seem to affect all stages of the decision-making process to the same extent. Efficient decision-making requires, as a first step, the representation and valuation of a set of possible options before the individual has to choose an option based on the assigned values. Then, the outcomes of the chosen action need to be evaluated in order to update value representations for future decisions (Rangel et al., 2008). A recent meta-analysis suggests that PD-related decision-making deficits can largely be attributed to alterations in this latter process of feedback evaluation (Ryterska et al., 2013).

The ERP technique offers some possibilities to further investigate this hypothesis at the cortical level. In a study by Mapelli et al. (2014), for example, ERPs elicited by positive and negative feedback stimuli in a gambling task have been compared between HC and PD patients on medication. In accordance with multiple studies using similar paradigms, negative outcomes evoked a relative fronto-central negativity about $300 \mathrm{~ms}$ after stimulus onset in HC. This socalled feedback-related negativity (FRN; Miltner et al., 1997) was absent in the patient group, indicating that neural responses from PD patients failed to distinguish between positive and negative outcomes. This evidence for impaired negative feedback processing in PD may also account for the finding that task performance in this study did not markedly improve over time in 
PD patients (Mapelli et al., 2014). In a further study, the PD-related reduction in FRN amplitude was found to be especially pronounced in patients showing elevated levels of apathy (MartínezHorta et al., 2014).

The PD-related insensitivity to feedback valence does not only become evident after outcome presentation of feedback stimuli, but also in anticipation of these events. The stimulus preceding negativity (SPN) over fronto-central electrode sites is typically enlarged when the occurrence of motivationally significant events can be expected (van Boxtel and Böcker, 2004). This notion could also be supported by Mattox et al. (2006), who found SPN amplitudes to be larger prior to high reward values as compared to low reward values in a sample of HCs. In PD patients, however, this effect was reversed, suggesting severe alterations in anticipation of outcome valence in PD.

Although there is a surprisingly small number of ERP studies on decision-making in PD, these studies paint a consistent picture of PD-related impairment at the stage of outcome evaluation (see also Frank et al., 2004). Future studies need to contrast different stages of the decision-making process and to disentangle effects of the primary disease pathology and dopaminergic medication.

\subsection{Emotion}

ERP correlates of emotional processing in PD patients were first examined by Wieser et al. (2006) who asked their participants to rate the emotional arousal associated with positive and negative visual stimuli. Compared to healthy controls, PD patients rated highly arousing stimuli as well as pictures of negative valence as less exciting. The early parietal negativity (EPN), an ERP waveform developing $200 \mathrm{~ms}$ after stimulus onset, could be demonstrated to vary with emotional arousal, but this potential did not reveal any alteration in the PD group. These results are quite consistent with a study by Dietz et al. (2013), showing that, in the absence of any early 
ERP alterations, PD patients rated unpleasant stimuli as less arousing in comparison to pleasant pictures and in comparison to healthy controls. This finding was accompanied by a selective PDrelated reduction of a late centro-parietal positivity in response to unpleasant words. Interestingly, this pattern of decreased emotional reactivity to aversive stimulation could be linked to patients' apathy scores and hence to one of the most prevalent non-motor symptoms in PD (Aarsland et al., 2007).

When PD patients are explicitly required to discriminate the valence of emotional stimuli, PD-related differences can also be identified at earlier stages of information processing. Participants in a more recent study by Wieser et al. (2012) were asked to distinguish different emotional categories from facial expressions. EPN was found to be enhanced for emotional faces when compared to neutral faces in healthy controls, but not in patients with PD. However, emotion recognition rates did not differentiate between the two groups. Auditory ERP paradigms have also been used to investigate PD patients' perception of emotional speech. By using sadly spoken and happily spoken target words in an oddball procedure, Schröder et al. (2006) were able to show that patients had difficulties discriminating emotional prosody. This performance decrement was also mirrored on the level of the ERPs with decreased P3b amplitude in PD patients for happy but not for sad targets. A further study by Garrido-Vásquez et al. (2013) demonstrated that when healthy controls were required to detect different emotions from prosody, the amplitude of the P2 waveform (Kopp et al., 2007; Kopp and Wessel, 2010) decreases for fear and disgust prosody compared to neutral prosody. While the same pattern could be observed in PD patients who showed predominantly right-sided motor symptoms, no disgust effect on P2 amplitude could be observed in patients showing predominantly left-sided motor symptoms. While providing additional ERP evidence for altered early processes of emotion recognition in 
$\mathrm{PD}$, this study also highlights the significance of asymmetric neuronal degeneration for understanding PD-related cognitive changes.

In sum, it appears that ERP correlates of emotional processing in PD are less sensitive to emotional content when patients are explicitly instructed to discriminate emotional content. However, this lack of sensitivity is not consistently associated with poorer emotion recognition performance. Moreover, ERP evidence suggests that PD patients are less aroused by emotional stimuli than healthy controls and future research in this area is needed to establish the role of this phenomenon in understanding PD-related symptoms of apathy and depression.

\section{General conclusions, open questions, and directions for future research}

We reviewed the available literature investigating cognitive ERPs in PD. The main findings are summarized in Table 6. We found that by-and-large two independent lines of ERP research were pursued in PD. Their results are in general agreement with the 'dual-syndrome hypothesis' of cognitive dysfunction in PD (Kehagia et al., 2013; Robbins and Cools, 2014), and this conclusion constitutes a highlight of the reviewed literature. The 'dual-syndrome hypothesis' defines one cluster of cognitive dysfunction in PD that comprises non-demented PD patients with mild cognitive impairment who primarily show deficits in executive functions. PD-related executive dysfunctions likely reflect fronto-striatal alterations (Dirnberger and Jahanshahi, 2013), and they are sensitive to dopaminergic medication (Kehagia et al., 2013). There is reasonably good evidence for attenuated NoGo-P3 amplitudes in medicated PD patients, and less clear-cut evidence which points to reduction of conflict-N2 amplitudes in individuals at risk for developing PD (as identified by gene mutations associated with PD) as well as in drug-naive, but not in chronically medicated, PD patients. In addition, the reviewed data on consistently attenuated $\mathrm{N}_{\mathrm{e}} / \mathrm{ERN}$ amplitudes imply that both insufficient and excessive levels of dopamine impair performance monitoring in PD (cf. Fig. 4, left panel). 
The second cluster of PD patients show decline in non-frontal cognitive functions (such as visuospatial abilities, Miller et al., 2013), and the presence of these cognitive dysfunctions during early stages of the disease predicts rapid progression to PDD (Robbins and Cools, 2014; Williams-Gray et al., 2009). PDD is a form of dementia which has been attributed to the degeneration of temporal and parietal cortical areas and the nucleus basalis of Meynert (Gratwicke et al., 2015; Kehagia et al., 2013). We found good evidence for prolonged P3b latencies in PDD, suggesting prolonged duration of stimulus evaluation. We also found a lack of consistent effects of dopaminergic medication on P3b latency prolongation in PDD. Taken together, prolonged P3b latencies in PDD do not seem to result from PD-specific neurodegeneration, i.e., from nigro-striatal dopamine depletion. This conclusion is further corroborated by the fact that P3b latency prolongation is known to occur in other forms of dementia as well, such as for example in $\mathrm{AD}$. Thus, prolonged P3b latency might serve as a biomarker of the presence of dementia in PD, but this lacks nosological specificity. The MMN data are much less clear-cut, but they indicate that the MMN amplitude may be attenuated in PDD in a nosologically specific manner, suggesting specifically disturbed sensory processing in Lewy-body related neurodegeneration. One of the reasons why P3b latency prolongation and MMN amplitude attenuation may differ with regard to their nosological specificity can be sought in the neural origins of these scalp-recorded ERPs: The P3b has its origins in posterior cortical regions, with no contribution from prefrontal regions, whereas the $\mathrm{MMN}$ is generated from the auditory cortices bilaterally, but there is an additional contribution from the right lateral prefrontal cortex (see Introduction).

In conclusion, the reviewed research suggests that ERPs might serve as useful biomarkers of different facets of cognitive impairment in PD. Attenuated amplitudes of the NoGo-P3, the conflict-N2, and, most promisingly, the $\mathrm{N}_{\mathrm{e}} / \mathrm{ERN}$ may indicate changes of executive functioning 
in PD, which possibly relate to early nigro-striatal and later mesocortical dopamine depletion. In contrast, prolonged P3b latencies and attenuated MMN amplitudes appear to be sensitive to the presence of PDD. In search of biomarkers for PDD, previous studies have already demonstrated the usefulness of cerebrospinal fluid levels of amyloid- $\beta$ and total and phosphorylated tau to discriminate patients with PDD from PD patients without dementia (see Aarsland, 2016; Delgado-Alvarado et al., 2016; Irwin et al., 2013; Svenningsson et al., 2012 for review). In combination with these markers, the electrophysiological indicators identified here could contribute to a multi-modal approach of disease diagnosis and prediction (Aarsland, 2016; Delgado-Alvarado et al., 2016; Svenningsson et al., 2012).

Despite the progress that has been made in the field that we document here for the first time in its entirety (see Růžička and El Massioui, 1993, for an earlier review), many questions remain open for future research. For example, further studies are required to clarify whether ERPs can make useful contributions to the routine assessment of cognitive symptoms. As correlates of cognitive processes, ERPs may mirror more accurately than conventional neuropsychological tests which specific cognitive functions are disturbed in PD and PDD. In this respect, it is important that the ERP technique offers unique solutions to the assessment of cognitive functions, particularly in patients with movement disorders (e.g., Lange et al., 2016a; Rustamov et al., 2013, 2014) or motor neuron disease (e.g., Lange et al., 2016b; Seer et al., 2015), where motor deficits are likely confounding the results of neuropsychological testing. In these disorders, ERPs may also facilitate the monitoring of cognitive change and the evaluation of new treatments for cognitive impairment.

In addition, ERPs might help identify meaningful subgroups of PD patients (e.g., patients with PDD; Luck et al., 2011). A promising approach to this problem is to use ERP data to classify individuals, e.g., as members of a group of patients with a given disease or as members 
of a group without that disease. This technique has been applied to classify patients with schizophrenia with some success, particularly when using multiple paradigms and outcome variables (Laton et al., 2014; Neuhaus et al., 2011).

Finally, ERPs can be even more useful if they predict individual differences in disease progression and/or treatment response. For example, it would be very interesting to know whether P3b latency provides a biomarker predicting - at the earliest stages of the disease progression to dementia in PD patients at later stages of the disease. Another remarkable possibility is that NoGo-P3, N2, and/or $\mathrm{N}_{\mathrm{e}} / \mathrm{ERN}$ amplitude measures may serve to titrate the treatment dose of dopaminergic therapy in individual PD patients.

However, there are limitations in the ERP technique as currently applied to the study of PD. These limitations require attention before ERPs can be considered a valuable contribution to care for PD patients. Due to small sample sizes, the statistical power of single studies is in most cases insufficient to detect the effects of interest. Sufficient statistical power and highly reliable results are best ensured by conducting multi-site, large- $N$ studies (e.g., $N>500$ ). It has been demonstrated by a number of multi-site, large- $N$ studies in psychiatric research that the technique ERP is feasible for these types of studies (e.g., Hesselbrock et al., 2001; Light et al., 2015; Olincy et al., 2010; Turetsky et al., 2015; see also Luck et al., 2011). An essential prerequisite for conducting multi-site, large- $N$ studies is to standardize assessment protocols adequately. To date, studies vary widely with regard to stimulus materials, recording procedures, response modes, and analysis methods. Standardized assessment protocols would not only be required for the conductance of multi-site, large- $N$ studies; they are also a prerequisite for implementing ERPs in clinical practice. The assessment of sensory evoked potentials, which are used as objective measures of sensory function in clinical practice, may serve as an example of a successful clinical implementation of the ERP technique (Chiappa, 1997; Duncan et al., 2009). 
The majority of previous ERP studies in PD relied on simple group comparisons between small groups of PD patients and matched controls, often aiming to investigate whether a particular ERP waveform is 'normal' or altered in PD. To benefit from the potential of ERPs as diagnostic tools, it is necessary to address more refined questions, such as whether ERPs are more state-like (i.e., sensitive for intra-individual fluctuations) or more trait-like (i.e., stable across intra-individual fluctuations) biomarkers of cognitive impairment in PD (Luck et al., 2011). The evidence to date suggests that prolonged P3b latencies should be considered as a traitlike marker of cognitive decline to dementia in PD, found to be largely independent of dopaminergic fluctuations. However, it still remains to be delineated to what degree NoGo-P3, $\mathrm{N} 2$, and/or $\mathrm{N}_{\mathrm{e}} / \mathrm{ERN}$ amplitude attenuation in PD are sensitive to dopaminergic fluctuations, i.e., to the depletion of dopamine in PD and to its substitution by dopaminergic therapy. Intraindividual (within-subjects) designs investigating the impact of different types and doses of dopaminergic medication may help clarify the relationship between dopamine and ERPs of executive processes in PD. These studies should preferably be conducted in a placebo-controlled and counterbalanced way to eliminate some of the confounding factors in previous medication studies on the ERP correlates of PD. Fig. 4 (right panel) shows testable predictions for intraindividual designs which can be derived from the reviewed data.

Advances in surgical treatment of PD, namely DBS, facilitate investigating the neuroanatomical basis of ERPs measured in patients with PD. Similar to intra-individual comparisons of dopaminergic medication states as proposed above, within-subjects comparisons can be performed on and off stimulation states (e.g., Gerschlager et al., 2001). Such studies may help to reveal the role of the stimulated basal ganglia nuclei for specific cognitive processes and their ERP correlates. In addition, DBS allows for electrophysiological recordings directly from the stimulated site (i.e., the recording of local field potentials; e.g., Siegert et al., 2014) and thus 
provides the possibility to examine electrophysiological correlates of cognitive processes at the level of neuronal populations (Münte et al., 2008).

In conclusion, we think that the progress that has been made in the reviewed field represents a currently widely underrecognized scientific achievement. Based on quality-assured (Luck et al., 2011) and source-resolved (Light and Makeig, 2015) ERP measures, the pursuance of multi-site, large- $N$ studies as well as of longitudinal studies will move the field one step forward toward the clinical utility and application of ERPs in PD. 


\section{References}

Aarsland, D., 2016. Cognitive impairment in Parkinson's disease and dementia with Lewy bodies. Parkinsonism Relat. Disord. 22 Suppl 1, S144-8.

Aarsland, D., Brønnick, K.S., Ehrt, U., De Deyn, P.P., Tekin, S., Emre, M., Cummings, J.L., 2007. Neuropsychiatric symptoms in patients with Parkinson's disease and dementia: frequency, profile and associated care giver stress. J. Neurol. Neurosurg. Psychiatry 78, 3642.

Antal, A., Dibo, G., Keri, S., Gabor, K., Janka, Z., Vecsei, L., Benedek, G., 2000. P300 component of visual event-related potentials distinguishes patients with idiopathic parkinson's disease from patients with essential tremor. J. Neural Transm. 107, 787-797.

Antal, A., Pfeiffer, R., Bodis-Wollner, I., 1996. Simultaneously evoked primary and cognitive visual evoked potentials distinguish younger and older patients with Parkinson's disease. J. Neural Transm. 103, 1053-1067.

Aotsuka, A., Weate, S.J., Drake, M.E.,Jr, Paulson, G.W., 1996. Event-related potentials in Parkinson's disease. Electromyogr. Clin. Neurophysiol. 36, 215-220.

Arakawa, K., Tobimatsu, S., Kato, M., Kira, J., 1999. Parvocellular and magnocellular visual processing in spinocerebellar degeneration and Parkinson's disease: an event-related potential study. Clin. Neurophysiol. 110, 1048-1057. 
Balaban, H., Şentürk, I.A., Yildiz, Ö.K., Bolayir, E., Topaktaş, S., 2012. The role of event-related potentials in subclinical cognitive dysfunction in essential tremor. J. Clin. Neurophysiol. 29, 65-69.

Bandini, F., Pierantozzi, M., Bodis-Wollner, I., 2002. The visuo-cognitive and motor effect of amantadine in non-Caucasian patients with Parkinson's disease. A clinical and electrophysiological study. J. Neural Transm. 109, 41-51.

Barceló, F., Periáñez, J.A., Knight, R.T., 2002. Think differently: A brain orienting response to task novelty. NeuroReport 13, 1887-1892.

Barry, R.J., MacDonald, B., Rushby, J.A., 2011. Single-trial event-related potentials and the orienting reflex to monaural tones. Int. J. Psychophysiol. 79, 127-136.

Bathien, N., Wu, Y., Rondot, P., 1996. Visual Event-Related Potentials (ERPs) in Nondemented Parkinson's Disease, in Ohye, C., Kimura, M., McKenzie, J.S. (Eds.), The Basal Ganglia V. Springer, New York, NY, pp. 303-315.

Bédard, M.A., El Massioui, F., Malapani, C., Dubois, B., Pillon, B., Renault, B., Agid, Y., 1998. Attentional deficits in Parkinson's disease: partial reversibility with naphtoxazine (SDZ NVI085), a selective noradrenergic $\alpha_{1}$ agonist. Clin. Neuropharmacol. 21, 108-117.

Bekker, E.M., Kenemans, J.L., Verbaten, M.N., 2005. Source analysis of the N2 in a cued Go/NoGo task. Cogn. Brain Res. 22, 221-231. 
Bernstein, P.S., Scheffers, M.K., Coles, M.G.H., 1995. "Where did I go wrong?" A psychophysiological analysis of error detection. J. Exp. Psychol. Hum. Percept. Perform. 21, $1312-1322$.

Beste, C., Dziobek, I., Hielscher, H., Willemssen, R., Falkenstein, M., 2009a. Effects of stimulusresponse compatibility on inhibitory processes in Parkinson's disease. Eur. J. Neurosci. 29, $855-860$.

Beste, C., Willemssen, R., Saft, C., Falkenstein, M., 2009b. Error processing in normal aging and in basal ganglia disorders. Neuroscience 159, 143-149.

Beste, C., Willemssen, R., Saft, C., Falkenstein, M., 2010. Response inhibition subprocesses and dopaminergic pathways: basal ganglia disease effects. Neuropsychologia 48, 366-373.

Bocquillon, P., Bourriez, J.L., Palmero-Soler, E., Destée, A., Defebvre, L., Derambure, P., Dujardin, K., 2012. Role of basal ganglia circuits in resisting interference by distracters: a swLORETA study. PLoS One 7, e34239.

Bodis-Wollner, I., Borod, J.C., Cicero, B., Haywood, C.S., Raskin, S., Mylin, L., Sliwinski, M., Falk, A., Yahr, M.D., 1995. Modality dependent changes in event-related potentials correlate with specific cognitive functions in nondemented patients with Parkinson's disease. J. Neural Transm. 9, 197-209.

Bokura, H., Yamaguchi, S., Kobayashi, S., 2005. Event-related potentials for response inhibition in Parkinson's disease. Neuropsychologia 43, 967-975. 
Bokura, H., Yamaguchi, S., Kobayashi, S., 2001. Electrophysiological correlates for response inhibition in a Go/NoGo task. Clin. Neurophysiol. 112, 2224-2232.

Botvinick, M.M., Braver, T.S., Barch, D.M., Carter, C.S., Cohen, J.D., 2001. Conflict monitoring and cognitive control. Psychol. Rev. 108, 624-652.

Braak, H., Del Tredici, K., 2008. Nervous system pathology in sporadic Parkinson disease. Neurology 70, 1916-1925.

Brønnick, K.S., Nordby, H., Larsen, J.P., Aarsland, D., 2010. Disturbance of automatic auditory change detection in dementia associated with Parkinson's disease: A mismatch negativity study. Neurobiol. Aging 31, 104-113.

Bruin, K.J., Wijers, A.A., van Staveren, A.S., 2001. Response priming in a go/nogo task: do we have to explain the go/nogo N2 effect in terms of response activation instead of inhibition? Clin. Neurophysiol. 112, 1660-1671.

Chen, K.J., Lin, R.T., Liu, C.K., Tai, C.T., Lai, C.L., 2006. Relationship between event-related potentials and frontal-subcortical dysfunction in Parkinson's disease. Parkinsonism Relat. Disord. 12, 453-458.

Chia, L.G., Cheng, L.J., Chuo, L.J., Cheng, F.C., Cu, J.S., 1995. Studies of dementia, depression, electrophysiology and cerebrospinal fluid monoamine metabolites in patients with Parkinson's disease. J. Neurol. Sci. 133, 73-78.

Chiappa, K.H., 1997. Evoked Potentials in Clinical Medicine, 3 ed. Lippincott Williams \& Wilkins, Philadelphia, PA. 
Clayson, P.E., Larson, M.J., 2011a. Conflict adaptation and sequential trial effects: support for the conflict monitoring theory. Neuropsychologia 49, 1953-1961.

Clayson, P.E., Larson, M.J., 2011b. Effects of repetition priming on electrophysiological and behavioral indices of conflict adaptation and cognitive control. Psychophysiology 48, 16211630.

Clayson, P.E., Larson, M.J., 2012. Cognitive performance and electrophysiological indices of cognitive control: a validation study of conflict adaptation. Psychophysiology 49, 627-637.

Cohen, J., 1992. A power primer. Psychol. Bull. 112, 155-159.

Cools, R., 2006. Dopaminergic modulation of cognitive function-implications for L-DOPA treatment in Parkinson's disease. Neurosci. Biobehav. Rev. 30, 1-23.

Cools, R., Barker, R.A., Sahakian, B.J., Robbins, T.W., 2001. Enhanced or impaired cognitive function in Parkinson's disease as a function of dopaminergic medication and task demands. Cereb. Cortex 11, 1136-1143.

Cools, R., Barker, R.A., Sahakian, B.J., Robbins, T.W., 2003. 1-Dopa medication remediates cognitive inflexibility, but increases impulsivity in patients with Parkinson's disease. Neuropsychologia 41, 1431-1441.

Cools, R., D'Esposito, M., 2011. Inverted-U-Shaped Dopamine Actions on Human Working Memory and Cognitive Control. Biol. Psychiatry 69, e113-e125.

Danielmeier, C., Wessel, J.R., Steinhauser, M., Ullsperger, M., 2009. Modulation of the errorrelated negativity by response conflict. Psychophysiology 46, 1288-1298. 
de Lau, L.M.L., Breteler, M.M.B., 2006. Epidemiology of Parkinson's disease. Lancet Neurol. 5, $525-535$.

De Letter, M., Van Borsel, J., Santens, P., 2012. An electrophysiological investigation of the effects of levodopa on semantic comprehension of action words in Parkinson's Disease. J. Neurolinguistics 25, 95-103.

Deguchi, K., Takeuchi, H., Sasaki, I., Tsukaguchi, M., Touge, T., Nishioka, M., 2001. Impaired novelty P3 potentials in multiple system atrophy--correlation with orthostatic hypotension. J. Neurol. Sci. 190, 61-67.

Delgado-Alvarado, M., Gago, B., Navalpotro-Gomez, I., Jiménez-Urbieta, H., Rodriguez-Oroz, M.C., 2016. Biomarkers for dementia and mild cognitive impairment in Parkinson's disease. Mov. Disord. 31, 861-881.

Demakis, G.J., 2003. A meta-analytic review of the sensitivity of the Wisconsin Card Sorting Test to frontal and lateralized frontal brain damage. Neuropsychology 17, 255-264.

Dietz, J., Bradley, M.M., Jones, J., Okun, M.S., Perlstein, W.M., Bowers, D., 2013. The late positive potential, emotion and apathy in Parkinson's disease. Neuropsychologia 51, 960966.

Dirnberger, G., Jahanshahi, M., 2013. Executive dysfunction in Parkinson's disease: a review. J. Neuropsychol. 7, 193-224.

Donkers, F.C., van Boxtel, G.J.M., 2004. The N2 in go/no-go tasks reflects conflict monitoring not response inhibition. Brain Cogn. 56, 165-176. 
Dubois, B., Pillon, B., 1997. Cognitive deficits in Parkinson's disease. J. Neurol. 244, 2-8.

Duncan, C.C., Barry, R.J., Connolly, J.F., Fischer, C., Michie, P.T., Näätänen, R., Polich, J., Reinvang, I., Van Petten, C., 2009. Event-related potentials in clinical research: guidelines for eliciting, recording, and quantifying mismatch negativity, P300, and N400. Clin. Neurophysiol. 120, 1883-1908.

Ebmeier, K.P., Potter, D.D., Cochrane, R.H., Crawford, J.R., Stewart, L., Calder, S.A., Besson, J.A., Salzen, E.A., 1992. Event related potentials, reaction time, and cognitive performance in idiopathic Parkinson's disease. Biol. Psychol. 33, 73-89.

Egner, T., 2007. Congruency sequence effects and cognitive control. Cogn. Affect. Behav. Neurosci. 7, 380-390.

Eigsti, I.M., Zayas, V., Mischel, W., Shoda, Y., Ayduk, O., Dadlani, M.B., Davidson, M.C., Lawrence Aber, J., Casey, B.J., 2006. Predicting cognitive control from preschool to late adolescence and young adulthood. Psychol. Sci. 17, 478-484.

Elwan, O.H., Baradah, O.H., Madkour, O., Elwan, H., Hassan, A.A., Elwan, F., Mahfouz, M., Ali, A., Fahmy, M., 1996. Parkinson's disease, cognition and aging. Clinical, neuropsychological, electrophysiological and cranial computerized tomographic assessment. J. Neurol. Sci. 143, 64-71.

Emre, M., Aarsland, D., Albanese, A., Byrne, E.J., Deuschl, G., De Deyn, P.P., Durif, F., Kulisevsky, J., van Laar, T., Lees, A., Poewe, W., Robillard, A., Rosa, M.M., Wolters, E., Quarg, P., Tekin, S., Lane, R., 2004. Rivastigmine for dementia associated with Parkinson's disease. N. Engl. J. Med. 351, 2509-2518. 
Eriksen, B.A., Eriksen, C.W., 1974. Effects of noise letters upon the identification of a target letter in a nonsearch task. Percept. Psychophys. 16, 143-149.

Escera, C., Alho, K., Schröger, E., Winkler, I., 2000. Involuntary attention and distractibility as evaluated with event-related brain potentials. Audiol. Neurootol. 5, 151-166.

Escera, C., Corral, M., 2007. Role of mismatch negativity and novelty-P3 in involuntary auditory attention. J. Psychophysiol. 21, 251-264.

Falkenstein, M., Hielscher, H., Dziobek, I., Schwarzenau, P., Hoormann, J., Sunderman, B., Hohnsbein, J., 2001. Action monitoring, error detection, and the basal ganglia: an ERP study. NeuroReport 12, 157-161.

Falkenstein, M., Hohnsbein, J., Hoormann, J., Blanke, L., 1990. Effects of errors in choice reaction tasks on the ERP under focused and divided attention, in Brunia, C.H.M., Gaillard, A.W.K., Kok, A. (Eds.), Psychophysiological Brain Research. Tilburg University Press, Tilburg, The Netherlands, pp. 192-195.

Falkenstein, M., Hohnsbein, J., Hoormann, J., Blanke, L., 1991. Effects of crossmodal divided attention on late ERP components. II. Error processing in choice reaction tasks. Electroencephalogr. Clin. Neurophysiol. 78, 447-455.

Falkenstein, M., Hoormann, J., Christ, S., Hohnsbein, J., 2000. ERP components on reaction errors and their functional significance: a tutorial. Biol. Psychol. 51, 87-107.

Falkenstein, M., Hoormann, J., Hohnsbein, J., 1999. ERP components in Go/Nogo tasks and their relation to inhibition. Acta Psychol. 101, 267-291. 
Falkenstein, M., Koshlykova, N.A., Kiroj, V.N., Hoormann, J., Hohnsbein, J., 1995. Late ERP components in visual and auditory Go/Nogo tasks. Electroencephalogr. Clin. Neurophysiol. $96,36-43$.

Fallon, S.J., Williams-Gray, C.H., Barker, R.A., Owen, A.M., Hampshire, A., 2013. Prefrontal dopamine levels determine the balance between cognitive stability and flexibility. Cereb. Cortex 23, 361-369.

Filipović, S., Kostić, V.S., Sternić, N., Marinković, Z., Ocić, G., 1990. Auditory event-related potentials in different types of dementia. Eur. Neurol. 30, 189-193.

Fogelson, N., Fernandez-del-Olmo, M., Santos-Garcia, D., 2011. Contextual processing deficits in Parkinson's disease: the role of the frontostriatal system. Clin. Neurophysiol. 122, 539545.

Folstein, J.R., Van Petten, C., 2008. Influence of cognitive control and mismatch on the N2 component of the ERP: a review. Psychophysiology 45, 152-170.

Folstein, M.F., Folstein, S.E., McHugh, P.R., 1975. "Mini-mental state": a practical method for grading the cognitive state of patients for the clinician. J. Psychiatr. Res. 12, 189-198.

Forster, S.E., Carter, C.S., Cohen, J.D., Cho, R.Y., 2011. Parametric manipulation of the conflict signal and control-state adaptation. J. Cogn. Neurosci. 23, 923-935.

Frank, M.J., Seeberger, L.C., O'Reilly, R.C., 2004. By carrot or by stick: cognitive reinforcement learning in parkinsonism. Science 306, 1940-1943. 
Friederici, A.D., Kotz, S.A., Werheid, K., Hein, G., von Cramon, D.Y., 2003. Syntactic comprehension in Parkinson's disease: investigating early automatic and late integrational processes using event-related brain potentials. Neuropsychology 17, 133-142.

Friedman, D., Cycowicz, Y.M., Gaeta, H., 2001. The novelty P3: an event-related brain potential (ERP) sign of the brain's evaluation of novelty. Neurosci. Biobehav. Rev. 25, 355-373.

Garrido-Vásquez, P., Pell, M.D., Paulmann, S., Sehm, B., Kotz, S.A., 2016. Impaired neural processing of dynamic faces in left-onset Parkinson's disease. Neuropsychologia 82, 123133.

Garrido-Vásquez, P., Pell, M.D., Paulmann, S., Strecker, K., Schwarz, J., Kotz, S.A., 2013. An ERP study of vocal emotion processing in asymmetric Parkinson's disease. Soc. Cogn. Affect. Neurosci. 8, 918-927.

Gaudreault, P.O., Gagnon, J.F., Montplaisir, J., Vendette, M., Postuma, R.B., Gagnon, K., Gosselin, N., 2013. Abnormal occipital event-related potentials in Parkinson's disease with concomitant REM sleep behavior disorder. Parkinsonism Relat. Disord. 19, 212-217.

Gehring, W.J., Goss, B., Coles, M.G.H., Meyer, D.E., Donchin, E., 1993. A neural system for error detection and compensation. Psychol. Sci. 4, 385-390.

Georgiev, D., Jahanshahi, M., Dreo, J., Čuš, A., Pirtošek, Z., Repovš, G., 2015. Dopaminergic medication alters auditory distractor processing in Parkinson's disease. Acta Psychol. 156, 45-56. 
Georgiev, D., Lange, F., Seer, C., Kopp, B., Jahanshahi, M., 2016. Movement-related potentials in Parkinson's disease. Clin. Neurophysiol. 127, 2509-2519.

Gerschlager, W., Bloem, B.R., Alesch, F., Lang, W., Deecke, L., Cunnington, R., 2001. Bilateral subthalamic nucleus stimulation does not improve prolonged P300 latencies in Parkinson's disease. J. Neurol. 248, 285-289.

Giard, M.H., Perrin, F., Pernier, J., Bouchet, P., 1990. Brain generators implicated in the processing of auditory stimulus deviance: a topographic event-related potential study. Psychophysiology 27, 627-640.

Gil, R., Neau, J.P., Toullat, G., Rivasseau-Jonveaux, T., Lefèvre, J.P., 1989. Maladie de Parkinson et potentiels évoqués cognitifs [Parkinson's disease and cognitive event-related potentials]. Rev. Neurol. 145, 201-207.

Golob, E.J., Starr, A., 2000. Effects of stimulus sequence on event-related potentials and reaction time during target detection in Alzheimer's disease. Clin. Neurophysiol. 111, 1438-1449.

Goodin, D.S., Aminoff, M.J., 1986. Electrophysiological differences between subtypes of dementia. Brain 109, 1103-1113.

Goodin, D.S., Aminoff, M.J., 1987. Electrophysiological differences between demented and nondemented patients with Parkinson's disease. Ann. Neurol. 21, 90-94.

Gotham, A.M., Brown, R.G., Marsden, C.D., 1988. 'Frontal' cognitive function in patients with Parkinson's disease 'on' and 'off' levodopa. Brain 111, 299-321. 
Graham, J.S., Yiannikas, C., Gordon, E., Coyle, S., Morris, J.G., 1990. P300 event-related potentials in de novo Parkinson's disease. Clin. Exp. Neurol. 27, 89-98.

Gratwicke, J., Jahanshahi, M., Foltynie, T., 2015. Parkinson's disease dementia: a neural networks perspective. Brain 138, 1454-1476.

Green, J., Woodard, J.L., Sirockman, B.E., Zakers, G.O., Maier, C.L., Green, R.C., Watts, R.L., 1996. Event-related potential P3 change in mild Parkinson's disease. Mov. Disord. 11, 32-42.

Hanafusa, H., Motomura, N., Fukai, M., 1991. Event-related potentials in senile dementia of Alzheimer's type, multiinfarct dementia and Parkinson's disease. Jpn. J. Psychiatry Neurol. 45, 667-670.

Hansch, E.C., Syndulko, K., Cohen, S.N., Goldberg, Z.I., Potvin, A.R., Tourtellotte, W.W., 1982. Cognition in Parkinson disease: an event-related potential perspective. Ann. Neurol. 11, 599607.

Hautecœur, P., Gallois, P., Forzy, G., Chatelet, P., Choteau, P., Dereux, J.F., 1991. Potentiels évoqués auditifs tardifs dans les détériorations cognitives sous-corticales [Late auditory evoked potentials in subcortical cognitive deterioration]. Rev. Neurol. 147, 293-299.

Hawkes, C.H., Del Tredici, K., Braak, H., 2010. A timeline for Parkinson's disease. Parkinsonism Relat. Disord. 16, 79-84.

Hayashi, R., Hanyu, N., Kurashima, T., Tokutake, T., Yanagisawa, N., 1996. Relationship between cognitive impairments, event-related potentials, and motor disability scores in patients with Parkinson's disease: 2-year follow-up study. J. Neurol. Sci. 141, 45-48. 
Hayashi, R., Hanyu, N., Shindo, M., Tamaru, F., Yanagisawa, N., 1993. Event-related potentials, reaction time, and cognitive state in patients with Parkinson's disease. Adv. Neurol. 60, 429433.

Heaton, R.K., Chelune, G.J., Talley, J.L., Kay, G.G., Curtiss, G., 1993. Wisconsin Card Sorting Test Manual. Revised and Expanded. Psychological Assessment Resources, Odessa, FL.

Hesselbrock, V., Begleiter, H., Porjesz, B., O'Connor, S., Bauer, L., 2001. P300 event-related potential amplitude as an endophenotype of alcoholism--evidence from the collaborative study on the genetics of alcoholism. J. Biomed. Sci. 8, 77-82.

Holroyd, C.B., Coles, M.G.H., 2002. The neural basis of human error processing: reinforcement learning, dopamine, and the error-related negativity. Psychol. Rev. 109, 679-709.

Holroyd, C.B., Praamstra, P., Plat, E., Coles, M.G.H., 2002. Spared error-related potentials in mild to moderate Parkinson's disease. Neuropsychologia 40, 2116-2124.

Hozumi, A., Hirata, K., Tanaka, H., Yamazaki, K., 2000. Perseveration for novel stimuli in Parkinson's disease: an evaluation based on event-related potentials topography. Mov. Disord. $15,835-842$.

Huster, R.J., Enriquez-Geppert, S., Lavallee, C.F., Falkenstein, M., Herrmann, C.S., 2013. Electroencephalography of response inhibition tasks: functional networks and cognitive contributions. Int. J. Psychophysiol. 87, 217-233. 
Huster, R.J., Westerhausen, R., Pantev, C., Konrad, C., 2010. The role of the cingulate cortex as neural generator of the N200 and P300 in a tactile response inhibition task. Hum. Brain Mapp. 31, 1260-1271.

Iijima, M., Osawa, M., Iwata, M., Miyazaki, A., Tei, H., 2000. Topographic mapping of P300 and frontal cognitive function in Parkinson's disease. Behav. Neurol. 12, 143-148.

Irwin, D.J., Lee, V.M., Trojanowski, J.Q., 2013. Parkinson's disease dementia: convergence of alpha-synuclein, tau and amyloid-beta pathologies. Nat. Rev. Neurosci. 14, 626-636.

Ito, J., 1994. Somatosensory event-related potentials (ERPs) in patients with different types of dementia. J. Neurol. Sci. 121, 139-146.

Ito, J., Kitagawa, J., 2006. Performance monitoring and error processing during a lexical decision task in patients with Parkinson's disease. J. Geriatr. Psychiatry Neurol. 19, 46-54.

Jahanshahi, M., Wilkinson, L., Gahir, H., Dharmaindra, A., Lagnado, D.A., 2010. Medication impairs probabilistic classification learning in Parkinson's disease. Neuropsychologia 48, 1096-1103.

Jiang, C., Kaseda, Y., Kumagai, R., Nakano, Y., Nakamura, S., 2000. Habituation of eventrelated potentials in patients with Parkinson's disease. Physiol. Behav. 68, 741-747.

Jocham, G., Ullsperger, M., 2009. Neuropharmacology of performance monitoring. Neurosci. Biobehav. Rev. 33, 48-60.

Johnson, R.,Jr., 1988. The amplitude of the P300 component of the event-related potential: Review and synthesis. Adv Psychophysiol 3, 69-137. 
Johnson, R.,Jr., 1995. Event-related potential insights into altered sensory and cognitive processing in dementia, in Boller, F., Grafman, J. (Eds.), Handbook of Neuropsychology: Vol. 10, Section 14. Event-Related Brain Potentials and Cognition. Elsevier, Amsterdam, pp. 241-267.

Kamitani, T., Kuroiwa, Y., 2009. Visual event-related potential changes in multiple system atrophy: delayed N2 latency in selective attention to a color task. Parkinsonism Relat. Disord. 15, 36-40.

Kamitani, T., Kuroiwa, Y., Wang, L., Li, M., Suzuki, Y., Takahashi, T., Ikegami, T., Matsubara, S., 2002. Visual event-related potential changes in two subtypes of multiple system atrophy, MSA-C and MSA-P. J. Neurol. 249, 975-982.

Karayanidis, F., Andrews, S., Ward, P.B., Michie, P.T., 1995. ERP indices of auditory selective attention in aging and Parkinson's disease. Psychophysiology 32, 335-350.

Karlin, L., Martz, M.J., Mordkoff, A.M., 1970. Motor performance and sensory-evoked potentials. Electroencephalogr. Clin. Neurophysiol. 28, 307-313.

Kaseda, Y., Kamei, H., Kohriyama, T., Mimori, Y., Yamaguchi, S., Yamamura, Y., Nakamura, S., 1996. Event-Related Potentials and Cerebral Blood Flow in Idiopathic Parkinson's Disease and Juvenile Parkinsonism, in Ohye, C., Kimura, M., McKenzie, J.S. (Eds.), The Basal Ganglia V. Springer, New York, NY, pp. 343-346.

Katsarou, Z., Bostantjopoulou, S., Kimiskidis, V., Rossopoulos, E., Kazis, A., 2004. Auditory event-related potentials in Parkinson's disease in relation to cognitive ability. Percept. Mot. Skills 98, 1441-1448. 
Kaufman, D.A., Bowers, D., Okun, M.S., Van Patten, R., Perlstein, W.M., 2016. Apathy, Novelty Processing, and the P3 Potential in Parkinson's Disease. Front Neurol 7, 95.

Kehagia, A.A., Barker, R.A., Robbins, T.W., 2013. Cognitive impairment in Parkinson's disease: the dual syndrome hypothesis. Neurodegener. Dis. 11, 79-92.

Kida, Y., Tachibana, H., Takeda, M., Yoshikawa, H., Okita, T., 2007. Recognition memory for unfamiliar faces in Parkinson's disease: behavioral and electrophysiologic measures. Parkinsonism Relat. Disord. 13, 157-164.

Kim, G.W., Sohn, Y.H., Huh, K., Kim, J.S., 1995. Relationship between the auditory P300 and the procedural memory function in drug-naive patients with Parkinson's disease. Yonsei Med. J. 36, 367-371.

Knight, R.T., 1984. Decreased response to novel stimuli after prefrontal lesions in man. Electroencephalogr. Clin. Neurophysiol. 59, 9-20.

Kobayashi, Y., Hirata, K., Hozumi, A., Tanaka, H., Arai, M., Kaji, Y., Kadowaki, T., Daimon, Y., 2004. Influence of the levodopa on frontal lobe dysfunction in patients with de novo Parkinson's disease. Int. Congr. Ser. 1270, 270-274.

Kok, A., 2001. On the utility of P3 amplitude as a measure of processing capacity. Psychophysiology 38, 557-577.

Kolossa, A., Fingscheidt, T., Wessel, K., Kopp, B., 2013. A model-based approach to trial-bytrial P300 amplitude fluctuations. Front. Hum. Neurosci. 6, 359. 
Kopp, B., Lange, F., 2013. Electrophysiological indicators of surprise and entropy in dynamic task-switching environments. Front. Hum. Neurosci. 7, 300.

Kopp, B., Mattler, U., Goertz, R., Rist, F., 1996a. N2, P3 and the lateralized readiness potential in a nogo task involving selective response priming. Electroencephalogr. Clin. Neurophysiol. 99, 19-27.

Kopp, B., Rist, F., Mattler, U., 1996b. N200 in the flanker task as a neurobehavioral tool for investigating executive control. Psychophysiology 33, 282-294.

Kopp, B., Tabeling, S., Moschner, C., Wessel, K., 2007. Temporal dynamics of selective attention and conflict resolution during cross-dimensional Go-NoGo decisions. BMC Neurosci. 8, 68.

Kopp, B., Wessel, K., 2010. Event-related brain potentials and cognitive processes related to perceptual-motor information transmission. Cogn. Affect. Behav. Neurosci. 10, 316-327.

Kovacs, N., Balas, I., Kellenyi, L., Janszky, J., Feldmann, A., Llumiguano, C., Doczi, T.P., Ajtay, Z., Nagy, F., 2008. The impact of bilateral subthalamic deep brain stimulation on longlatency event-related potentials. Parkinsonism Relat. Disord. 14, 476-480.

Kurita, A., Murakami, M., Takagi, S., Matsushima, M., Suzuki, M., 2010. Visual hallucinations and altered visual information processing in Parkinson disease and dementia with Lewy bodies. Mov. Disord. 25, 167-171.

Kutas, M., Hillyard, S.A., 1980. Reading senseless sentences: brain potentials reflect semantic incongruity. Science 207, 203-205. 
Kutas, M., McCarthy, G., Donchin, E., 1977. Augmenting mental chronometry: the P300 as a measure of stimulus evaluation time. Science 197, 792-795.

Kutukcu, Y., Marks, W.J.,Jr, Goodin, D.S., Aminoff, M.J., 1998. Cerebral accompaniments to simple and choice reaction tasks in Parkinson's disease. Brain Res. 799, 1-5.

Lagopoulos, J., Clouston, P., Barhamali, H., Gordon, E., Li, W.M., Lesley, J., Morris, J.G., 1998a. Late components of the event-related potentials and their topography in Parkinson's disease. Mov. Disord. 13, 262-267.

Lagopoulos, J., Gordon, E., Barhamali, H., Lim, C.L., Li, W.M., Clouston, P., Morris, J.G., 1998b. Dysfunctions of automatic (P300a) and controlled (P300b) processing in Parkinson's disease. Neurol. Res. 20, 5-10.

Lange, F., Eggert, F., 2015. Mapping self-reported to behavioral impulsiveness: the role of task parameters. Scand. J. Psychol. 56, 115-123.

Lange, F., Seer, C., Finke, M., Dengler, R., Kopp, B., 2015. Dual routes to cortical orienting responses: novelty detection and uncertainty reduction. Biol. Psychol. 105, 66-71.

Lange, F., Seer, C., Rapior, M., Rose, J., Eggert, F., 2014. Turn it all you want: Still no effect of sugar consumption on ego depletion. J. Eur. Psychol. Stud. 5, 1-8.

Lange, F., Seer, C., Salchow, C., Dengler, R., Dressler, D., Kopp, B., 2016a. Meta-analytical and electrophysiological evidence for executive dysfunction in primary dystonia. Cortex 82, 133146. 
Lange, F., Vogts, M., Seer, C., Fürkötter, S., Abdulla, S., Dengler, R., Kopp, B., Petri, S., 2016b. Impaired set-shifting in amyotrophic lateral sclerosis: An event-related potential study of executive function. Neuropsychology 30, 120-134.

Larson, M.J., Clayson, P.E., Baldwin, S.A., 2012. Performance monitoring following conflict: internal adjustments in cognitive control? Neuropsychologia 50, 426-433.

Laton, J., Van Schependom, J., Gielen, J., Decoster, J., Moons, T., De Keyser, J., De Hert, M., Nagels, G., 2014. Single-subject classification of schizophrenia patients based on a combination of oddball and mismatch evoked potential paradigms. J. Neurol. Sci. 347, 262267.

Lavric, A., Pizzagalli, D.A., Forstmeier, S., 2004. When 'go' and 'nogo' are equally frequent: ERP components and cortical tomography. Eur. J. Neurosci. 20, 2483-2488.

Lee, E.Y., Cowan, N., Vogel, E.K., Rolan, T., Valle-Inclán, F., Hackley, S.A., 2010. Visual working memory deficits in patients with Parkinson's disease are due to both reduced storage capacity and impaired ability to filter out irrelevant information. Brain 133, 2677-2689.

Leuthold, H., 2011. The Simon effect in cognitive electrophysiology: A short review. Acta Psychol. 136, 203-211.

Li, M., Kuroiwa, Y., Wang, L., Kamitani, T., Omoto, S., Hayashi, E., Takahashi, T., Suzuki, Y., Koyano, S., Ikegami, T., Matsubara, S., 2005. Visual event-related potentials under different interstimulus intervals in Parkinson's disease: relation to motor disability, WAIS-R, and regional cerebral blood flow. Parkinsonism Relat. Disord. 11, 209-219. 
Light, G.A., Makeig, S., 2015. Electroencephalographic biomarkers of psychosis: present and future. Biol. Psychiatry 77, 87-89.

Light, G.A., Swerdlow, N.R., Thomas, M.L., Calkins, M.E., Green, M.F., Greenwood, T.A., Gur, R.E., Gur, R.C., Lazzeroni, L.C., Nuechterlein, K.H., Pela, M., Radant, A.D., Seidman, L.J., Sharp, R.F., Siever, L.J., Silverman, J.M., Sprock, J., Stone, W.S., Sugar, C.A., Tsuang, D.W., Tsuang, M.T., Braff, D.L., Turetsky, B.I., 2015. Validation of mismatch negativity and P3a for use in multi-site studies of schizophrenia: characterization of demographic, clinical, cognitive, and functional correlates in COGS-2. Schizophr. Res. 163, 63-72.

Liotti, M., Pliszka, S.R., Perez, R., Kothmann, D., Woldorff, M.G., 2005. Abnormal brain activity related to performance monitoring and error detection in children with ADHD. Cortex 41, 377-388.

Lopes, M.S., Melo, A.S., Nóbrega, A.C., 2014. Delayed latencies of auditory evoked potential P300 are associated with the severity of Parkinson's disease in older patients. Arq. Neuropsiquiatr. 72, 296-300.

Luck, S.J., 2014. An Introduction to the Event-Related Potential Technique, 2 ed. MIT Press, Cambridge, MA.

Luck, S.J., Mathalon, D.H., O'Donnell, B.F., Hämäläinen, M.S., Spencer, K.M., Javitt, D.C., Uhlhaas, P.J., 2011. A Roadmap for the Development and Validation of Event-Related Potential Biomarkers in Schizophrenia Research. Biol. Psychiatry 70, 28-34. 
Lukhanina, E.P., Kapustina, M.T., Berezetskaya, N.M., Karaban, I.N., 2009. Reduction of the postexcitatory cortical inhibition upon paired-click auditory stimulation in patients with Parkinson's disease. Clin. Neurophysiol. 120, 1852-1858.

Lukhanina, E.P., Mel'nik, N.A., Berezetskaya, N.M., Karaban, I.N., 2008. Correlations between indices of P300 EEG potential, cognitive tests, and variational pulsometry in Parkinsonian patients. Neurophysiology 40, 39-47.

Luria, R., Balaban, H., Awh, E., Vogel, E.K., 2016. The contralateral delay activity as a neural measure of visual working memory. Neurosci. Biobehav. Rev. 62, 100-108.

Maeshima, S., Itakura, T., Komai, N., Matsumoto, T., Ueyoshi, A., 2002. Relationships between event-related potentials (P300) and activities of daily living in Parkinson's disease. Brain Inj. $16,1-8$.

Mapelli, D., Di Rosa, E., Cavalletti, M., Schiff, S., Tamburin, S., 2014. Decision and dopaminergic system: an ERPs study of Iowa gambling task in Parkinson's disease. Front. Psychol. 5, 684.

Martínez-Horta, S., Riba, J., de Bobadilla, R.F., Pagonabarraga, J., Pascual-Sedano, B., Antonijoan, R.M., Romero, S., Mañanas, M.À, García-Sanchez, C., Kulisevsky, J., 2014. Apathy in Parkinson's disease: neurophysiological evidence of impaired incentive processing. J. Neurosci. 34, 5918-5926.

Mathalon, D.H., Whitfield, S.L., Ford, J.M., 2003. Anatomy of an error: ERP and fMRI. Biol. Psychol. 64, 119-141. 
Mathis, S., Neau, J.P., Pluchon, C., Fargeau, M.N., Karolewicz, S., Iljicsov, A., Gil, R., 2014. Apathy in Parkinson's disease: an electrophysiological study. Neurol. Res. Int. 2014, 290513.

Matsui, H., Nishinaka, K., Oda, M., Kubori, T., Udaka, F., 2007. Auditory event-related potentials in Parkinson's disease: prominent correlation with attention. Parkinsonism Relat. Disord. 13, 394-398.

Mattox, S.T., Valle-Inclán, F., Hackley, S.A., 2006. Psychophysiological evidence for impaired reward anticipation in Parkinson's disease. Clin. Neurophysiol. 117, 2144-2153.

McCarthy, G., Donchin, E., 1981. A metric for thought: a comparison of P300 latency and reaction time. Science $211,77-80$.

Miller, I.N., Neargarder, S., Risi, M.M., Cronin-Golomb, A., 2013. Frontal and posterior subtypes of neuropsychological deficit in Parkinson's disease. Behav. Neurosci. 127, 175183.

Milner, B., 1963. Effects of different brain lesions on card sorting: The role of the frontal lobes. Arch. Neurol. 9, 90-100.

Miltner, W.H., Braun, C.H., Coles, M.G.H., 1997. Event-related brain potentials following incorrect feedback in a time-estimation task: evidence for a "generic" neural system for error detection. J. Cogn. Neurosci. 9, 788-798.

Minamoto, H., Tachibana, H., Sugita, M., Okita, T., 2001. Recognition memory in normal aging and Parkinson's disease: behavioral and electrophysiologic measures. Cogn. Brain Res. 11, 23-32. 
Monchi, O., Petrides, M., Doyon, J., Postuma, R.B., Worsley, K., Dagher, A., 2004. Neural bases of set-shifting deficits in Parkinson's disease. J. Neurosci. 24, 702-710.

Monchi, O., Petrides, M., Petre, V., Worsley, K., Dagher, A., 2001. Wisconsin Card Sorting revisited: distinct neural circuits participating in different stages of the task identified by event-related functional magnetic resonance imaging. J. Neurosci. 21, 7733-7741.

Morita, K., Shoji, H., Yamamoto, H., Nishiura, S., Shoji, Y., Matuoka, T., Maeda, H., 2005. Characteristics of cognitive function in patients with Parkinson's disease: a comparison with healthy subjects. Int. Congr. Ser. 1278, 344-347.

Münte, T.F., Heldmann, M., Hinrichs, H., Marco-Pallares, J., Krämer, U.M., Sturm, V., Heinze, H.J., 2008. Contribution of subcortical structures to cognition assessed with invasive electrophysiology in humans. Front. Neurosci. 2, 72-78.

Münte, T.F., Joppich, G., Dauper, J., Schrader, C., Dengler, R., Heldmann, M., 2015. Random Number Generation and Executive Functions in Parkinson's Disease: An Event-Related Brain Potential Study. J. Parkinsons Dis. 5, 613-620.

Näätänen, R., Gaillard, A.W., Mantysalo, S., 1978. Early selective-attention effect on evoked potential reinterpreted. Acta Psychol. 42, 313-329.

Näätänen, R., Paavilainen, P., Rinne, T., Alho, K., 2007. The mismatch negativity (MMN) in basic research of central auditory processing: a review. Clin. Neurophysiol. 118, 2544-2590.

Näätänen, R., Winkler, I., 1999. The concept of auditory stimulus representation in cognitive neuroscience. Psychol. Bull. 125, 826-859. 
Naskar, S., Sood, S.K., Goyal, V., 2010. Effect of acute deep brain stimulation of the subthalamic nucleus on auditory event-related potentials in Parkinson's disease. Parkinsonism Relat. Disord. 16, 256-260.

Neuhaus, A.H., Popescu, F.C., Grozea, C., Hahn, E., Hahn, C., Opgen-Rhein, C., Urbanek, C., Dettling, M., 2011. Single-subject classification of schizophrenia by event-related potentials during selective attention. NeuroImage 55, 514-521.

Nieuwenhuis, S., Aston-Jones, G., Cohen, J.D., 2005. Decision making, the P3, and the locus coeruleus-norepinephrine system. Psychol. Bull. 131, 510-532.

Nieuwenhuis, S., Yeung, N., van den Wildenberg, W., Ridderinkhof, K.R., 2003.

Electrophysiological correlates of anterior cingulate function in a go/no-go task: effects of response conflict and trial type frequency. Cogn. Affect. Behav. Neurosci. 3, 17-26.

Nojszewska, M., Pilczuk, B., Zakrzewska-Pniewska, B., Rowińska-Marcińska, K., 2009. The auditory system involvement in Parkinson disease: electrophysiological and neuropsychological correlations. J. Clin. Neurophysiol. 26, 430-437.

O'Donnell, B.F., Squires, N.K., Martz, M.J., Chen, J.R., Phay, A.J., 1987. Evoked potential changes and neuropsychological performance in Parkinson's disease. Biol. Psychol. 24, 2337.

Oishi, M., Mochizuki, Y., Hara, M., Du, C.M., Takasu, T., 1996. Effects of intravenous L-dopa on P300 and regional cerebral blood flow in parkinsonism. Int. J. Neurosci. 85, 147-154. 
Olichney, J.M., Yang, J.C., Taylor, J., Kutas, M., 2011. Cognitive event-related potentials: biomarkers of synaptic dysfunction across the stages of Alzheimer's disease. J. Alzheimers Dis. 26 Suppl 3, 215-228.

Olincy, A., Braff, D.L., Adler, L.E., Cadenhead, K.S., Calkins, M.E., Dobie, D.J., Green, M.F., Greenwood, T.A., Gur, R.E., Gur, R.C., Light, G.A., Mintz, J., Nuechterlein, K.H., Radant, A.D., Schork, N.J., Seidman, L.J., Siever, L.J., Silverman, J.M., Stone, W.S., Swerdlow, N.R., Tsuang, D.W., Tsuang, M.T., Turetsky, B.I., Wagner, B.D., Freedman, R., 2010. Inhibition of the P50 cerebral evoked response to repeated auditory stimuli: results from the Consortium on Genetics of Schizophrenia. Schizophr. Res. 119, 175-182.

Olvet, D.M., Hajcak, G., 2012. The error-related negativity relates to sadness following mood induction among individuals with high neuroticism. Soc. Cogn. Affect. Neurosci. 7, 289295.

Osawa, M., Takeuchi, M., Iijima, M., Ushijima, R., Iwata, M., 2005. Depressive state in Parkinson's disease: evaluation by the self-rating depression scale and nogo components of event-related potentials. Int. Congr. Ser. 1278, 341-343.

Osterhout, L., Holcomb, P.J., 1992. Event-related brain potentials elicited by syntactic anomaly. Journal of Memory and Language 31, 785-806.

Pekkonen, E., Ahveninen, J., Teräväinen, H., 2000. Auditory discrimination is preserved in Parkinson's disease. NeuroImage 11, S142. 
Pekkonen, E., Jousmäki, V., Reinikainen, K., Partanen, J., 1995. Automatic auditory discrimination is impaired in Parkinson's disease. Electroencephalogr. Clin. Neurophysiol. 95, 47-52.

Philipova, D., Gatchev, G., Vladova, T., Georgiev, D., 1997. Event-related potentials in parkinsonian patients under auditory discrimination tasks. Int. J. Psychophysiol. 27, 69-78.

Pierrot-Deseilligny, C., Turell, E., Penet, C., Lebrigand, D., Pillon, B., Chain, F., Agid, Y., 1989. Increased wave P 300 latency in progressive supranuclear palsy. J. Neurol. Neurosurg. Psychiatry 52, 656-658.

Pires, L., Leitão, J., Guerrini, C., Simões, M.R., 2014. Event-related brain potentials in the study of inhibition: cognitive control, source localization and age-related modulations. Neuropsychol. Rev. 24, 461-490.

Pirtošek, Z., Jahanshahi, M., Barrett, G., Lees, A.J., 2001. Attention and cognition in bradykinetic-rigid syndromes: An event-related potential study. Ann. Neurol. 50, 567-573.

Polich, J., 2007. Updating P300: an integrative theory of P3a and P3b. Clin. Neurophysiol. 118, 2128-2148.

Polich, J., Ehlers, C.L., Otis, S., Mandell, A.J., Bloom, F.E., 1986. P300 latency reflects the degree of cognitive decline in dementing illness. Electroencephalogr. Clin. Neurophysiol. $63,138-144$.

Polich, J., Ladish, C., Bloom, F.E., 1990. P300 assessment of early Alzheimer's disease. Electroencephalogr. Clin. Neurophysiol. 77, 179-189. 
Potagas, C., Bathien, N., Hugelin, A., 2003. Visuo-Spatial Attention in Non-Demented Patients with Parkinson's Disease: An Event-Related Potential Study, in Graybiel, A.M., Delong, M.R., Kitai, S.T. (Eds.), The Basal Ganglia VI. Springer, New York, NY, pp. 61-81.

Praamstra, P., Plat, F.M., 2001. Failed suppression of direct visuomotor activation in Parkinson's disease. J. Cogn. Neurosci. 13, 31-43.

Praamstra, P., Stegeman, D.F., Cools, A.R., Horstink, M.W., 1998. Reliance on external cues for movement initiation in Parkinson's disease. Evidence from movement-related potentials. Brain 121, 167-177.

Prabhakar, S., Syal, P., Srivastava, T., 2000. P300 in newly diagnosed non-dementing Parkinson's disease: effect of dopaminergic drugs. Neurol. India 48, 239-242.

Prasher, D., Findley, L., 1991. Dopaminergic induced changes in cognitive and motor processing in Parkinson's disease: an electrophysiological investigation. J. Neurol. Neurosurg. Psychiatry 54, 603-609.

Pulvermüller, F., Lutzenberger, W., Müller, V., Mohr, B., Dichgans, J., Birbaumer, N., 1996. P3 and contingent negative variation in Parkinson's disease. Electroencephalogr. Clin. Neurophysiol. 98, 456-467.

Rangel, A., Camerer, C., Montague, P.R., 2008. A framework for studying the neurobiology of value-based decision making. Nat. Rev. Neurosci. 9, 545-556.

Raudino, F., Garavaglia, P., Beretta, S., Pellegrini, G., 1997. Auditory event-related potentials in Parkinson's disease. Electromyogr. Clin. Neurophysiol. 37, 409-413. 
Ritter, W., Vaughan, H.G.,Jr, 1969. Averaged evoked responses in vigilance and discrimination: a reassessment. Science 164, 326-328.

Robbins, T.W., Cools, R., 2014. Cognitive deficits in Parkinson's disease: a cognitive neuroscience perspective. Mov. Disord. 29, 597-607.

Roberts, L.E., Rau, H., Lutzenberger, W., Birbaumer, N., 1994. Mapping P300 waves onto inhibition: Go/No-Go discrimination. Electroencephalogr. Clin. Neurophysiol. 92, 44-55.

Roche, R.A., Garavan, H., Foxe, J.J., O'Mara, S.M., 2005. Individual differences discriminate event-related potentials but not performance during response inhibition. Exp. Brain Res. 160, 60-70.

Rumbach, L., Tranchant, C., Viel, J.F., Warter, J.M., 1993. Event-related potentials in Parkinson's disease: a 12-month follow-up study. J. Neurol. Sci. 116, 148-151.

Rustamov, N., Rodriguez-Raecke, R., Timm, L., Agrawal, D., Dressler, D., Schrader, C., Tacik, P., Wegner, F., Dengler, R., Wittfoth, M., Kopp, B., 2013. Absence of congruency sequence effects reveals neurocognitive inflexibility in Parkinson's disease. Neuropsychologia 51, 2976-2987.

Rustamov, N., Rodriguez-Raecke, R., Timm, L., Agrawal, D., Dressler, D., Schrader, C., Tacik, P., Wegner, F., Dengler, R., Wittfoth, M., Kopp, B., 2014. Attention shifting in Parkinson's disease: an analysis of behavioral and cortical responses. Neuropsychology 28, 929-944.

Růžička, E., El Massioui, F., 1993. Event-related potentials in Parkinson's disease: a review. Behav. Neurol. 6, 15-26. 
Růžička, E., El Massioui, F., Pillon, B., Dubois, B., Renault, B., Agid, Y., 1998. Dopaminergic modulation of cognition in Parkinson's disease: the effects of apomorphine. Med. Sci. Monit. 4, CR786-CR796.

Růžička, E., Roth, J., Špačková, N., Mečíř, P., Jech, R., 1994. Apomorphine induced cognitive changes in Parkinson's disease. J. Neurol. Neurosurg. Psychiatry 57, 998-1001.

Ryterska, A., Jahanshahi, M., Osman, M., 2013. What are people with Parkinson's disease really impaired on when it comes to making decisions? A meta-analysis of the evidence. Neurosci. Biobehav. Rev. 37, 2836-2846.

Sagliocco, L., Bandini, F., Pierantozzi, M., Mari, Z., Tzelepi, A., Ko, C., Gulzar, J., BodisWollner, I., 1997. Electrophysiological evidence for visuocognitive dysfunction in younger non Caucasian patients with Parkinson's disease. J. Neural Transm. 104, 427-439.

Sarikaya, S., Yoldas, T.K., Yavasoglu, N.G., 2014. Evaluation of cognitive functions in Parkinson's patients without dementia with auditory event related potential (P300). Dusunen Adam 27, 132-137.

Sartucci, F., Massetani, R., Tognoni, G., Guerrini, V., Murri, L., Muratorio, A., 1990. Il potenziale evocato lento P300 da stimoli acustici nel morbo di Parkinson, in Agnoli, A., Battistin, L. (Eds.), Atti XVI Riun. LIMPE Palermo 1989. Don Guanella, Roma, pp. 265279.

Schimmack, U., 2012. The ironic effect of significant results on the credibility of multiple-study articles. Psychol. Methods 17, 551-566. 
Schmajuk, M., Liotti, M., Busse, L., Woldorff, M.G., 2006. Electrophysiological activity underlying inhibitory control processes in normal adults. Neuropsychologia 44, 384-395.

Schomaker, J., Berendse, H.W., Foncke, E.M., van der Werf, Y.D., van den Heuvel, O.A., Theeuwes, J., Meeter, M., 2014. Novelty processing and memory formation in Parkinson's disease. Neuropsychologia 62, 124-136.

Schröder, C., Möbes, J., Schütze, M., Szymanowski, F., Nager, W., Bangert, M., Münte, T.F., Dengler, R., 2006. Perception of emotional speech in Parkinson's disease. Mov. Disord. 21, 1774-1778.

Schröger, E., Wolff, C., 1998. Behavioral and electrophysiological effects of task-irrelevant sound change: a new distraction paradigm. Cogn. Brain Res. 7, 71-87.

Seer, C., Fürkötter, S., Vogts, M., Lange, F., Abdulla, S., Dengler, R., Petri, S., Kopp, B., 2015. Executive dysfunctions and event-related brain potentials in patients with amyotrophic lateral sclerosis. Front. Aging Neurosci. 7, 225.

Seer, C., Lange, F., Boos, M., Dengler, R., Kopp, B., 2016. Prior probabilities modulate cortical surprise responses: A study of event-related potentials. Brain Cogn. 106, 78-89.

Siegert, S., Herrojo Ruiz, M., Brücke, C., Huebl, J., Schneider, G.H., Ullsperger, M., Kühn, A.A., 2014. Error signals in the subthalamic nucleus are related to post-error slowing in patients with Parkinson's disease. Cortex 60, 103-120.

Simon, J.R., Rudell, A.P., 1967. Auditory S-R compatibility: the effect of an irrelevant cue on information processing. J. Appl. Psychol. 51, 300-304. 
Smolnik, R., Fischer, S., Hagenah, J., Kis, B., Born, J., Vieregge, P., 2002. Brain potential signs of slowed stimulus processing following cholecystokinin in Parkinson's disease. Psychopharmacology 161, 70-76.

Sohn, Y.H., Kim, G.W., Huh, K., Kim, J.S., 1998. Dopaminergic influences on the P300 abnormality in Parkinson's disease. J. Neurol. Sci. 158, 83-87.

Solís-Vivanco, R., Ricardo-Garcell, J., Rodríguez-Camacho, M., Prado-Alcalá, R.A., Rodríguez, U., Rodríguez-Violante, M., Rodríguez-Agudelo, Y., 2011. Involuntary attention impairment in early Parkinson's disease: an event-related potential study. Neurosci. Lett. 495, 144-149.

Solís-Vivanco, R., Rodríguez-Violante, M., Rodríguez-Agudelo, Y., Schilmann, A., RodríguezOrtiz, U., Ricardo-Garcell, J., 2015. The P3a wave: A reliable neurophysiological measure of Parkinson's disease duration and severity. Clin. Neurophysiol. 126, 2142-2149.

Spencer, K.M., Dien, J., Donchin, E., 2001. Spatiotemporal analysis of the late ERP responses to deviant stimuli. Psychophysiology 38, 343-358.

Squires, N.K., Squires, K.C., Hillyard, S.A., 1975. Two varieties of long-latency positive waves evoked by unpredictable auditory stimuli in man. Electroencephalogr. Clin. Neurophysiol. $38,387-401$.

Stamenović, J., Đurić, S., Đorđević, G., Đurić, V., 2005. The correlation between neuropsychological and neurophysiological parameters in early stages of Parkinson's Disease. Facta Univ Ser Med Biol 12, 104-112. 
Stanzione, P., Fattapposta, F., Giunti, P., D'Alessio, C., Tagliati, M., Affricano, C., Amabile, G., 1991. P300 variations in parkinsonian patients before and during dopaminergic monotherapy: a suggested dopamine component in P300. Electroencephalogr. Clin. Neurophysiol. 80, 446-453.

Stanzione, P., Semprini, R., Pierantozzi, M., Santilli, A.M., Fadda, L., Traversa, R., Peppe, A., Bernardi, G., 1998. Age and stage dependency of P300 latency alterations in non-demented Parkinson's disease patients without therapy. Electroencephalogr. Clin. Neurophysiol. 108, $80-91$.

Starkstein, S.E., Esteguy, M., Berthier, M.L., Garcia, H., Leiguarda, R., 1989. Evoked potentials, reaction time and cognitive performance in on and off phases of Parkinson's disease. J. Neurol. Neurosurg. Psychiatry 52, 338-340.

Stemmer, B., Segalowitz, S.J., Dywan, J., Panisset, M., Melmed, C., 2007. The error negativity in nonmedicated and medicated patients with Parkinson's disease. Clin. Neurophysiol. 118, 1223-1229.

Stroop, J.R., 1935. Studies of interference in serial verbal reactions. J. Exp. Psychol. 18, 643-662.

Sutton, S., Braren, M., Zubin, J., John, E.R., 1965. Evoked-potential correlates of stimulus uncertainty. Science 150, 1187-1188.

Svenningsson, P., Westman, E., Ballard, C., Aarsland, D., 2012. Cognitive impairment in patients with Parkinson's disease: diagnosis, biomarkers, and treatment. Lancet Neurol. 11, 697-707. 
Swainson, R., SenGupta, D., Shetty, T., Watkins, L.H., Summers, B.A., Sahakian, B.J., Polkey, C.E., Barker, R.A., Robbins, T.W., 2006. Impaired dimensional selection but intact use of reward feedback during visual discrimination learning in Parkinson's disease.

Neuropsychologia 44, 1290-1304.

Tachibana, H., Aragane, K., Miyata, Y., Sugita, M., 1997. Electrophysiological analysis of cognitive slowing in Parkinson's disease. J. Neurol. Sci. 149, 47-56.

Tachibana, H., Miyata, Y., Takeda, M., Sugita, M., Okita, T., 1999. Event-related potentials reveal memory deficits in Parkinson's disease. Cogn. Brain Res. 8, 165-172.

Tachibana, H., Toda, L., Sugita, M., 1992. Actively and passively evoked P3 latency of eventrelated potentials in Parkinson's disease. J. Neurol. Sci. 111, 134-142.

Takeda, M., Tachibana, H., Okuda, B., Kawabata, K., Sugita, M., 1998. Electrophysiological comparison between corticobasal degeneration and progressive supranuclear palsy. Clin. Neurol. Neurosurg. 100, 94-98.

Tanaka, H., Koenig, T., Pascual-Marqui, R.D., Hirata, K., Kochi, K., Lehmann, D., 2000. Eventrelated potential and EEG measures in Parkinson's disease without and with dementia.

Dement. Geriatr. Cogn. Disord. 11, 39-45.

Tang, H., Huang, J., Nie, K., Gan, R., Wang, L., Zhao, J., Huang, Z., Zhang, Y., Wang, L., 2016. Cognitive profile of Parkinson's disease patients: a comparative study between early-onset and late-onset Parkinson's disease. Int. J. Neurosci. 126, 227-234. 
Toda, K., Tachibana, H., Sugita, M., Konishi, K., 1993. P300 and reaction time in Parkinson's disease. J. Geriatr. Psychiatry Neurol. 6, 131-136.

Tsuchiya, H., Yamaguchi, S., Kobayashi, S., 2000. Impaired novelty detection and frontal lobe dysfunction in Parkinson's disease. Neuropsychologia 38, 645-654.

Turetsky, B.I., Dress, E.M., Braff, D.L., Calkins, M.E., Green, M.F., Greenwood, T.A., Gur, R.E., Gur, R.C., Lazzeroni, L.C., Nuechterlein, K.H., Radant, A.D., Seidman, L.J., Siever, L.J., Silverman, J.M., Sprock, J., Stone, W.S., Sugar, C.A., Swerdlow, N.R., Tsuang, D.W., Tsuang, M.T., Light, G., 2015. The utility of P300 as a schizophrenia endophenotype and predictive biomarker: clinical and socio-demographic modulators in COGS-2. Schizophr. Res. 163, 53-62.

Ullman, M.T., 2001. The neural basis of lexicon and grammar in first and second language: the declarative/procedural model. Biling. Lang. Cogn. 4, 105-122.

Ullsperger, M., Danielmeier, C., Jocham, G., 2014a. Neurophysiology of performance monitoring and adaptive behavior. Physiol. Rev. 94, 35-79.

Ullsperger, M., Fischer, A.G., Nigbur, R., Endrass, T., 2014b. Neural mechanisms and temporal dynamics of performance monitoring. Trends Cogn. Sci. 18, 259-267.

van Boxtel, G.J.M., Böcker, K.B.E., 2004. Cortical measures of anticipation. J. Psychophysiol. $18,61-76$. 
Verleger, R., 2003. Event-related EEG potential research in neurological patients, in Zani, A., Proverbio, A.M. (Eds.), The Cognitive Electrophysiology of Mind and Brain. Academic Press, San Diego, pp. 309-341.

Verleger, R., Hagenah, J., Weiss, M., Ewers, T., Heberlein, I., Pramstaller, P.P., Siebner, H.R., Klein, C., 2010. Responsiveness to distracting stimuli, though increased in Parkinson's disease, is decreased in asymptomatic PINK1 and Parkin mutation carriers. Neuropsychologia 48, 467-476.

Verleger, R., Schroll, H., Hamker, F.H., 2013. The unstable bridge from stimulus processing to correct responding in Parkinson's disease. Neuropsychologia 51, 2512-2525.

Vidal, F., Hasbroucq, T., Grapperon, J., Bonnet, M., 2000. Is the 'error negativity' specific to errors? Biol. Psychol. 51, 109-128.

Vieregge, P., Verleger, R., Wascher, E., Stuven, F., Kompf, D., 1994. Auditory selective attention is impaired in Parkinson's disease - event-related evidence from EEG potentials. Cogn. Brain Res. 2, 117-129.

Vogel, E.K., Machizawa, M.G., 2004. Neural activity predicts individual differences in visual working memory capacity. Nature $428,748-751$.

Volpe, U., Mucci, A., Bucci, P., Merlotti, E., Galderisi, S., Maj, M., 2007. The cortical generators of P3a and P3b: a LORETA study. Brain Res. Bull. 73, 220-230.

von Restorff, H., 1933. Über die Wirkung von Bereichsbildungen im Spurenfeld. Psychol. Forsch. 18, 299-342. 
Wang, L., Kuroiwa, Y., Kamitani, T., Li, M., Takahashi, T., Suzuki, Y., Shimamura, M., Hasegawa, O., 2000. Visual event-related potentials in progressive supranuclear palsy, corticobasal degeneration, striatonigral degeneration, and Parkinson's disease. J. Neurol. 247, 356-363.

Wang, L., Kuroiwa, Y., Kamitani, T., Takahashi, T., Suzuki, Y., Hasegawa, O., 1999. Effect of interstimulus interval on visual P300 in Parkinson's disease. J. Neurol. Neurosurg. Psychiatry 67, 497-503.

Wieser, M.J., Klupp, E., Weyers, P., Pauli, P., Weise, D., Zeller, D., Classen, J., Mühlberger, A., 2012. Reduced early visual emotion discrimination as an index of diminished emotion processing in Parkinson's disease? - Evidence from event-related brain potentials. Cortex 48, 1207-1217.

Wieser, M.J., Mühlberger, A., Alpers, G.W., Macht, M., Ellgring, H., Pauli, P., 2006. Emotion processing in Parkinson's disease: dissociation between early neuronal processing and explicit ratings. Clin. Neurophysiol. 117, 94-102.

Willemssen, R., Falkenstein, M., Schwarz, M., Müller, T., Beste, C., 2011. Effects of aging, Parkinson's disease, and dopaminergic medication on response selection and control. Neurobiol. Aging 32, 327-335.

Willemssen, R., Müller, T., Schwarz, M., Falkenstein, M., Beste, C., 2009. Response monitoring in de novo patients with Parkinson's disease. PLoS One 4, e4898. 
Willemssen, R., Müller, T., Schwarz, M., Hohnsbein, J., Falkenstein, M., 2008. Error processing in patients with Parkinson's disease: the influence of medication state. J. Neural Transm. $115,461-468$.

Williams-Gray, C.H., Evans, J.R., Goris, A., Foltynie, T., Ban, M., Robbins, T.W., Brayne, C., Kolachana, B.S., Weinberger, D.R., Sawcer, S.J., Barker, R.A., 2009. The distinct cognitive syndromes of Parkinson's disease: 5 year follow-up of the CamPaIGN cohort. Brain 132, 2958-2969.

Wolters, E.C., Braak, H., 2006. Parkinson's disease: premotor clinico-pathological correlations. J. Neural Transm. 70, 309-319.

Woodman, G.F., 2010. A brief introduction to the use of event-related potentials in studies of perception and attention. Atten Percept. Psychophys. 72, 2031-2046.

Wright, M.J., Geffen, G.M., Geffen, L.B., 1996. ERP measures of stimulus processing during an auditory oddball task in Parkinson's disease: Evidence for an early information processing deficit. Parkinsonism Relat. Disord. 2, 13-21.

Wronka, E., Kaiser, J., Coenen, A.M., 2012. Neural generators of the auditory evoked potential components P3a and P3b. Acta Neurobiol. Exp. 72, 51-64.

Yeung, N., Botvinick, M.M., Cohen, J.D., 2004. The neural basis of error detection: conflict monitoring and the error-related negativity. Psychol. Rev. 111, 931-959. 
Zeng, X.H., Hirata, K., Tanaka, H., Hozumi, A., Yamazaki, K., 2002. Insufficient processing resources in Parkinson's disease: evaluation using multimodal event-related potentials paradigm. Brain Topogr. 14, 299-311.

\section{Funding}

This work was supported by a research grant to BK (Petermax-Müller-Stiftung, Hannover, Germany). FL received a grant from the German National Academic Foundation. 
Table 1

Overview of the studies assessing P3b measures using oddball paradigms in patients with Parkinson's disease.

\begin{tabular}{|c|c|c|c|c|c|c|c|c|c|c|c|c|c|}
\hline \multirow[b]{2}{*}{ Study } & \multicolumn{2}{|c|}{$N$} & \multirow[b]{2}{*}{ med } & \multirow[b]{2}{*}{ HY } & \multirow[b]{2}{*}{ age } & \multirow[b]{2}{*}{ dur } & \multirow[b]{2}{*}{ dem } & \multirow{2}{*}{$\begin{array}{c}\text { oddball } \\
\text { task }\end{array}$} & \multirow{2}{*}{$\begin{array}{l}\text { stimulus } \\
\text { modality }\end{array}$} & \multirow{2}{*}{$\begin{array}{c}\% \\
\text { target }\end{array}$} & \multirow{2}{*}{$\begin{array}{l}\text { response } \\
\text { mode }\end{array}$} & \multicolumn{2}{|c|}{$\mathrm{P} 3 \mathrm{~b}$} \\
\hline & PD & $\mathrm{HC}$ & & & & & & & & & & latency & amplitude \\
\hline Antal et al. (1996)* & 20 & 20 & on & 1.9 & 63.2 & 6.7 & no & 2stim & vis & $\operatorname{mix}$ & press & $\rightarrow$ & $\downarrow$ \\
\hline Antal et al. (2000) & 20 & 20 & on & 2.3 & 65.3 & 4.8 & no & 2stim & vis & 20 & press & $\uparrow$ & $\downarrow$ \\
\hline Aotsuka et al. (1996) & 21 & - & - & - & - & & no & 2stim & aud & 20 & - & $\uparrow$ & $\downarrow$ \\
\hline $\begin{array}{l}\text { Bathien et al. (1996) } \\
\text { cognitively unimpaired }\end{array}$ & 15 & 10 & - & 2.1 & 64.5 & 10.0 & no & $\mathrm{m}$ & vis & 20 & press & $\rightarrow$ & $\rightarrow$ \\
\hline $\begin{array}{l}\text { Bathien et al. (1996) } \\
\text { cognitively impaired }\end{array}$ & 10 & 10 & - & 3.1 & 70.6 & 13.8 & no & 2stim & vis & 20 & press & $\uparrow$ & $\rightarrow$ \\
\hline Bocquillon et al. (2012) & 15 & 15 & on & 1.5 & 59.2 & 4.8 & no & 3stim & vis & 8 & press & $\uparrow$ & $\rightarrow$ \\
\hline Chen et al. (2006) & 27 & 27 & on & - & 63.3 & 40.1 & no & 2stim & aud & 15.4 & press & $\rightarrow$ & $\rightarrow$ \\
\hline Chia et al. (1995) & 22 & 16 & on & 2.4 & 67.2 & 7.4 & $\operatorname{mix}$ & 2stim & aud & 15 & recognize & $\uparrow$ & - \\
\hline Ebmeier et al. (1992)* & 16 & 16 & on & 2.4 & 69.0 & 9.3 & no & 2stim & aud & 12.5 & $\operatorname{mix}$ & $\rightarrow$ & - \\
\hline Elwan et al. (1996) & 43 & 37 & off & 2.6 & 61.8 & 2.4 & $\operatorname{mix}$ & 2stim & aud & 30 & press & $\uparrow$ & - \\
\hline Fogelson et al. (2011) & 8 & 8 & on & 2.3 & 61.6 & 6.8 & no & 2stim & vis & 15 & press & $\downarrow$ & $\uparrow$ \\
\hline Gaudreault et al. (2013) & 15 & 16 & on & 2.2 & 63.1 & 5.4 & no & 3stim & vis & 15 & press & $\rightarrow$ & $\rightarrow$ \\
\hline Georgiev et al. (2015) & 14 & 13 & $\begin{array}{l}\text { on/ } \\
\text { off }\end{array}$ & 1.8 & 60.4 & 3.5 & no & 3stim & $\operatorname{mix}$ & 15 & count & $\rightarrow$ & $\rightarrow$ \\
\hline
\end{tabular}




\begin{tabular}{|c|c|c|c|c|c|c|c|c|c|c|c|c|c|}
\hline Gerschlager et al. (2001) & 8 & 8 & off & - & 66.9 & 14.5 & no & 2 stim & aud & 20 & press & $\uparrow$ & $\rightarrow$ \\
\hline Gil et al. (1989) & 24 & 24 & $\operatorname{mix}$ & - & 63.8 & 4.6 & $\operatorname{mix}$ & 2stim & aud & 33 & count & $\uparrow$ & $\downarrow$ \\
\hline $\begin{array}{l}\text { Goodin \& Aminoff (1987) } \\
\text { dem }\end{array}$ & 14 & 40 & on & 2.5 & 71.4 & 4.8 & yes & 2stim & aud & 14 & count & $\uparrow$ & - \\
\hline $\begin{array}{l}\text { Goodin \& Aminoff (1987) } \\
\text { non-dem }\end{array}$ & 14 & 40 & on & 2.7 & 67.2 & & no & 2 stim & aud & 14 & count & $\rightarrow$ & - \\
\hline Graham et al. (1990) & - & - & off & - & - & & no & 2 stim & aud & - & press & $\rightarrow$ & $\rightarrow$ \\
\hline Green et al. (1996) & 20 & 20 & off & 1.3 & 54.1 & & no & 2 stim & aud & 14 & press & $\rightarrow$ & $\uparrow$ \\
\hline Hanafusa et al. (1991) & 8 & 29 & & - & & & yes & 2 stim & aud & 20 & press & $\uparrow$ & - \\
\hline Hansch et al. (1982) & 20 & 20 & on & - & & ת & $\operatorname{mix}$ & 2 stim & aud & 15 & count & $\uparrow$ & $\rightarrow$ \\
\hline $\begin{array}{l}\text { Hautecœur et al. (1991) } \\
\text { dem }\end{array}$ & 28 & 20 & - & 2.3 & 72.4 & 3.3 & yes & 2 stim & aud & 15 & count & $\uparrow$ & $\downarrow$ \\
\hline $\begin{array}{l}\text { Hautecœur et al. (1991) } \\
\text { non-dem }\end{array}$ & 55 & 20 & & 2.0 & 69.0 & 3.1 & no & 2 stim & aud & 15 & count & $\rightarrow$ & $\rightarrow$ \\
\hline Hayashi et al. (1993) & 53 & & & - & _- & - & - & 2 stim & - & - & press & $\uparrow$ & - \\
\hline $\begin{array}{l}\text { Hayashi et al. (1996) } \\
\text { HY stage } 2\end{array}$ & 11 & & & 2.0 & 54.4 & 5.4 & $\operatorname{mix}$ & 2 stim & aud & 20 & count & $\rightarrow$ & - \\
\hline $\begin{array}{l}\text { Hayashi et al. (1996) } \\
\text { HY stage } 3\end{array}$ & 18 & 13 & on & 3.0 & 60.8 & 6.0 & $\operatorname{mix}$ & 2 stim & aud & 20 & count & $\uparrow$ & - \\
\hline Hozumi et al. (2000) & 15 & 13 & on & 2.1 & 65.4 & 5.6 & no & 3stim & aud & 20 & count & $\rightarrow$ & $\rightarrow$ \\
\hline Iijima et al. (2000) & 20 & 55 & on & 2.2 & 63.1 & 4.9 & no & 2 stim & aud & 20 & count & $\uparrow$ & $\rightarrow$ \\
\hline
\end{tabular}




\begin{tabular}{|c|c|c|c|c|c|c|c|c|c|c|c|c|c|}
\hline $\begin{array}{l}\text { Ito (1994) } \\
\text { dem }\end{array}$ & 13 & 18 & on & - & 66.0 & - & yes & 2stim & som & 20 & count & $\uparrow$ & $\rightarrow$ \\
\hline $\begin{array}{l}\text { Ito (1994) } \\
\text { non-dem }\end{array}$ & 11 & 18 & on & - & 65.0 & - & no & 2stim & som & 20 & count & $\rightarrow$ & $\rightarrow$ \\
\hline Jiang et al. (2000) & 12 & 9 & on & $2-3$ & 66.3 & 6.3 & no & 2 stim & aud & 20 & count & $\uparrow$ & $\downarrow$ \\
\hline Karayanidis et al. (1995) & 16 & 15 & on & $1-2$ & 67.2 & 3.0 & no & 2stim & aud & 7 & press & $\rightarrow$ & $\rightarrow$ \\
\hline Katsarou et al. (2004) & 45 & 40 & on & $2-3$ & 59.3 & 6.1 & no & 2 stim & aud & 20 & count & $\uparrow$ & $\rightarrow$ \\
\hline Kim et al. (1995) & 16 & 15 & off & 2.1 & 62.6 & 2.3 & no & 2 stim & aud & - & count & $\uparrow$ & - \\
\hline Kurita et al. (2010)* & 17 & 20 & on & 3.7 & 73.9 & 9.2 & yes & 2stim & $\operatorname{mix}$ & 20 & count & $\uparrow$ & - \\
\hline Lagopoulos et al. (1998b) & 15 & 15 & $\operatorname{mix}$ & $1-3$ & 60.1 & 5.1 & no & 2stim & aud & 15 & press & $\rightarrow$ & $\rightarrow$ \\
\hline Lagopoulos et al. (1998a) & 15 & 50 & & & - & & no & 2stim & aud & - & press & $\uparrow$ & $\rightarrow$ \\
\hline Li et al. (2005) & 22 & 23 & on & 2.6 & 64.2 & 6.3 & - & 3 stim & vis & 20 & press & $\uparrow$ & $\downarrow$ \\
\hline Lopes et al. (2014) & 43 & 33 & $\mathrm{n}$ & 2.3 & 63.1 & 7.0 & $\operatorname{mix}$ & 2 stim & aud & 20 & count & $\uparrow$ & - \\
\hline Lukhanina et al. (2009) & 61 & 21 & & 2.4 & 61.4 & 7.6 & $\operatorname{mix}$ & 2 stim & aud & 22.5 & count & $\uparrow$ & $\rightarrow$ \\
\hline Lukhanina et al. (2008) & 35 & 18 & & $1.5-3$ & 61.1 & 4.5 & $\operatorname{mix}$ & 2 stim & aud & 20 & count & $\uparrow$ & $\rightarrow$ \\
\hline Morita et al. (2005) & 18 & 18 & & 3.5 & 67.3 & 9.9 & no & 2stim & vis & 20 & $\operatorname{mix}$ & $\uparrow$ & $\rightarrow$ \\
\hline Nojszewska et al. (2009) & 42 & 14 & on & 2.5 & 65.8 & 7.8 & no & 2 stim & aud & 20 & count & $\rightarrow$ & - \\
\hline Oishi et al. (1996) & 10 & 10 & off & $2-3$ & 63.0 & - & no & 2 stim & aud & 20 & count & $\uparrow$ & $\rightarrow$ \\
\hline O'Donnell et al. (1987) & 16 & 11 & on & 2.6 & 65.8 & 6.3 & $\operatorname{mix}$ & 2stim & aud & 15 & count & $\uparrow$ & - \\
\hline
\end{tabular}




\begin{tabular}{|c|c|c|c|c|c|c|c|c|c|c|c|c|c|}
\hline Philipova et al. (1997) & 17 & 17 & on & - & 54.0 & 2.9 & no & 2 stim & aud & 60 & count & $\rightarrow$ & $\downarrow$ \\
\hline Pirtošek et al. (2001) & 19 & 8 & off & 2.5 & 67.0 & 3.0 & no & 3 stim & aud & 15 & press & $\rightarrow$ & $\rightarrow$ \\
\hline Potagas et al. (2003) & 53 & 20 & on & 2.5 & 67.7 & 7.8 & no & 2 stim & vis & 20 & press & $\uparrow$ & $\uparrow$ \\
\hline Prabhakar et al. (2000) & 25 & 25 & off & - & 58.2 & 1.8 & no & 2 stim & aud & & count & $\rightarrow$ & - \\
\hline Prasher \& Findley (1991) & 27 & 27 & off & $1-2$ & 56.0 & 2.0 & $\operatorname{mix}$ & 2 stim & aud & 30 & press & $\rightarrow$ & - \\
\hline Raudino et al. (1997) & 49 & 39 & on & - & 65.7 & 4.9 & $\operatorname{mix}$ & 2 stim & aud & 20 & count & $\rightarrow$ & $\downarrow$ \\
\hline Rumbach et al. (1993) & 26 & 32 & on & 2.2 & 66.0 & 4.2 & $\operatorname{mix}$ & 2 stim & aud & 20 & press & $\uparrow$ & $\rightarrow$ \\
\hline Růžička et al. (1994) & 8 & 9 & off & 2.5 & 59.4 & 8.3 & no & 2 stim & aud & 20 & count & $\rightarrow$ & $\rightarrow$ \\
\hline Sagliocco et al. (1997) & 17 & 17 & on & 2.1 & 61.9 & 31.3 & no & 2stim & vis & 20 & count & $\rightarrow$ & $\rightarrow$ \\
\hline Sarikaya et al. (2014) & 38 & 39 & on & 1.9 & 58.8 & 5.8 & no & 2 stim & aud & 20 & count & $\uparrow$ & $\rightarrow$ \\
\hline Sartucci et al. (1990) & 21 & 13 & $111 X$ & 2.4 & 61.8 & 6.9 & $\operatorname{mix}$ & 2 stim & aud & 25 & count & $\rightarrow$ & $\rightarrow$ \\
\hline Smolnik et al. (2002) & 13 & 13 & off & - & 67.0 & 8.4 & no & 2 stim & aud & 20 & press & $\rightarrow$ & $\rightarrow$ \\
\hline $\begin{array}{l}\text { Sohn et al. (1998) } \\
\text { off }\end{array}$ & & & & 2.1 & 64.0 & 2.3 & no & 2 stim & aud & - & count & $\uparrow$ & - \\
\hline $\begin{array}{l}\text { Sohn et al. (1998) } \\
\text { on }\end{array}$ & 18 & 13 & n & 2.6 & 61.0 & 3.6 & no & 2 stim & aud & - & count & $\uparrow$ & - \\
\hline Stamenović et al. (2005) & 30 & 15 & off & 1.4 & 61.3 & - & no & 2 stim & aud & - & count & $\uparrow$ & - \\
\hline Stanzione et al. (1991) & 18 & 20 & off & 2.3 & 64.9 & 3.0 & no & 2 stim & aud & 20 & count & $\uparrow$ & - \\
\hline Stanzione et al. (1998) & 44 & 31 & off & 2.1 & 60.7 & 2.3 & no & 2 stim & aud & 20 & count & $\rightarrow$ & $\rightarrow$ \\
\hline
\end{tabular}


Tachibana et al. (1992)

dem

\begin{tabular}{|c|c|c|c|c|c|c|c|c|c|c|c|c|}
\hline 6 & 37 & on & 3.0 & 70.7 & 5.4 & yes & 3stim & vis & 19 & press & $\uparrow$ & $\rightarrow$ \\
\hline 25 & 37 & on & 2.3 & 66.0 & 2.7 & no & 3 stim & vis & 19 & press & $\rightarrow$ & $\rightarrow$ \\
\hline 29 & 19 & $\operatorname{mix}$ & 2.4 & 63.9 & 6.0 & no & 2 stim & vis & 20 & press & $\uparrow$ & $\rightarrow$ \\
\hline 7 & 11 & on & 3.3 & 64.1 & & yes & 2stim & aud & 20 & count & $\uparrow$ & $\rightarrow$ \\
\hline 15 & 11 & on & 2.4 & 64.1 & 6 & U & 2 stim & aud & 20 & count & $\rightarrow$ & $\uparrow$ \\
\hline 9 & 15 & on & 2.4 & 67.9 & & yes & 3stim & vis & 19 & press & $\uparrow$ & $\rightarrow$ \\
\hline 26 & 15 & on & 2.4 & 67.2 & & no & 3 stim & vis & 19 & press & $\rightarrow$ & $\rightarrow$ \\
\hline 18 & 35 & on & 2.2 & 64.4 & 5.5 & no & $3 \mathrm{stim}$ & aud & 20 & press & $\rightarrow$ & $\downarrow$ \\
\hline 14 & 16 & on & 2.2 & 61.0 & 5.0 & no & 2stim & aud & 14 & press & $\rightarrow$ & $\rightarrow$ \\
\hline 38 & 24 & on & 2.5 & 65.8 & 7.4 & no & 3stim & vis & 20 & press & $\rightarrow$ & $\rightarrow$ \\
\hline 17 & 28 & $\mathrm{niv}$ & 2.0 & 62.5 & 6.8 & no & 2 stim & aud & 25 & $\operatorname{mix}$ & $\rightarrow$ & . \\
\hline 18 & 16 & on & 1.7 & 63.9 & 4.6 & no & $\operatorname{mix}$ & $\operatorname{mix}$ & 20 & press & $\rightarrow$ & $\uparrow$ \\
\hline
\end{tabular}

Tachibana et al. (1992)

non-dem

Tachibana et al. (1997)

Tanaka et al. (2000)

dem

Tanaka et al. (2000)

non-dem

Toda et al. (1993)

dem

Toda et al. (1993)

non-dem

Tsuchiya et al. (2000)

Vieregge et al. (1994)

Wang et al. (1999)

Wright et al. (1996)* 18

$63.9 \quad 4.6$

Note. For studies reporting a within-subject manipulation of task parameters (e.g., visual vs. auditory; on vs. off medication), P3b results were evaluated based on the mean across different conditions. These studies are marked with an asterisk $(*)$ in the table.

2 stim = two-stimulus oddball task; 3 stim $=$ three-stimulus oddball task; aud $=$ auditory; dem $=$ demented; dur $=$ disease duration in years;

$\mathrm{HC}=$ healthy controls; $\mathrm{HY}=$ mean score obtained on the Hoehn \& Yahr scale; med = antiparkinsonian medication state; mix = mixed; non-dem = non-demented; PD = patients with Parkinson's disease; vis = visual; $\uparrow$ indicates larger values of the respective measure in PD; 
$\downarrow$ indicates smaller values of the respective measure in PD; $\rightarrow$ indicates that no significant difference was found in the respective measure between PD and HC; - indicates that the measure could not be extracted from the respective study, either because it was not reported, or because the full version of the article could not be accessed. 
Table 2

Overview of the studies investigating novelty processing and deviance detection in patients with Parkinson's disease.

\begin{tabular}{|c|c|c|c|c|c|c|c|c|c|c|c|c|c|c|c|}
\hline \multirow{4}{*}{ Study } & \multicolumn{2}{|c|}{$N$} & \multirow{4}{*}{ med } & \multirow{4}{*}{$\mathrm{HY}$} & \multirow{4}{*}{ age } & \multirow{4}{*}{ dur } & \multirow{4}{*}{ dem } & \multirow{4}{*}{$\begin{array}{l}\text { stim } \\
\text { mod }\end{array}$} & \multirow{4}{*}{$\begin{array}{l}\% \\
\operatorname{tar}\end{array}$} & \multirow{4}{*}{$\begin{array}{c}\% \\
\text { distr }\end{array}$} & \multirow{4}{*}{$\begin{array}{l}\text { task } \\
\text { dim }\end{array}$} & \multirow{4}{*}{$\begin{array}{l}\text { distr } \\
\text { type }\end{array}$} & \multirow{4}{*}{$\begin{array}{l}\text { resp } \\
\text { mode }\end{array}$} & \multirow{3}{*}{\multicolumn{2}{|c|}{\begin{tabular}{l}
\multicolumn{1}{c}{ P3a } \\
hree-stimulus \\
oddball task
\end{tabular}}} \\
\hline & PD & $\mathrm{HC}$ & & & & & & & & & & & & & \\
\hline & & & & & & & & & & & & & & & \\
\hline & & & & & & & & & & & & & & latency & amplitude \\
\hline $\begin{array}{l}\text { Bocquillon } \\
\text { et al. (2012) }\end{array}$ & 15 & 15 & on & 1.5 & 59.2 & 4.8 & no & vis & & 8 & size & $\begin{array}{r}\text { dev } \\
\text { shape }\end{array}$ & press & $\rightarrow$ & $\rightarrow$ \\
\hline $\begin{array}{l}\text { Gaudreault } \\
\text { et al. (2013) }\end{array}$ & 15 & 16 & on & 2.2 & 63.1 & 5 & & & 15 & 15 & pos & $\begin{array}{l}\text { novel } \\
\text { shape }\end{array}$ & press & $\rightarrow$ & $\rightarrow$ \\
\hline $\begin{array}{l}\text { Georgiev et } \\
\text { al. }(2015) \\
\text { on | aud }\end{array}$ & 14 & 13 & on & 1.8 & 60.4 & 3.5 & no & aud & 15 & 15 & freq & noise & count & $\rightarrow$ & $\rightarrow$ \\
\hline $\begin{array}{l}\text { Georgiev et } \\
\text { al. }(2015) \\
\text { on | vis }\end{array}$ & 14 & 13 & $n$ & 1.8 & 6 & 3.5 & no & vis & 15 & 15 & size & $\begin{array}{r}\text { dev } \\
\text { shape }\end{array}$ & count & $\rightarrow$ & $\rightarrow$ \\
\hline $\begin{array}{l}\text { Georgiev et } \\
\text { al. }(2015) \\
\text { off } \mid \text { aud }\end{array}$ & 14 & 13 & off & 1.8 & 60.4 & 3.5 & no & aud & 15 & 15 & freq & noise & count & $\rightarrow$ & $\rightarrow$ \\
\hline $\begin{array}{l}\text { Georgiev et } \\
\text { al. }(2015) \\
\text { off | vis }\end{array}$ & 14 & 13 & off & 1.8 & 60.4 & 3.5 & no & vis & 15 & 15 & size & $\begin{array}{r}\text { dev } \\
\text { shape }\end{array}$ & count & $\rightarrow$ & $\rightarrow$ \\
\hline
\end{tabular}


Hozumi et

15 13 dev

al. (2000)

1513

on $\quad 2.1 \quad 65.4 \quad 5.6$

Li et al.

(2005)

$22 \quad 23$

on $\quad 2.6 \quad 64.2 \quad 6.3$

Pirtošek et

al. (2001)

$19 \quad 8$ off 2.5

Tachibana

et al. (1992)

non-dem

$25 \quad 37$

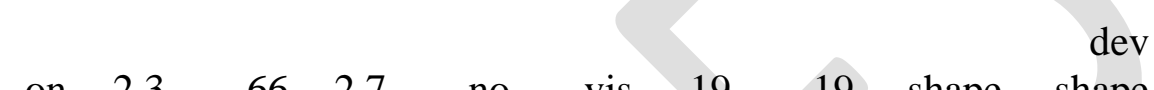

Tachibana

et al. (1992)

dem

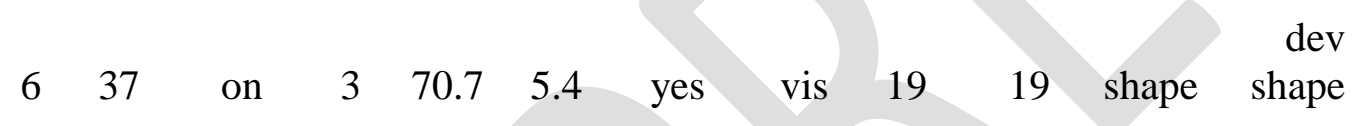

dev

Toda et al.

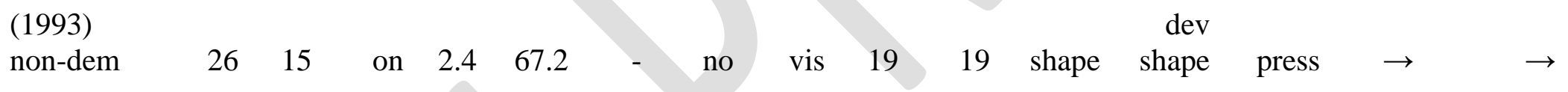

Toda et al.

(1993)

dem

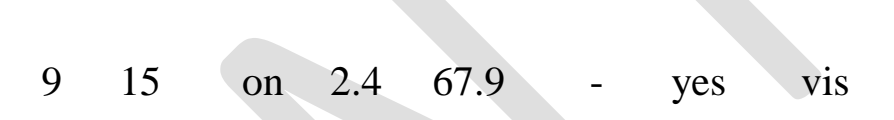

19

dev

Tsuchiya et

al. (2000)

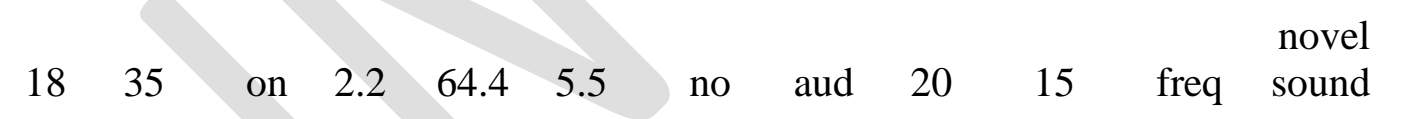

Wang et al.

(1999)

382

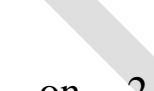

Wang et al.

(2000)

162

on $\quad 2.5 \quad 65.8 \quad 7.4$

vis $20 \quad 20$ shape rev

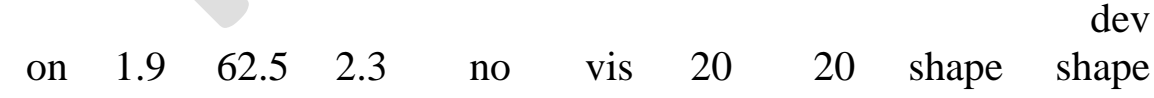


Zeng et al.

(2002)

aud

$\begin{array}{lllllllll} & 18 & 16 & 0 & 17 & 63.9 & 4.6 & \text { novel }\end{array}$

press $\quad \uparrow \quad \rightarrow$

Zeng et al.

(2002)

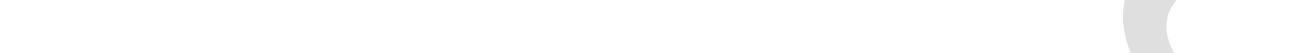

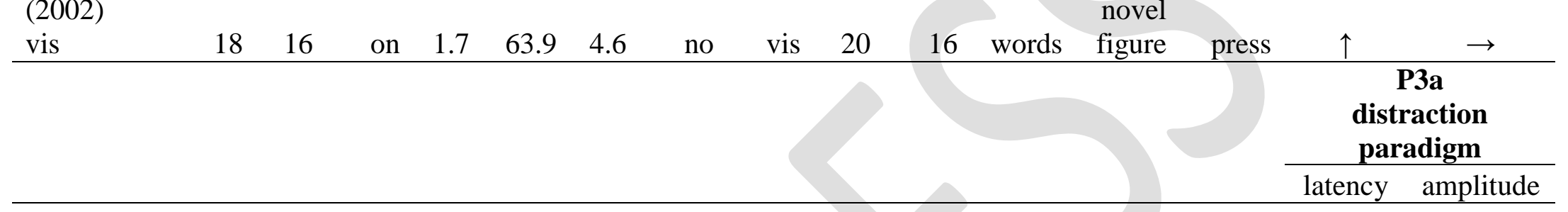

Solís-

Vivanco et

al. (2011)

on

2520

on

on

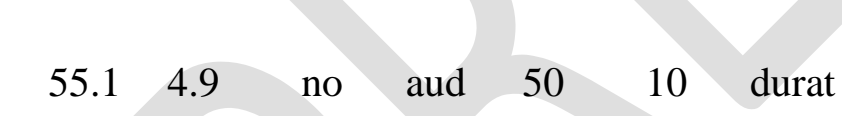

dev

Solís-

Vivanco et

al. (2011)

off

$17 \quad 20 \quad$ off

$-56.9 \quad 2.4$

no aud 50

10 durat

dev

freq press $\rightarrow \quad \downarrow$

Solís-

Vivanco et

al. (2015)

HY stage 1

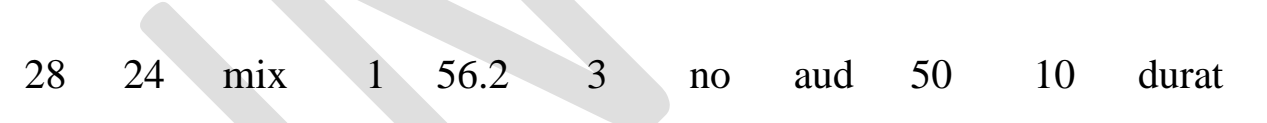

dev

Solís-

Vivanco et

al. (2015)

HY stage 2

$14 \quad 24 \quad \operatorname{mix}$

$\begin{array}{llllllll}2 & 57.2 & 5.3 & \text { no } & \text { aud } & 50 & 10 & \text { durat }\end{array}$

dev

freq press $\rightarrow \quad \downarrow$ 
Solís-

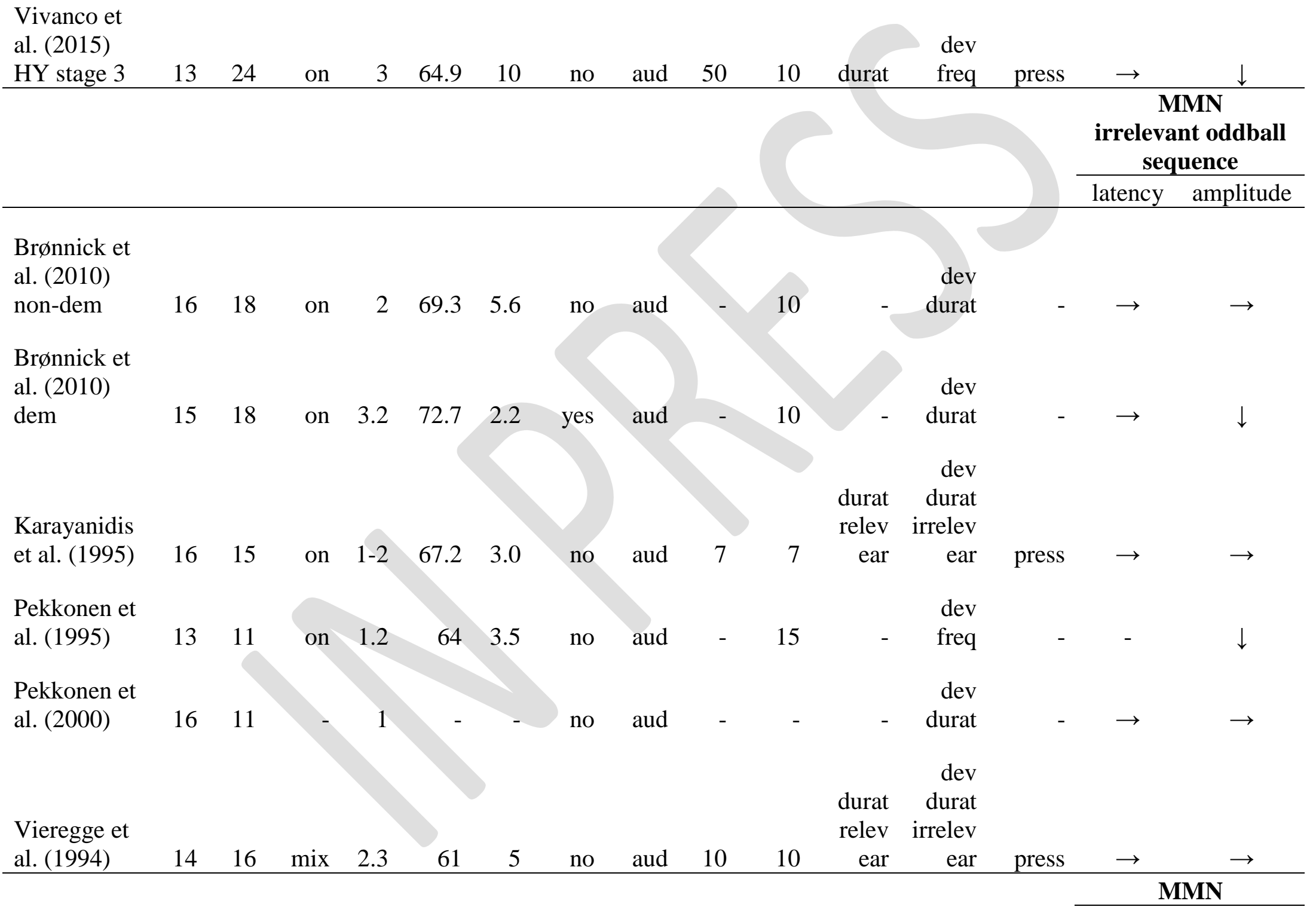




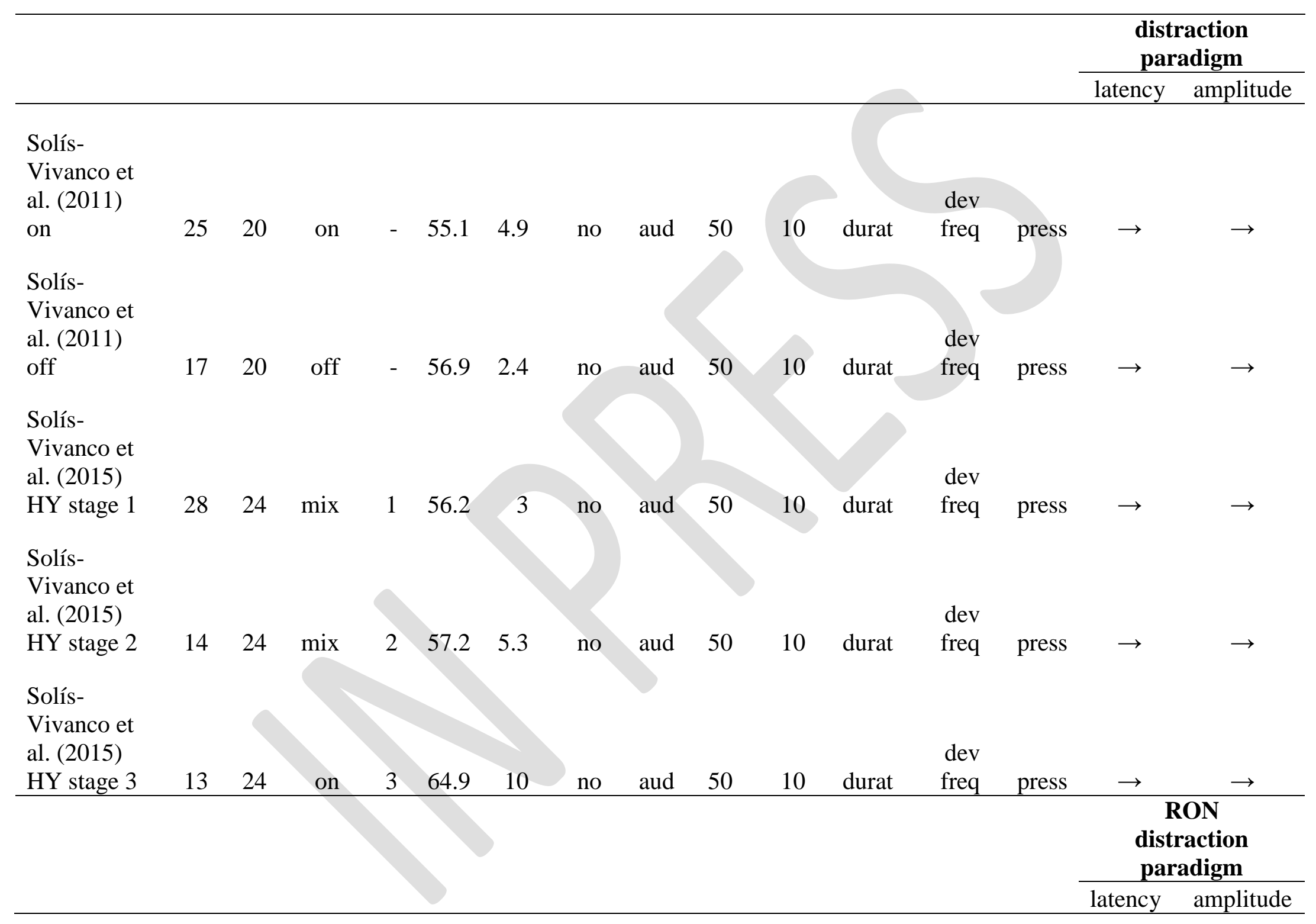


Solís-

Vivanco et

al. (2011)

on

20

on

$55.1 \quad 4.9$

no

aud $\quad 50 \quad 10 \quad$ durat

dev

freq press $\rightarrow \quad \rightarrow$

Solís-

Vivanco et

al. (2011)

off

$17 \quad 20$

20

off

$-56.9$

2.4

no

aud $\quad 50$

10 durat

dev

freq press

$\rightarrow$

$\downarrow$

Solís-

Vivanco et

al. (2015)

HY stage 1

$\operatorname{mix}$

156.2
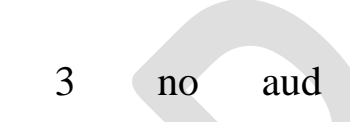

50

dev

Solís-

Vivanco et

al. (2015)

HY stage 2

$1424 \quad \operatorname{mix}$

$\begin{array}{llll}2 & 57.2 & 5.3 & \text { no }\end{array}$

aud $\quad 50$

10 durat

dev

freq press $\rightarrow \quad \rightarrow$

Solís-

Vivanco et

al. (2015)

HY stage 3

$13 \quad 24$

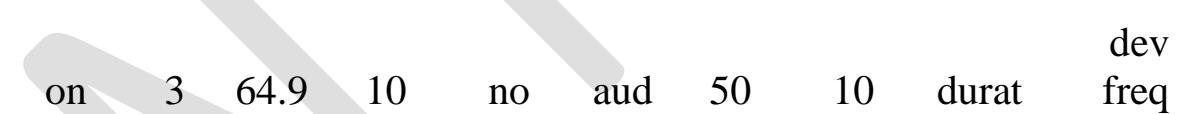

Note. aud = auditory; dem = demented; dev = deviant; distr = distractor; dur = disease duration in years; durat = duration; freq = frequency; $\mathrm{HC}=$ healthy controls; $\mathrm{HY}=$ mean score obtained on the Hoehn \& Yahr scale; irrelev = irrelevant; med = antiparkinsonian medication state; $\operatorname{mix}=$ mixed; $\mathrm{MMN}=$ mismatch negativity; non-dem = non-demented; $\mathrm{PD}=$ patients with Parkinson's disease; pos = position; relev = relevant; resp mode $=$ response mode; $\mathrm{RON}=$ reorienting negativity; stim mod $=$ stimulus modality; tar $=$ target; task $\operatorname{dim}=$ task-relevant dimension; vis = visual; $\uparrow$ indicates larger values of the respective measure in PD; $\downarrow$ indicates smaller values of the respective measure in PD; $\rightarrow$ indicates that no significant difference was found in the respective measure between PD and HC; - indicates that the measure could not be extracted from the respective study. 
Table 3

Overview of the studies investigating N2 and P3 measures using Go/NoGo tasks in patients with Parkinson's disease.

\begin{tabular}{|c|c|c|c|c|c|c|c|c|c|c|c|c|c|}
\hline \multirow[b]{2}{*}{ Study } & \multicolumn{2}{|c|}{$N$} & \multirow[b]{2}{*}{ med } & \multirow[b]{2}{*}{ HY } & \multirow[b]{2}{*}{ UPDRS } & \multirow[b]{2}{*}{ age } & \multirow[b]{2}{*}{ dur } & \multirow[b]{2}{*}{ dem } & \multirow[b]{2}{*}{ trial type } & \multicolumn{2}{|c|}{$\mathrm{N} 2$} & \multicolumn{2}{|c|}{ P3 } \\
\hline & PD & $\mathrm{HC}$ & & & & & & & & latency & amplitude & latency & amplitude \\
\hline \multirow{4}{*}{$\begin{array}{l}\text { Beste et al. } \\
(2009 a)^{a}\end{array}$} & \multirow{4}{*}{15} & \multirow{4}{*}{15} & \multirow{4}{*}{ on } & \multirow{4}{*}{ - } & \multirow{4}{*}{ - } & \multirow{4}{*}{61.1} & \multirow{4}{*}{ - } & \multirow{4}{*}{ no } & all trials & $\uparrow$ & $\uparrow$ & $\rightarrow$ & $\downarrow$ \\
\hline & & & & & & & & & Go & - & $\rightarrow$ & - & $\rightarrow$ \\
\hline & & & & & & & & & NoGo & - & $\uparrow$ & - & $\downarrow$ \\
\hline & & & & & & & & & NoGo - Go & $\rightarrow$ & - & $\begin{array}{l}\text { comp: } \rightarrow \\
\text { incomp: } \uparrow\end{array}$ & - \\
\hline \multirow{2}{*}{$\begin{array}{l}\text { Beste et al. } \\
(2010)\end{array}$} & \multirow{2}{*}{18} & \multirow{2}{*}{18} & \multirow{2}{*}{ off } & \multirow{2}{*}{ - } & \multirow{2}{*}{14.6} & \multirow{2}{*}{60.5} & & \multirow{2}{*}{ no } & all trials & - & $\uparrow$ & $\rightarrow$ & $\rightarrow$ \\
\hline & & & & & & & & & NoGo - Go & - & $\rightarrow$ & - & $\rightarrow$ \\
\hline \multirow{3}{*}{$\begin{array}{l}\text { Bokura et al. } \\
\text { (2005) }\end{array}$} & \multirow{3}{*}{13} & \multirow{3}{*}{14} & \multirow{3}{*}{ on } & \multirow{3}{*}{2.9} & \multirow{3}{*}{ - } & & & & & - & - & $\rightarrow$ & $\rightarrow$ \\
\hline & & & & & & $71^{b}$ & 7.2 & no & NoGo & - & - & $\uparrow$ & $\downarrow$ \\
\hline & & & & & & & & & NoGo - Go & $\rightarrow$ & $\downarrow$ & - & - \\
\hline $\begin{array}{l}\text { Osawa et al. } \\
(2005)\end{array}$ & 17 & 17 & $\operatorname{mix}$ & 2.1 & - & 66.4 & 4.1 & $\operatorname{mix}$ & $\mathrm{NoGo}^{\mathrm{c}}$ & - & $\rightarrow$ & - & $\downarrow$ \\
\hline & & & & & & & & & all trials & - & - & - & $\downarrow$ \\
\hline Puivermuner el & 18 & 14 & on & 2.2 & - & 60.6 & 8.3 & no & Go & - & - & - & $\downarrow$ \\
\hline & & & & & & & & & NoGo & - & - & - & $\downarrow$ \\
\hline
\end{tabular}

Note . dem = demented; dur = disease duration in years; $\mathrm{HC}=$ healthy controls; $\mathrm{HY}=$ mean score obtained on the Hoehn \& Yahr scale; med $=$ antiparkinsonian medication state; $\operatorname{mix}=$ mixed; $P D=$ patients with Parkinson's disease; UPDRS $=$ mean score obtained on Part III of the Unified Parkinson's Disease Rating Scale; all trials = main effect of group (PD vs HC) obtained irrespective of the Go/NoGo condition; Go = group effect observed on Go-trials; NoGo = group effect observed on NoGo-trials; NoGo - Go $=$ group effect observed on NoGo-minus-Go trials; $\uparrow$ indicates larger values of the respective measure in PD; $\downarrow$ indicates smaller values of the respective measure in PD; $\rightarrow$ indicates that no significant difference was found in the respective measure between PD and HC; - indicates that the measure could not be extracted from the respective study.

${ }^{a}$ Beste et al. (2009a) used two versions of the Go/NoGo task where imperative stimuli were either semantically compatible (comp; i.e. Go:

'PRESS', NoGo: 'STOP') or incompatible (incomp; i.e. Go: 'STOP', NoGo: 'PRESS') with the task, respectively.

${ }^{\mathrm{b}}$ According to the text in Bokura et al. (2005). 
cAccording to Osawa et al. (2005), "the amplitude of nogo N2 trended to be higher ( $p=0.08$ ) in PD" (p. 342), but it remains unclear whether N2 amplitudes tended to be enhanced (i.e., numerically more negative) or attenuated (i.e., numerically more positive) in PD patients. 
Table 4

Overview of the studies investigating N2 and P3 measures using interference tasks in patients with Parkinson's disease.

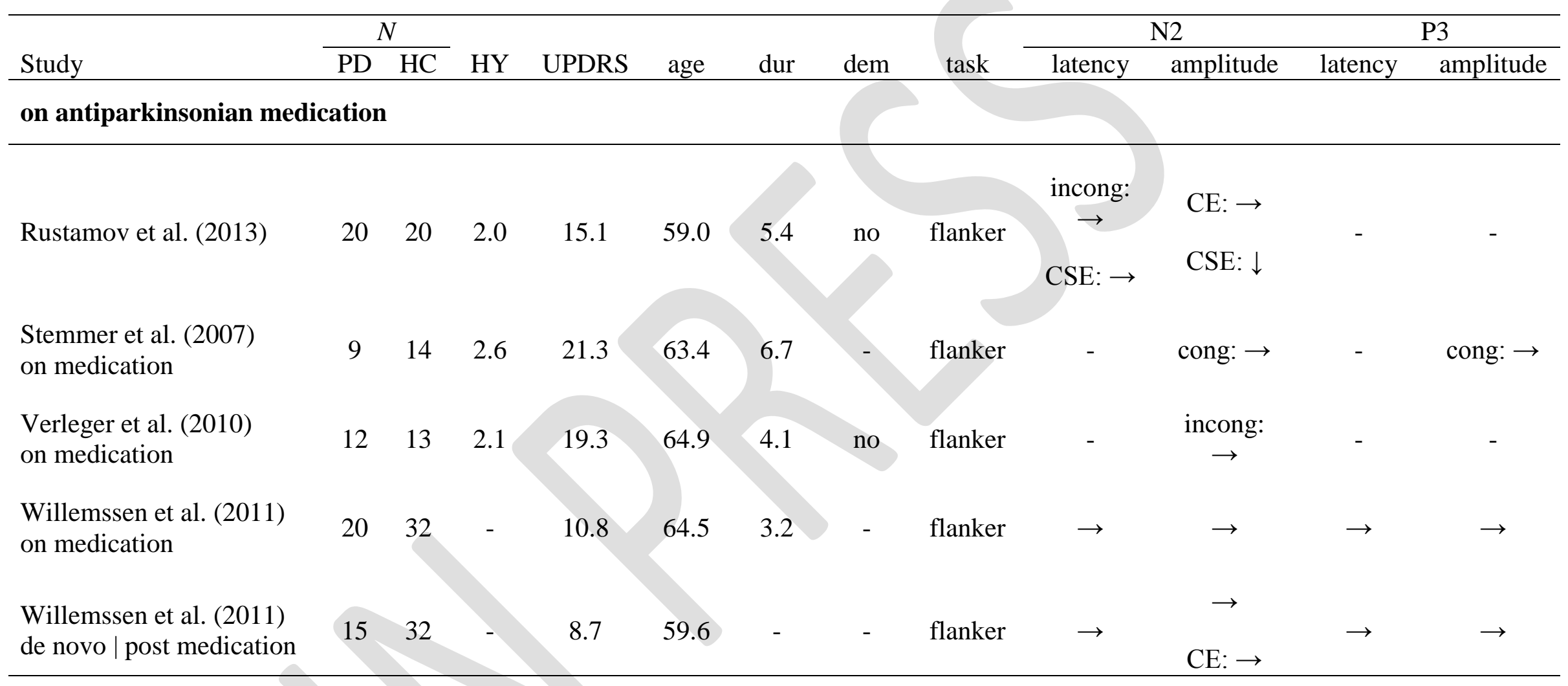

off antiparkinsonian medication

\begin{tabular}{|c|c|c|c|c|c|c|c|c|c|c|c|c|}
\hline Praamstra \& Plat (2001) & 8 & 8 & 2.4 & 37.3 & 57.8 & 5.8 & - & Simon & - & $\rightarrow-\downarrow$ & - & - \\
\hline Praamstra et al. (1998) & 7 & 7 & 2.4 & 31.0 & 58.4 & 5.4 & - & flanker & $\rightarrow$ & $\rightarrow$ & $\rightarrow$ & $\rightarrow$ \\
\hline $\begin{array}{l}\text { Willemssen et al. (2011) } \\
\text { off medication }\end{array}$ & 20 & 32 & - & 14.8 & 64.5 & 3.2 & - & flanker & $\rightarrow$ & $\rightarrow$ & $\rightarrow$ & $\rightarrow$ \\
\hline
\end{tabular}




\section{drug-naive}

Stemmer et al. (2007) de novo

Verleger et al. (2010) mutation carriers

Willemssen et al. (2011) de novo | pre medication $\begin{array}{lll}9 & 14 & 2.1\end{array}$

- $\quad$ flanker

- $\quad$ cong: $\rightarrow$

cong: $\rightarrow$

$\begin{array}{lll}19 & 13 & 0.5\end{array}$

$\begin{array}{llll}15 & 32 & - & 12.7\end{array}$

59.6

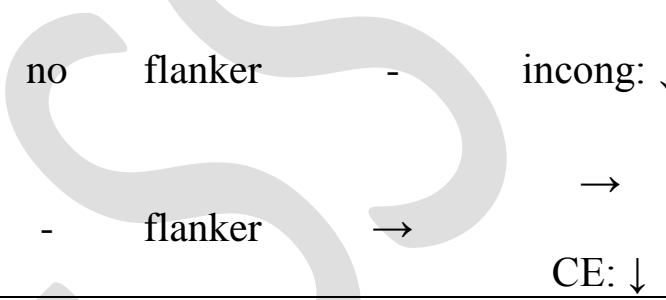

Note. $\mathrm{CE}=$ congruency effect; cong = congruent trials; $\mathrm{CSE}=$ congruency sequence effect; dem = demented; dur $=$ disease duration in years; $\mathrm{HC}=$ healthy controls; $\mathrm{HY}=$ mean score obtained on the Hoehn \& Yahr scale; incong = incongruent trials; PD = patients with Parkinson's disease; UPDRS = mean score obtained on Part III of the Unified Parkinson's Disease Rating Scale; $\downarrow$ indicates smaller values of the respective measure in PD; $\rightarrow$ indicates that no significant difference was found in the respective measure between PD and $\mathrm{HC} ; \rightarrow-\downarrow$ indicates that multiple analyses were reported, yielding either no significant difference $(\rightarrow)$ or smaller values of the respective measure in PD $(\downarrow)$; - indicates that the measure could not be extracted from the respective study. 
Table 5

Overview of the studies investigating electrophysiological measures of performance monitoring in patients with Parkinson's disease.

\begin{tabular}{|c|c|c|c|c|c|c|c|c|c|c|c|c|}
\hline \multirow[b]{2}{*}{ Study } & \multicolumn{2}{|c|}{$N$} & \multirow[b]{2}{*}{$\mathrm{HY}$} & \multirow[b]{2}{*}{ UPDRS } & \multirow[b]{2}{*}{ age } & \multirow[b]{2}{*}{ dur } & \multirow[b]{2}{*}{ dem } & \multirow[b]{2}{*}{ task } & \multicolumn{2}{|c|}{$\mathrm{N}_{\mathrm{e}} / \mathrm{ERN}$} & \multicolumn{2}{|c|}{$\mathrm{N}_{\mathrm{c}} / \mathrm{CRN}$} \\
\hline & $\mathrm{PD}$ & $\mathrm{HC}$ & & & & & & & latency & amplitude & latency & amplitude \\
\hline \multicolumn{13}{|c|}{ on antiparkinsonian medication } \\
\hline Falkenstein et al. (2001) & 13 & 13 & - & 25 & 61.1 & & no & flanker & $\rightarrow$ & $\downarrow$ & $\rightarrow$ & $\rightarrow$ \\
\hline Falkenstein et al. (2001) & 13 & 13 & - & 25 & 61.1 & & no & Simon & $\downarrow$ & $\downarrow$ & $\rightarrow$ & $\rightarrow$ \\
\hline Falkenstein et al. (2001) & 14 & 14 & - & 25 & 61.1 & & no & Go/NoGo & $\rightarrow$ & $\downarrow$ & $\rightarrow$ & $\rightarrow$ \\
\hline Ito \& Kitagawa (2006) & 17 & 15 & 2.1 & - & 64.1 & 6.1 & no & $\begin{array}{l}\text { lexical } \\
\text { decision }\end{array}$ & $\rightarrow$ & $\downarrow$ & $\rightarrow$ & $\rightarrow$ \\
\hline Rustamov et al. (2014) & 20 & 20 & 2.1 & .9 & 59.8 & 5.7 & no & flanker & - & $\downarrow$ & - & - \\
\hline $\begin{array}{l}\text { Stemmer et al. (2007) } \\
\text { on }\end{array}$ & 9 & 14 & 2.6 & 21.3 & 63.4 & 6.7 & - & flanker & - & $\downarrow$ & - & - \\
\hline Verleger et al. (2013) & 12 & 12 & 2.1 & 19.3 & 64.9 & 4.1 & no & flanker & $\rightarrow$ & $\rightarrow$ & - & - \\
\hline \multicolumn{13}{|c|}{ off antiparkinsonian medication } \\
\hline $\begin{array}{l}\text { Beste et al. (2009b) } \\
\text { off }\end{array}$ & 17 & & & 15.9 & 66.8 & - & - & flanker & $\rightarrow$ & $\downarrow$ & $\rightarrow$ & $\rightarrow$ \\
\hline Holroyd et al. (2002) & 9 & 9 & 2.5 & 26.9 & 56.1 & 6.1 & no & flanker & - & $\rightarrow$ & - & - \\
\hline Willemssen et al. (2008) & 18 & 18 & _. & 14.8 & 66.3 & 3.2 & - & flanker & - & $\downarrow$ & - & $\rightarrow$ \\
\hline
\end{tabular}

drug-naive 


\begin{tabular}{|c|c|c|c|c|c|c|c|c|c|c|c|c|}
\hline $\begin{array}{l}\text { Beste et al. (2009b) } \\
\text { de novo }\end{array}$ & 15 & 17 & - & 12.6 & 59.6 & - & - & flanker & $\rightarrow$ & $\downarrow$ & $\rightarrow$ & $\rightarrow$ \\
\hline $\begin{array}{l}\text { Stemmer et al. (2007) } \\
\text { de novo }\end{array}$ & 9 & 14 & 2.1 & 22.7 & 64.2 & 2.2 & - & flanker & - & $\downarrow$ & - & - \\
\hline Willemssen et al. (2009) & 14 & 14 & - & 12.5 & $59.6^{\mathrm{a}}$ & - & - & flanker & $\rightarrow$ & $\downarrow$ & $\rightarrow$ & $\uparrow$ \\
\hline
\end{tabular}

Note. dem = demented; dur = disease duration in years; $\mathrm{HC}=$ healthy controls; HY = mean score obtained on the Hoehn \& Yahr scale; med = antiparkinsonian medication state; $\mathrm{N}_{\mathrm{c}} / \mathrm{CRN}=\operatorname{correct}\left(-\right.$ related) negativity; $\mathrm{N}_{\mathrm{e}} / \mathrm{ERN}=$ error(-related) negativity; PD = patients with Parkinson's disease; UPDRS = mean score obtained on Part III of the Unified Parkinson's Disease Rating Scale; $\uparrow$ indicates larger values of the respective measure in PD; $\downarrow$ indicates smaller values of the respective measure in PD; $\rightarrow$ indicates that no significant difference was found in the respective measure between PD and HC; - indicates that the measure could not be extracted from the respective study. ${ }^{a}$ According to the text in Willemssen et al. (2009). 
Table 6

Overview of the main findings on cognitive ERPs in PD.

ERP

Classical cognitive ERPs

$\mathrm{P} 3 \mathrm{~b}$

P3a

mismatch negativity (MMN)

Cognitive ERP correlates of executive control

(conflict-)N2

NoGo-P3

error(-related) negativity $\left(\mathrm{N}_{\mathrm{e}} / \mathrm{ERN}\right)$

\section{PD-related changes in comparison to healthy controls}

good evidence for a sensitivity of P3b latency to PDD, with prolongation in demented, but not in non-demented PD patients

preliminary evidence for a relation of $\mathrm{P} 3 \mathrm{a}$ amplitude attenuation to disease duration in PD

preliminary evidence for a sensitivity of MMN amplitude to PDD, with attenuation in demented, but not in non-demented PD patients

preliminary evidence for attenuation of $\mathrm{N} 2$ amplitudes in drug-naive PD patients and in pre-symptomatic mutation carriers

preliminary evidence for attenuation of the contextual modulation of conflict-N2 amplitude in PD patients

preliminary evidence for Nogo-P3 amplitude attenuation in (medicated) PD patients good evidence for $\mathrm{N}_{\mathrm{e}} / \mathrm{ERN}$ amplitude attenuation in PD patients

Note. $\mathrm{PDD}=$ Parkinson's disease dementia; $\mathrm{PD}=$ Parkinson's disease 


\section{Figure captions}

Fig. 1. Standard paradigms for recording of event-related potentials. In the two-stimulus oddball task depicted here, participants have to respond to rare target stimuli (large circles) embedded in a series of frequent standard stimuli (small circles). In the three-stimulus oddball task, infrequent novel or complex stimuli (deviant shapes) are added to the oddball series. The Go/NoGo task requires participants to respond on Go-trials (e.g., green circles) while withholding responses on NoGo-trials (e.g., red circles). In the flanker task, the participant is required to respond to a central target stimulus which is flanked by either congruent or incongruent distractor stimuli.

Fig. 2. Predictors of P3b latency prolongation in PD patients. Depicted is the proportion of studies that reported significantly prolonged P3b latencies in PD patients (when compared to healthy controls) as a function of sample and task characteristics. $p$-values are the result of chisquare tests for independence.

Fig. 3. Graphical summary of the key results of this review. Left: The latency of the P3b waveform, elicited by rare target stimuli, has been found to be prolonged in patients with Parkinson's disease (PD) dementia, but not in non-demented PD patients. Right: ERP markers of executive functioning (including the error(-related) negativity, $\mathrm{N}_{\mathrm{e}} / \mathrm{ERN}$ ) have been shown to be altered in non-demented PD patients. Here, the amplitude of the $\mathrm{N}_{\mathrm{e}} / \mathrm{ERN}$, elicited by erroneous responses, is attenuated in PD patients compared to healthy controls.

Fig. 4. A. An illustration of the hypothesized inverted U-shaped relationship between dopamine levels (major effect of disease: severe dopamine depletion in the dorsal striatum; proposed effect of dopaminergic treatment: dopamine overdosing in the ventral striatum and/or the prefrontal cortex) and absolute values of ERP amplitudes. Table 3 shows that the NoGo-P3 data are compatible with optimal (i.e., corresponding - by definition - to those of age-stratified healthy 
controls) amplitude values in PD patients who are off dopaminergic medication (one study) and attenuated amplitude values in PD patients who are on dopaminergic medication (four studies; shown in red). Table 5 shows that several $\mathrm{N}_{\mathrm{e}} / \mathrm{ERN}$ studies in PD patients yielded attenuated $\mathrm{N}_{\mathrm{e}} / \mathrm{ERN}$ amplitudes in PD patients who are off dopaminergic medication (two out of three studies) as well as attenuated amplitude values in PD patients who are on dopaminergic medication (six out of seven studies; shown in blue). B. The reviewed evidence leads to testable predictions for intra-individual ERP studies. Specifically, NoGo-P3 data in PD patients who are off dopaminergic medication should show amplitude values similar to those of healthy controls (i.e., age-stratified optimal values) and attenuated amplitude values in these PD patients when they are on dopaminergic medication (shown in red). Attenuated $\mathrm{N}_{\mathrm{e}} / \mathrm{ERN}$ amplitudes are expected in PD patients irrespective of dopaminergic medication (shown in blue). 
Fig. 1.

two-stimulus oddball

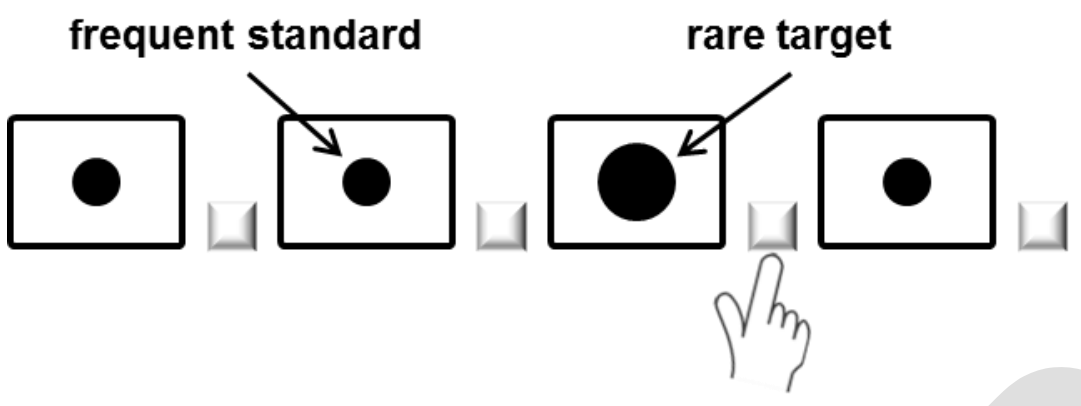

three-stimulus oddball

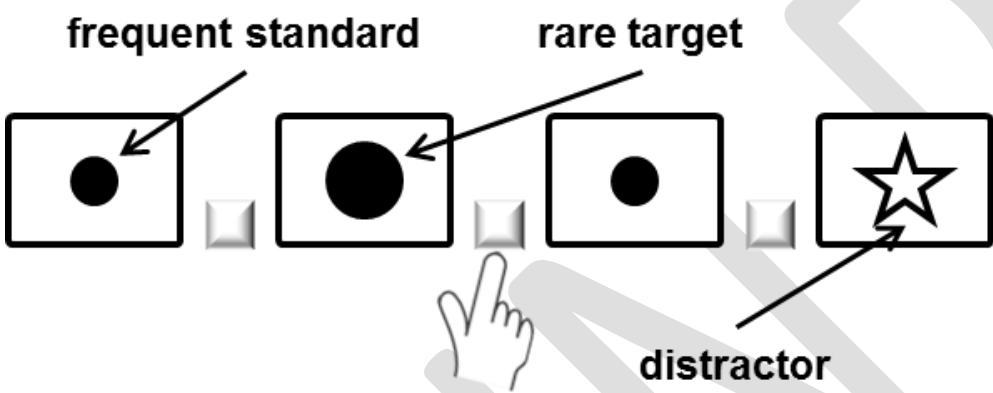

Go/Nogo task

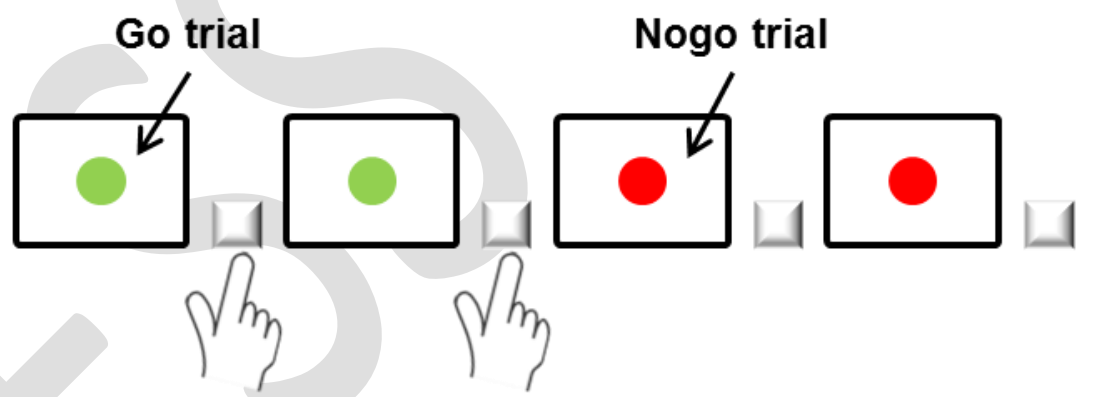

\section{flanker task}

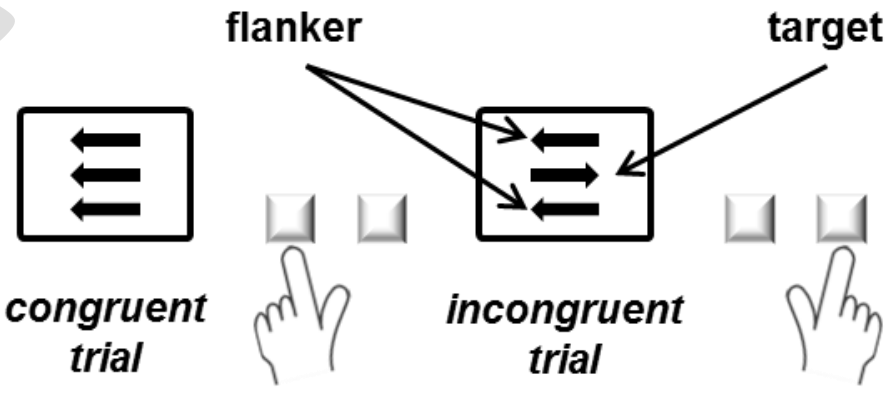


Fig. 2.

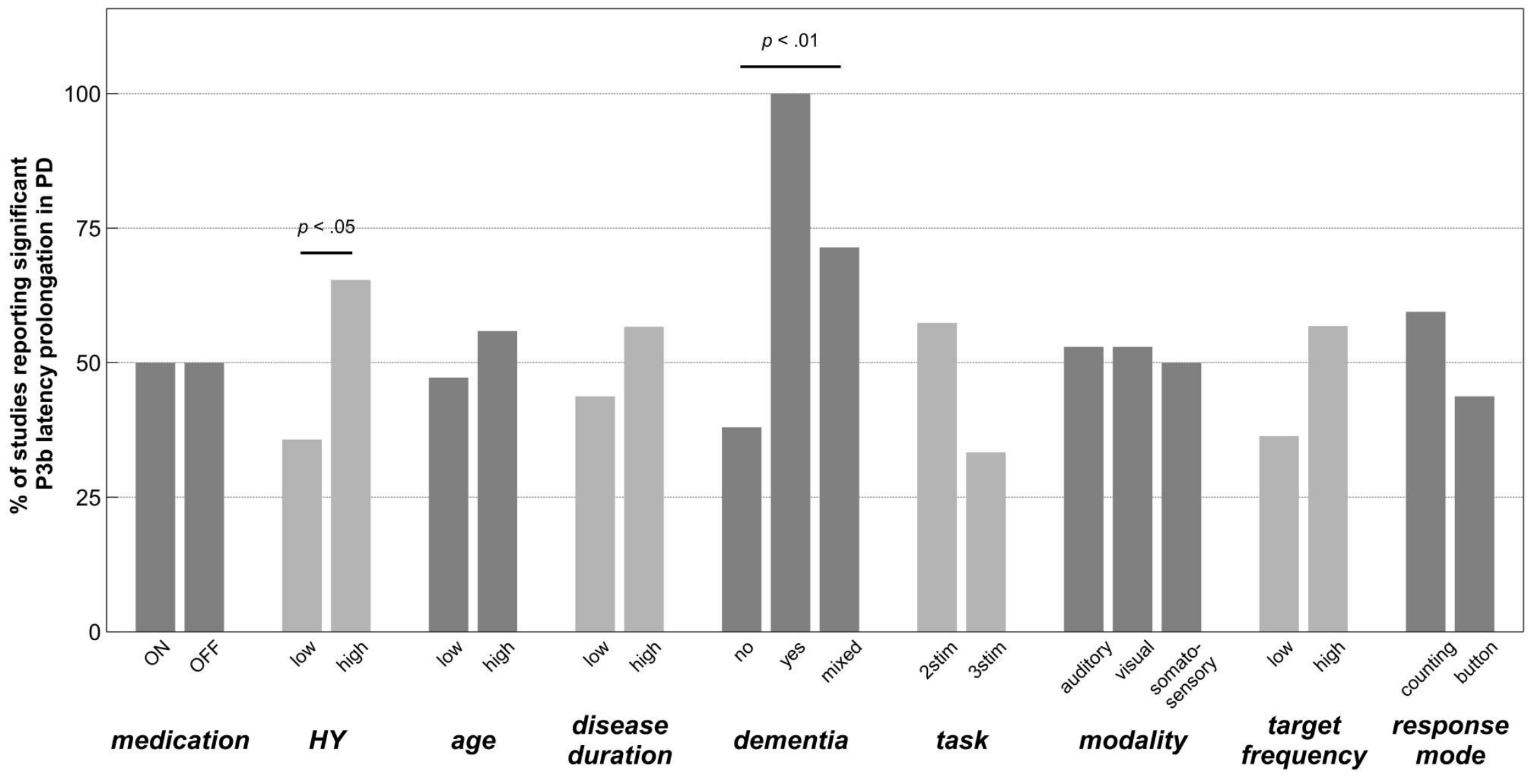


Fig. 3.
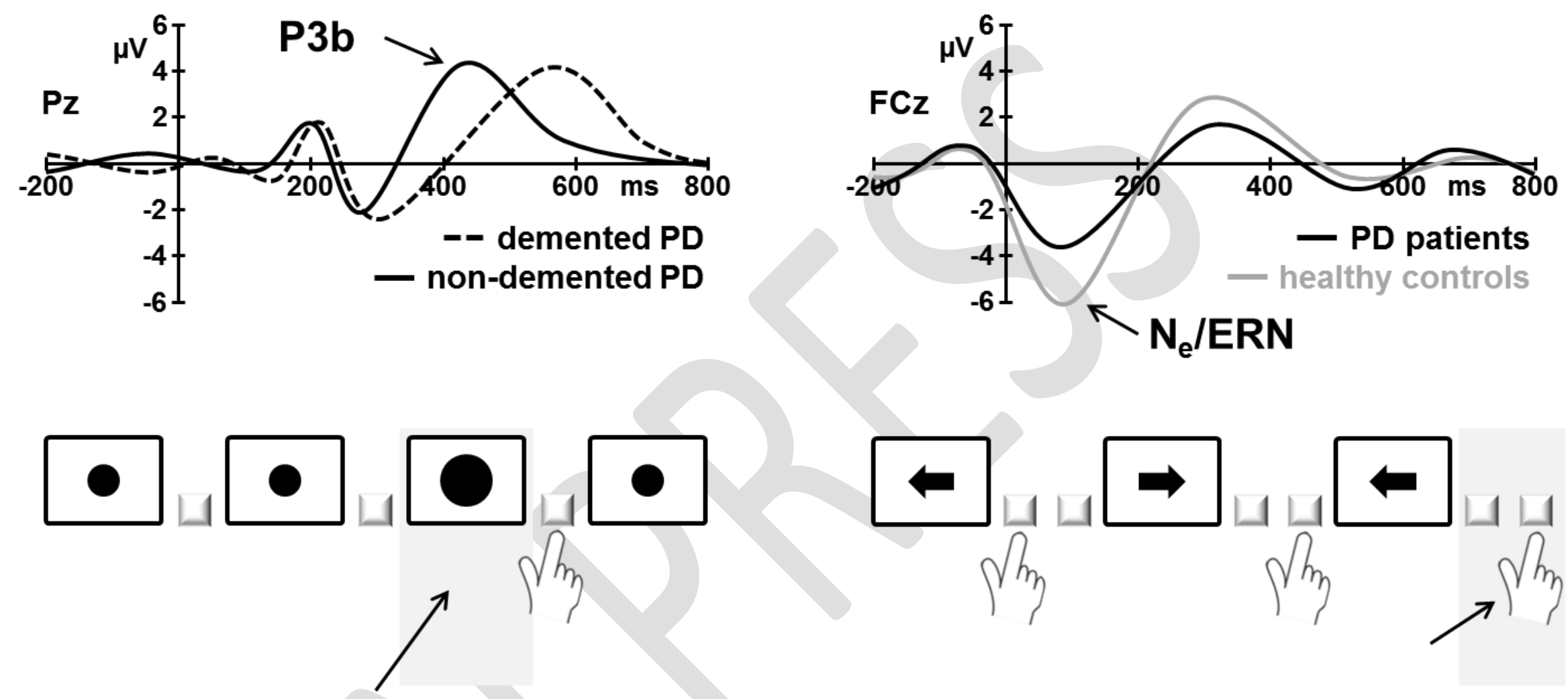

Rare target stimuli elicit the P3b.

Erroneous responses elicit the $\mathrm{N}_{\mathrm{e}}$ /ERN. 
Fig. 4.

A

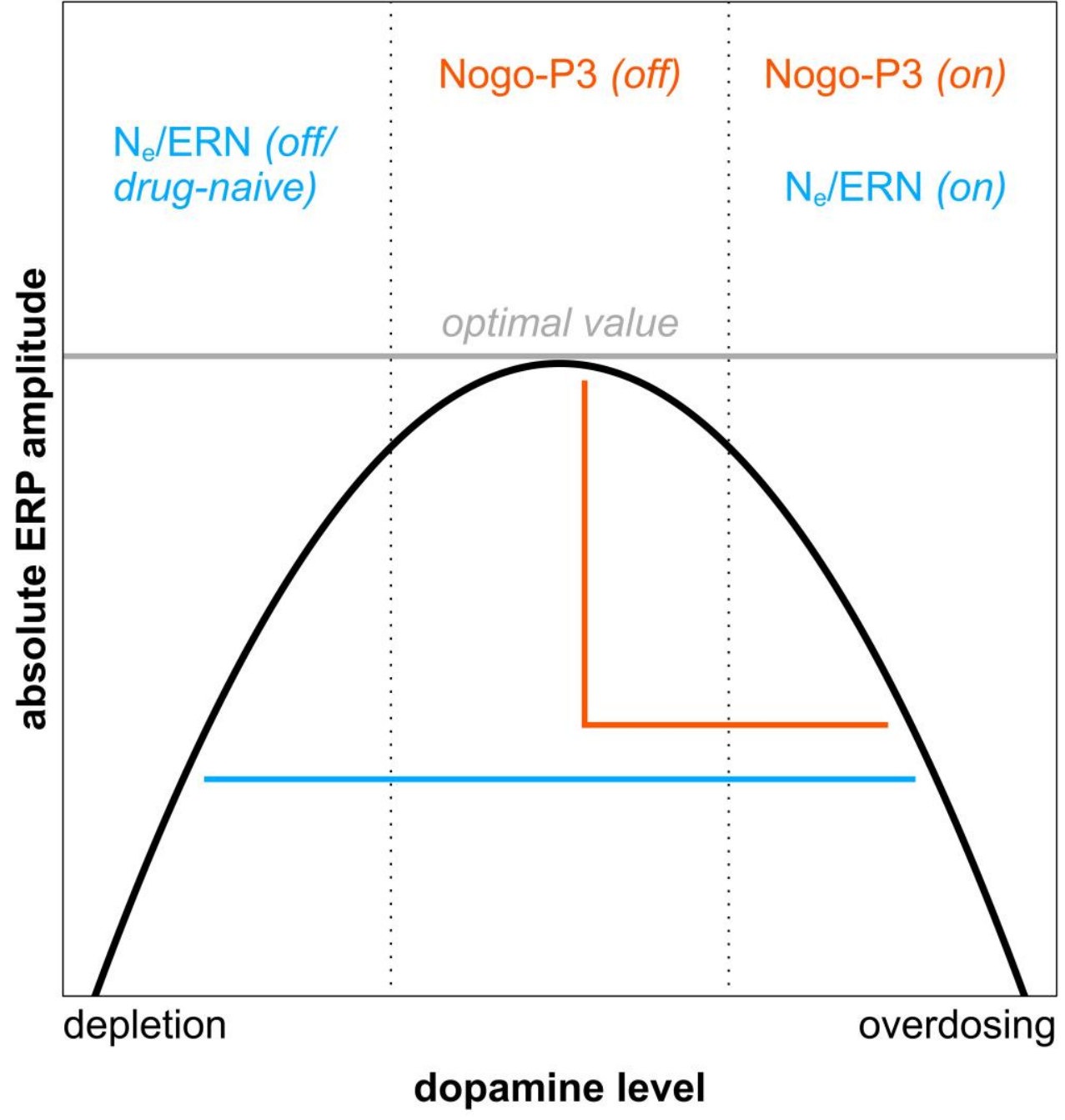

B

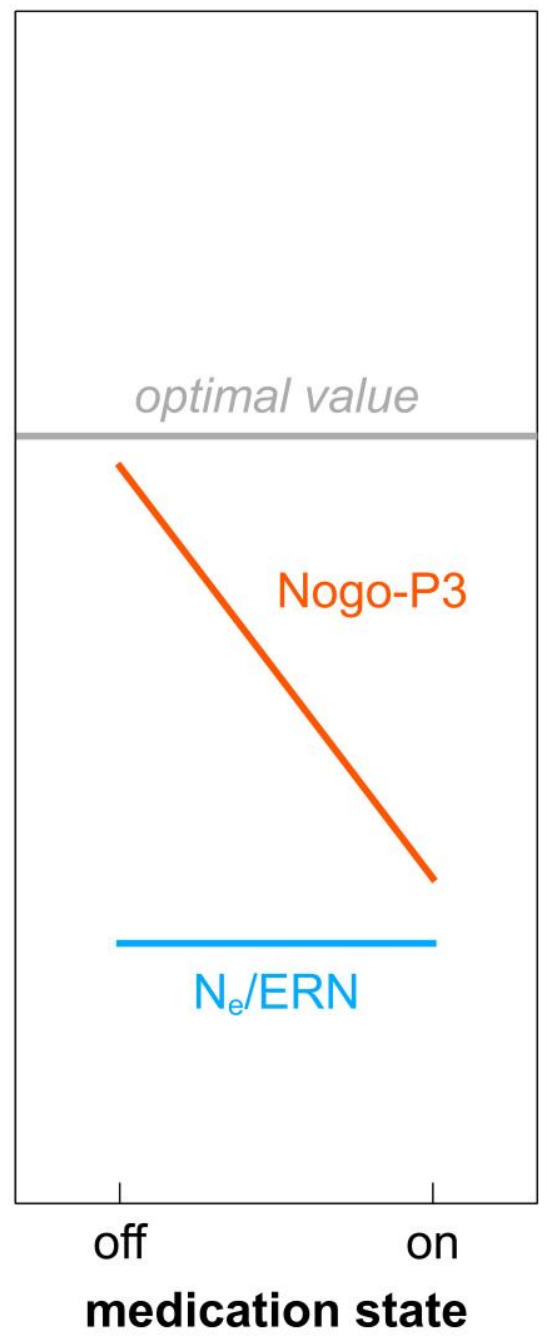

